\title{
Metallographic Examination of Surveillance Coupons from the Wilsonville, Alabama, Solvent Refined Coal Pilot Plant, 1977-1978
}
V. B. Baylor
R. T. King
B. C. Leslie
R. S. Crouse
A. J. Patko
K. C. Taber

OPERATED BY

UNION CARBIDE CORPORATION

FOR THE UNITED STATES DEPARTMENT OF ENERGY 


\section{DISCLAIMER}

This report was prepared as an account of work sponsored by an agency of the United States Government. Neither the United States Government nor any agency Thereof, nor any of their employees, makes any warranty, express or implied, or assumes any legal liability or responsibility for the accuracy, completeness, or usefulness of any information, apparatus, product, or process disclosed, or represents that its use would not infringe privately owned rights. Reference herein to any specific commercial product, process, or service by trade name, trademark, manufacturer, or otherwise does not necessarily constitute or imply its endorsement, recommendation, or favoring by the United States Government or any agency thereof. The views and opinions of authors expressed herein do not necessarily state or reflect those of the United States Government or any agency thereof. 


\section{DISCLAIMER}

Portions of this document may be illegible in electronic image products. Images are produced from the best available original document. 


\section{Printed in the United States of America. Availahle from National Technical Information Service \\ U.S. Department of Commerce \\ 5285 Port Royal Road, Springfield, Virginia 22161 \\ NTIS price codes-Printed Copy: A05 Microfiche A01}

This report was prepared as an account of work sponsored by an agency of the United States Government. Neither the United States Government nor any agency thereof, nor any of their employees, makes any warranty, express or implied, or assumes any legal liability or responsibility for the accuracy, completeness, or usefulness of any information, apparatus, product, or process disclosed, or represents that its use would not infringe privately owned rights. Reference herein to any specific commercial product, process, or service by trade name, trademark, manufacturer, or otherwise, does not ner,essarily rnnștitute or imply ito endorsement, recommendation, or favoring by the United States Government or any agency thereof. The views and opinions of authors expressed herein do not necessarily state or reflect those of the United States Government or any agency thereof. 
ORNL/TM-7365

Category UC-90\&

Contract No. W-7405-eng-26

METALS AND CERAMICS DIVISION

METALLOGRAPHIC EXAMINATION OF SURVEILLANCE COUPONS FROM THE WILSONVILLE, ALABAMA, SOLVENT REFINED

COAL PILOT PLANT, 1977-1978

V. B. Baylor, R. T. King, B. C. Leslie, R. S. Crouse, A. J. Patko, and K. C. Taber

Date Published: July 1980

NOTICE: This document contains information of a preliminary nature. It is subject to revision or correction and therefore does not represent a final report.

OAK RIDCE NATIONAL I.ARORATORY

Oak Ridge, Tennessee 37830

operated by

UNION CARBIDE CORPORATION

for the

DEPARTMENT OF ENERGY 


\section{THIS PAGE WAS INTENTIONALLY LEFT BLANK}




\section{CONTENTS}

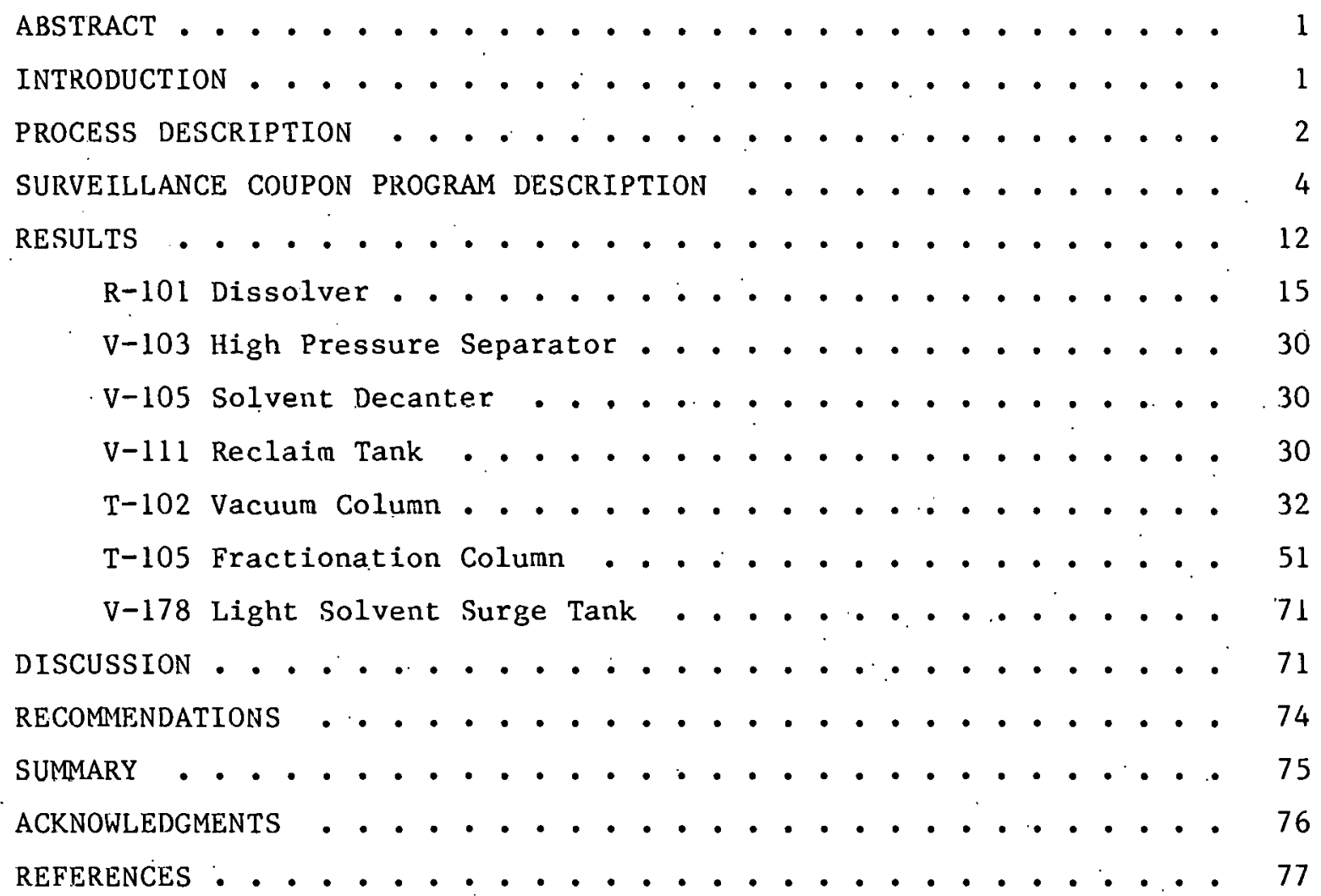


METALLOGRAPHIC EXAMINATION OF SURVEILLANCE COUPONS FROM THE WILSONVILLE, ALABAMA, SOLVENT REFINED COAL PILOT PLANT, 1977-1978 V. B. Baylor, R. T. King ${ }^{*}$ B. C. Leslie, R. S. Crouse,
A. J. Patko, ${ }^{\dagger}$ and K. C. Taber

ABSTRACT

Commercialization of the solvent refined coal (SRC) process requires corrosion-resistant yet economical materials of construction. A corrosion surveillance program was initiated at the Wilsonville, Alabama, SRC pilot plant to expose racks of welded specimens of engineering alloys to the various process conditions in major plant vessels. To observe the longteril cumulative exposure effects, sections were taken from the specimens after six months. The coupons were replaced in the vessels for another year and then reexamined. These sections were evaluated at ORNL by standard procedures. Microprobe analyses were performed on the scale on selected specimens. The scale, both on and below the surface, proved to be varying complex mtxtures of oxides and sulfides sometimes intermixed with process stream material. Weight change records indicate that corrosion was not a serious problem during these exposures, with the coals processed to date.

\section{INTRODUCTION}

The conversion of coal to produce clean-burning fuels has been demonstrated to be technically feasible by the Solvent Refined Coal (SRC) process. A 6 ton/ $\mathrm{d}^{\ddagger}$ SRC pilot plant in. Wilsonville, Alabama, and a 50 ton/d $\mathrm{d}^{\dagger}$ SRC pilot plant at Fort Lewis, Washingtón, have been operated since 1974, producing low-sulfur, virtually ash-free products from coal.1,2. The Wilsonville plant was designed and constructed by

\footnotetext{
${ }^{*}$ Formerly with ORNL, now with Sprague Electric Co., North Adams, Mass.

${ }^{\dagger}$ Catalytic, Inc.

$\ddagger_{\text {Nameplate }}$ capacities; 1 ton $=907 \mathrm{~kg}$.
} 
Catalytic, Inc., who operates it under management of Southern Company Services, Inc., under sponsorship of the Department of Energy (DOE) and the Electric Power Research Institute (EPRI).

Coal is processed at the Wilsonville plant by slurrying pulverized coal with process-derived solvent and heating to $416-460^{\circ} \mathrm{C} \cdot\left(780-860^{\circ} \mathrm{F}\right)$ under hydrogen pressure of $11.7-16.6 \mathrm{MPa}$ (1700-2400 psig). 1 These conditions promote the hydrocracking of the coal molecular structure and the removal of sulfur by the formation of hydrogen sulfide. The reaction product is separated, filtered, and further fractionated to form light organic liquids, wash snlvent for the filtration systeiu, recycle process sulvent, and liguid SRr, whirh is solidifiod by cooling. 1

Scale-up of the SRC process to commercial size demands materials of construction with long-term resistance to corrosion. A1.though eroeion has been the most publicized problem at the SRC pilot plants, streams lacking solids have contributed to metal wastage through corrosion, particularly in the fractionation areas. ${ }^{3,4}$. In order to investigate the possibility of corrosion damage, Catalytic began a program to expose surveillance coupons of important engineering alloys to plant conditions: Coupons have been exposed since 1974 in most of the major process vessels. The racks of specimens we examined were inserted in March 1977 and were removed in September 1977. Specimens were sectioned and replaced in the vessels to accrue further exposure. They were removed again in September 1978. Sections of these specimens were examined at Oak Ridge Natinnal Laboratory (ORNL) by standard metallographic procedures and electron microprobe analysis to determine the extent and nature of the corrosion during each exposure period.

\section{PROCESS DESCRIPTION}

A simplified flowsheet of the Wilsonville SRC pilot plant is shown in Fig. 1. In the V-101A Slurry Blend Tank, pulverized feed coal, $95 \%$ of which is typically 200 -mesh or smaller, is mixed with prucess-derived solvent, which has a boiling range of $232-482^{\circ} \mathrm{C}\left(450-900^{\circ} \mathrm{F}\right)$. Gas containing $85 \% \mathrm{H}_{2}$ by volume is fed to the slurry, and the mixture is then 
ORNL-DWG 80-11965

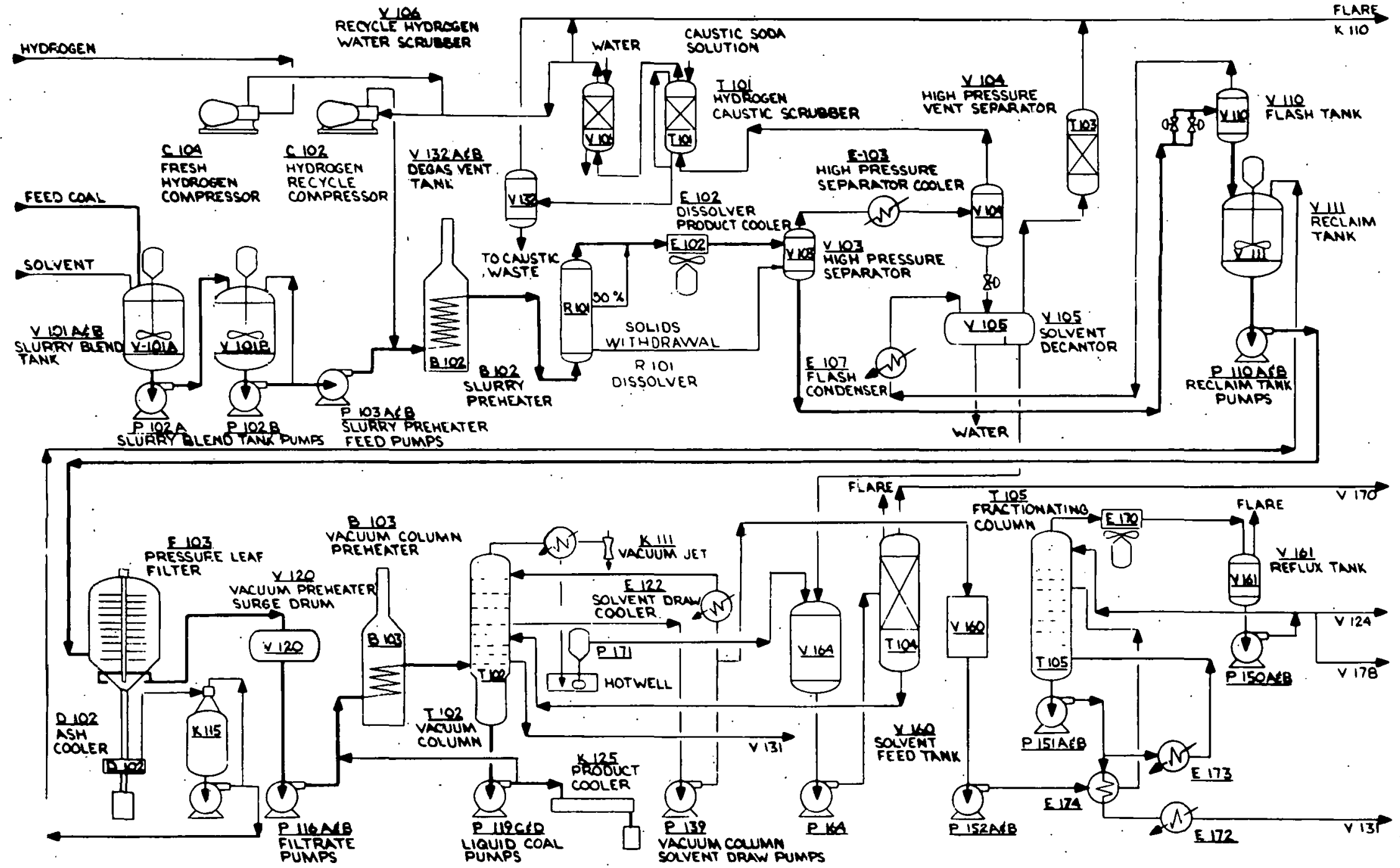

Fig. 1. Wilsonville SRC Flowsheet. 
heated to $400-450^{\circ} \mathrm{C}$ in the $\mathrm{B}-102$ Slurry Preheater before flowing into the $\mathrm{R}-101$ Dissolver, where a residence time of $30-60 \mathrm{~min}$ at $400-450^{\circ} \mathrm{C}$ allows the coal to react.

The slurry flows next to the V-103 High Pressure Separator, where the vapor is separated from the slurry. The vapor from the separator is cooled and again separated in the V-104 High Pressure Vent Separator. The V-104 vapor phase consists primarily of hydrogen sulfide, hydrocarbon gases, and unreacted hydrogen. The liquid phase includes water and organic compounds. The liquid condensed by cooling after the V-103, primarily water and organic compounds, flows to the V-105 Solvent Decanter, where the organic liquids are separated.

After pressure reduction, the slurry from the $\mathrm{V}-103$ is sent to the V-111 Reclaim Tank. Liquid from the reclaim tank is filtered to remove the ash, unreacted coal, and other solid particles. The filtered solution is fed to the T-102 Vacuum Column, which distills the solution into various organic fractions. The bottoms from T-102 are drawn of $f$ and cooled to form solid SkC. The wash solvent and recycle process solvent are drawn from two trays in the column, combined and sent to the $\mathrm{T}-105$ Fractionation Column. The overhead vapors are later condensed and fed t. the T-104 Light Solvent Recovery Column, along with the organic liquid from the V-105 Solvent Decanter. Those liquids that boil at $177^{\circ} \mathrm{C}\left(350^{\circ} \mathrm{F}\right.$ ) or higher are fed back to the T-102 for further separation. Some wash solvent from the $\mathrm{T}-102$ and the process solvent are pumped to the $\mathrm{T}-105$ Solvent Fractionation Column, where wash solvent, which boils between 177 and $232^{\circ} \mathrm{C}$, is separated from recycle process solvent. Both are then sent to storage tanks for use in filtration and slurrying, respectively.

\section{SURVEILLANCE COIIPON PROSRAM DESGRIPTION}

Figure 2(a) shows the configuration used in mounting racks of coupons in the various process vessels. Typically a 16-mm (5/8-in.) nut is welded to a blind flange, bolted cover, or nozzle in one or more locations in a vessel. Corrosion specimens are mounted on a 16-mm (5/8-in.) rod threaded on both ends and are secured by a nut on one end. The assembly is inserted into the vessel by screwing the other end into the nut previously 
ORNL:DWG 80-11966

TEST ASSEMBLY

$16(5 / 8)$ NUT WELDED TO

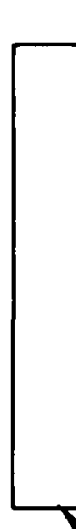

BLIND FLANGE OR BOLTED COVER

(a)

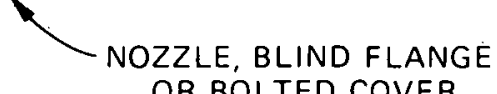

CERAMIC

COATING

OR BOLTED COVER

$17.5(11 / 16)$ DIAM HOLE

TEST COUPON

(b)
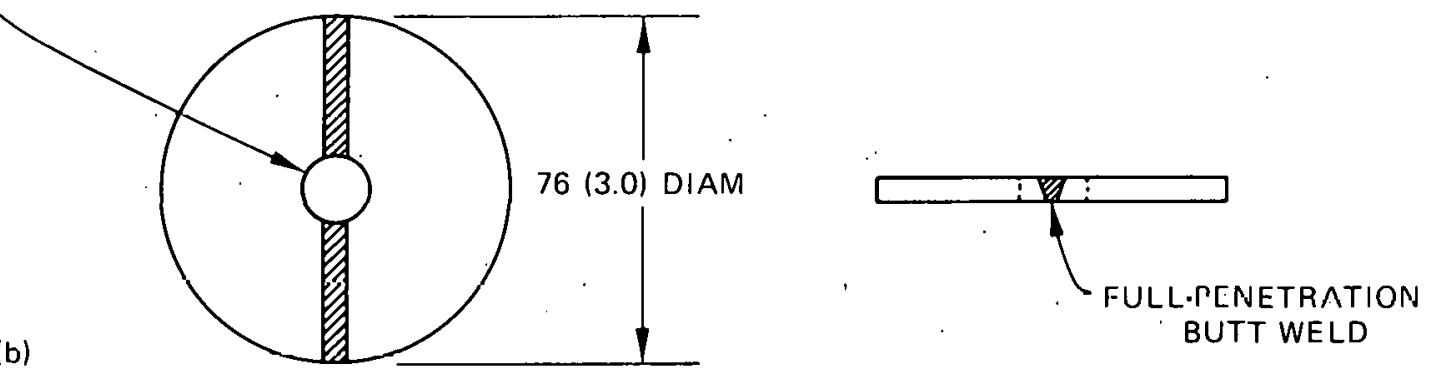

Fig. 2. Test Assembly and Typical Coupon Section for Wilsonville SRC Plant Surveillance Program. 
welded to the vessel. The specimens are electrically insulated from the rod and from each other by coating the rod and the spacers with ceramic material. Typically, the specimens are disks, $76 \mathrm{~mm}$ in diameter, $3.2 \mathrm{~mm}$ thick with a hole in the middle. They contain a diametral weld, as illustrated in Fig. 2(b). Welds are made by either the shielded metal-arc process with a covered electrode or the gas tungsten-arc proccoo.

The specimen rods are of various lengths depending on vessel dimensions and contain from three to nine specimens each. Some are hung vertically and others horizontally. The coupons are exposed to vapor phase, to liquid phase, or to the vapor-liquid interface. Details from plant records on coupon location, sample material, and pertinent proceec conditions, as well as they are known, are shown in Table 1. Composition specitications for coupon materials are listed in Table 2.

One surveillance coupon rack was placed in each of the following vessels: R-101 Dissolver, V-103 High Pressure Separator, V-105 Solvent Decanter, V-111 Reclaim Tank, and V-178 Light Solvent Surge Tank. Two racks were inserted into the T-102 Vacuum Column and three racks were placed in the T-105 Fractionation Column. The program originally was planned to include the V-110 Flash Tank and the V-120 Filter Flash Feed Drum; however, no coupons were inserted in these vessels during the first two exposures. Coupons were inserted on March 4, 1977, in all vessels except the T-105 Fractionation Column; which had specimens inserted on May 16, 1977. Al1 racks were removed September 12, 1977. Actual exposure times, when the plant was operating normally, were calculated to be $2350 \mathrm{~h}$ for the $\mathrm{T}-105$ coupons and $401.5 \mathrm{~h}$ for all others for the first exposure periud. The spectmens were reinserted in September 1977 and removed in September 1978 after accruing an additiona.1. $5730 \mathrm{~h}$ of expusure time.

Two types of coal were processed during the first exposure, Fmery coal from Utah and Indiana $V$. Proceesing of the Indiald $V$ coal continued during the second exposure. The compositions varied between the two coals, as did the compositions of the resultant SRC product as shown in Table 3. Because of the different coal chemistries and the frequently changing operating conditions, it is difficult to pinpoint the exact nature and contents of the vessels of interest over a given period. Not only were samples not taken from some locations of interest, but analyses 
Table 1. Summary of Corrosion Coupons Exposed at Wilsonville SRC Pilot Plant from March 1977 to September 1978

\begin{tabular}{|c|c|c|c|c|c|c|c|c|}
\hline Vessel & Location & $\begin{array}{c}\text { Test Coupon } \\
\text { Material }\end{array}$ & $\begin{array}{c}\text { Weld } \\
\text { Material }\end{array}$ & Pressure & $\begin{array}{l}\text { Temperature } \\
{ }^{\circ} \mathrm{C}\left({ }^{\circ} \mathrm{F}\right)\end{array}$ & Typical Contents & (wt & $\%)$ \\
\hline $\begin{array}{l}\mathrm{R}-101 \\
\text { Dissolver }\end{array}$ & $\begin{array}{l}\text { Bolted } \\
\text { cover } \\
\text { Vertical } \\
\text { Vapor phase }\end{array}$ & $\begin{array}{l}316 \\
347 \\
410 \\
20 b \\
304 \\
800 \\
330 \\
22-13-5 \\
26-1\end{array}$ & $\begin{array}{l}\text { E316-15 } \\
\text { E347-15 } \\
\text { E410-15 } \\
\text { E320-15 } \\
\text { E308-15 } \\
\text { Inco Weld A } \\
\text { Inco Weld A } \\
\text { E312-15 } \\
\text { GTA 26-1 } \\
\text {. }\end{array}$ & $\begin{array}{l}12-17 \mathrm{MPa} \\
1700-2450 \\
\text { psig }\end{array}$ & $\begin{array}{l}430-450 \\
(805-845)\end{array}$ & $\begin{array}{l}\text { SRC } \\
\text { Organic liquid } \\
\text { Water } \\
\text { Unreacted coal } \\
\text { Ash } \\
\text { Hydrocarbon gases } \\
\text { CO+CO } 2 \\
\mathrm{H}_{2} \mathrm{~S}\end{array}$ & 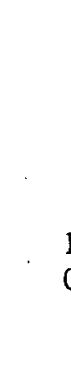 & $\begin{array}{l}40-60 a \\
5-25 \\
3-8 \\
5-25 \\
7-12 \\
4-12 \\
1.0-4 \\
0.5-4\end{array}$ \\
\hline $\begin{array}{l}\text { V-103 } \\
\text { High } \\
\text { Pressure } \\
\text { Separator }\end{array}$ & $\begin{array}{l}\text { Nozzle } \\
\text { Horizontal } \\
\text { Vafor phase }\end{array}$ & $\begin{array}{l}26-1 \\
304 \mathrm{~L} \\
316 \\
410 \\
22-13-5\end{array}$ & $\begin{array}{l}\text { GTA } 26-1 \\
\text { E308L-15 } \\
\text { E316-15 } \\
\text { E410-15 } \\
\text { E312-15 }\end{array}$ & $\begin{array}{l}\text { Same as } \mathrm{R}-101 \\
\text { dissolver }\end{array}$ & $\begin{array}{l}310-340 \\
(590-650)\end{array}$ & $\begin{array}{l}\text { Same as } \mathrm{R}-10 \mathrm{l} \\
\text { dissolver }\end{array}$ & & \\
\hline $\begin{array}{l}\text { V-105 } \\
\text { Solvent } \\
\text { Decanter }\end{array}$ & $\begin{array}{l}\text { Nozzle } \\
\text { Vertical } \\
\text { Liquid-yapor } \\
\quad \text { interEace }\end{array}$ & $\begin{array}{l}1018 \mathrm{CS} \\
304 \mathrm{~L} \\
410\end{array}$ & $\begin{array}{l}\text { E6010 } \\
\text { E308L-15 } \\
\text { E410-15 }\end{array}$ & $\begin{array}{l}0.17 \mathrm{MPa} \\
10 \mathrm{psig}\end{array}$ & $\begin{array}{l}38 \\
(100)\end{array}$ & $\begin{array}{l}\text { Ammonia } \\
\text { Organic liquid } \\
\text { Decanter oil } \\
\text { Decanter water } \\
\text { Vent gas }\end{array}$ & & $\cdot$ \\
\hline $\begin{array}{l}\text { V-111. } \\
\text { Reclaim } \\
\text { Tank }\end{array}$ & $\begin{array}{l}\text { Nozzle } \\
\text { Horizontal } \\
\text { Lifuid phase }\end{array}$ & $\begin{array}{l}1018 \text { CS } \\
304 \mathrm{~L} \\
410\end{array}$ & $\begin{array}{l}\text { E6010 } \\
\text { E308L-15 } \\
\text { E410-15 }\end{array}$ & $\begin{array}{l}0.90 \mathrm{MPa} \\
115 \mathrm{psig}\end{array}$ & $\begin{array}{l}260-315 \\
(500-600)\end{array}$ & $\begin{array}{l}\text { Cresol insolubles } \\
\text { Ash } \\
\text { SRC } \\
\text { Distillate }\end{array}$ & & $\begin{array}{l}7-14 \\
2-6 \\
16-25 \\
65-70\end{array}$ \\
\hline
\end{tabular}


Table 1. (Continued)

\begin{tabular}{|c|c|c|c|c|c|c|c|}
\hline $\begin{array}{c}\text { Vessel } \\
\text {, }\end{array}$ & Location: & $\begin{array}{c}\text { Test Coupon } \\
\text { Material }\end{array}$ & $\begin{array}{c}W \in-d \\
\text { Mat } \in \mathbf{r} i a l\end{array}$ & ?ressure & $\begin{array}{l}\text { Temperature } \\
{ }^{\circ} \mathrm{C}\left({ }^{\circ} \mathrm{F}\right)\end{array}$ & Typical Contents (wt & $\%)$ \\
\hline $\begin{array}{l}\mathrm{T}-102 \\
\text { Vacuum } \\
\text { Column } \\
\mathrm{Ml}\end{array}$ & $\begin{array}{l}\text { Manway } \\
\quad \text { top } \\
\text { Horizontal } \\
\text { Vapor phase }\end{array}$ & $\begin{array}{l}1018 \mathrm{cS} \\
304 \mathrm{~L} \\
410\end{array}$ & $\begin{array}{l}E 6010 \\
E 303 \mathrm{~L}-15 \\
E 41 J-15\end{array}$ & $\begin{array}{l}2-27 \mathrm{kPa} \\
0.3-3.9 \text { psia }\end{array}$ & $\begin{array}{l}93-102 \\
(201)-215)\end{array}$ & $\begin{array}{l}\text { Product } \\
\text { Dverhead light solvent } \\
\text { Wash solvent } \\
\text { Recycle process solvent }\end{array}$ & \\
\hline $\begin{array}{l}\mathrm{T}-102 \\
\text { Vacuum } \\
\text { Column } \\
\text { M2 }\end{array}$ & 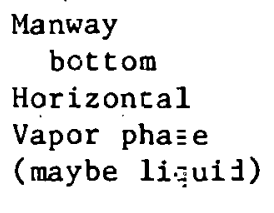 & $\begin{array}{l}1018 \mathrm{CS} \\
304 \mathrm{~L} \\
410\end{array}$ & $\begin{array}{l}E 6 \supset 0 J \\
\text { E3D3L-1:5 } \\
\text { E41J-15 }\end{array}$ & $\begin{array}{l}\text { See above for } \\
\text { overhead } \\
\text { pressure }\end{array}$ & $\begin{array}{l}300-325 \\
(590-615)\end{array}$ & & . \\
\hline $\begin{array}{l}\text { T-105 } \\
\text { Fraction- } \\
\text { ation } \\
\text { Column } \\
\text { M1 }\end{array}$ & $\begin{array}{l}\text { Manway } \\
\text { top } \\
\text { Horizontal } \\
\text { Liquid phase }\end{array}$ & $\begin{array}{l}316 \\
20 \text { b } \\
304 \mathrm{~L} \\
321 \\
330 \\
410 \\
=018 \mathrm{CS} \\
800\end{array}$ & $\begin{array}{l}\text { E316-15 } \\
\text { E320-15. } \\
\text { E308L-15 } \\
\text { E34:-15 } \\
\text { Inca We1d A } \\
\Xi 41(1-15 \\
\Xi 6010 \\
\text { Incc Welc A }\end{array}$ & $\begin{array}{l}1.13-0.14 \mathrm{MPa} \\
i-5 \text { psig }\end{array}$ & $\begin{array}{l}190-220 \\
(380-430)\end{array}$ & $\begin{array}{l}\text { Column feed: } \\
\text { Light organic liquid } \\
\text { Wash solvent } \\
\text { Process solvent }\end{array}$ & $\begin{array}{l}0-2 \\
15-30 \\
60-85\end{array}$ \\
\hline $\begin{array}{l}\text { T-105 } \\
\text { Fraction- } \\
\text { ation } \\
\text { Column } \\
\text { M2 }\end{array}$ & $\begin{array}{l}\text { Manway } \\
\quad \text { middle } \\
\text { Horizontal } \\
\text { Liquid phase }\end{array}$ & $\begin{array}{l}316 \\
\$ 04 \mathrm{~L} \\
\vdots 21 \\
410 \\
1018 \mathrm{CS} \\
800\end{array}$ & $\begin{array}{l}\equiv 31 \epsilon-15 \\
\text { E30EL-15 } \\
\text { E347-15 } \\
\text { E41G-15 } \\
\text { L6010 } \\
\text {-nco WE-d A }\end{array}$ & $\begin{array}{l}\text { See above for } \\
\text { overhead } \\
\text { pressure }\end{array}$ & $\begin{array}{l}250-260 \\
(480-500)\end{array}$ & $\begin{array}{l}\text { Overhead proluct: } \\
\text { Light organic liquid } \\
\text { Wash solvent } \\
\text { Process solvent }\end{array}$ & $\begin{array}{l}11 \\
81-85 \\
4-8\end{array}$ \\
\hline
\end{tabular}


Table 1. (Continued)

\begin{tabular}{|c|c|c|c|c|c|c|c|}
\hline Vessel & Location & $\begin{array}{l}\text { Test Coufon } \\
\text { Materiel }\end{array}$ & $\begin{array}{l}\text { Weld } \\
\text { Material }\end{array}$ & Pressure & $\begin{array}{l}\text { Temperature } \\
{ }^{\circ} \mathrm{C}\left({ }^{\circ} \mathrm{F}\right)\end{array}$ & Typical Contents (wt & $\%)$ \\
\hline $\begin{array}{l}\text { T-105 } \\
\text { Fraction- } \\
\text { ation } \\
\text { Column } \\
\text { M3 }\end{array}$ & $\begin{array}{l}\text { Marway } \\
\quad \text { totton } \\
\text { Horizontal } \\
\text { Liquid phase }\end{array}$ & $\begin{array}{l}316 \\
304 \mathrm{~L} \\
321 \\
410 \\
1018 \mathrm{CS} \\
800\end{array}$ & $\begin{array}{l}\text { E316-15 } \\
\text { E308L-15 } \\
\text { E347-15 } \\
\text { E410-15 } \\
\text { E6010 } \\
\text { Inco Weld A }\end{array}$ & $\begin{array}{l}\text { See above for } \\
\text { overhead } \\
\text { pressure }\end{array}$ & $\begin{array}{l}290-300 \\
(550-570)\end{array}$ & $\begin{array}{l}\text { Bottom product: } \\
\text { Light organic liquid } \\
\text { Wash solvent } \\
\text { Process solvent }\end{array}$ & $\begin{array}{l}1 \\
2-5 \\
94-97\end{array}$ \\
\hline $\begin{array}{l}\text { V-178 } \\
\text { Light } \\
\text { Solvent } \\
\text { Surge. } \\
\text { Tank }\end{array}$ & $\begin{array}{l}\text { Manway } \\
\text { Horizontal } \\
\text { Liquid phase }\end{array}$ & $\begin{array}{l}316 \\
304 \mathrm{~L} \\
321 \\
410 \\
1018 \mathrm{CS} \\
800\end{array}$ & $\begin{array}{l}\text { E316-15 } \\
\text { E308L-15 } \\
\text { E347-15 } \\
\text { E410-15 } \\
\text { E6010 } \\
\text { Inco Weld A }\end{array}$ & $\begin{array}{l}0.90 \mathrm{MPa} \\
115 \mathrm{psig}\end{array}$ & $\begin{array}{ll}110(230) & \text { Top } \\
290(560) & \text { Bottom }\end{array}$ & Wash solvent from $\mathrm{T}-102$ & \\
\hline
\end{tabular}

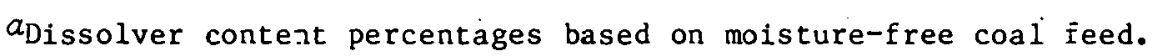

barpenter $20 \mathrm{Cb}-3$. 
Tabie 2. Typical Specificaticns of Chemical Composition for Materials Used as Corrosion Coupons in Weight Percent

\begin{tabular}{|c|c|c|c|c|c|c|c|c|c|}
\hline Alloy & $\mathrm{Cr}$ & $\mathrm{Ni}$ & C & $\mathrm{vn}$ & Si & $P$ & $\mathrm{~s}$ & other & $\mathrm{Fe}$ \\
\hline 316 & $16-18$ & $10-14$ & 0.08 & 2.0 & 1.0 & 0.045 & 0.0 .30 & $2.0-3.0 \mathrm{Mo}$ & $\mathrm{Bal}$ \\
\hline 347 & $17-19$ & $9-13$ & 0.08 & 2.0 & 1.0 & 0.045 & 0.030 & $10 \times \% \mathrm{C} \mathrm{Nb}+\mathrm{Ta}$ & $\mathrm{Bal}$ \\
\hline 410 & $11.5-13.5^{\circ}$ & & 0.15 & 1.0 & 1.0 & 0.040 & 0.030 & & $\mathrm{Bal}$ \\
\hline $\begin{array}{l}\text { Carpenter } \\
20 \mathrm{Cb}-3\end{array}$ & $19-21$ & $32-38$ & 0.07 & 2.0 & 1.0 & 0.035 & 0.035 & $\begin{array}{l}2.0-3.0 \mathrm{Mo}, 1.0 \mathrm{Nb}+\mathrm{Ta} \text {, } \\
3.0-4.0 \mathrm{Cu}\end{array}$ & $\mathrm{Bal}$ \\
\hline 304 & $18-20$ & $8-10.50$ & 3.08 & 2.0 & 1.0 & 0.045 & 0.030 & & $\mathrm{Bal}$ \\
\hline 800 & 21 & 32.5 & 3.05 & 0.8 & 0.5 & & 0.008 & $0.4 \mathrm{Ti}, 0.4 \mathrm{Al}, 0.4 \mathrm{cu}$ & 46 \\
\hline 330 & 19 & 35 & 0.05 & 1.5 & 1.25 & & . & & 43 \\
\hline $22-13-5$ & $20.5-\approx 3.5$ & $11.5-1 \cong .5$ & 0.06 & $4-6$ & 1.0 & , & & $\begin{array}{l}1.5-3.0 \mathrm{Mo}, 0.2-0.4 \mathrm{~N}, \\
0.1-0.3 \mathrm{~V}, 0.1-0.3 \mathrm{Nb}\end{array}$ & $\mathrm{Ba} 1$ \\
\hline $26-1$ & $25.0-27.5$ & $0.20^{a}$ & 0.010 & 0.40 & 0.40 & 0.02 & 0.32 & $\begin{array}{l}0.75-1.50 \mathrm{Mo}, 0.20 \mathrm{Cu}, a \\
0.015 \mathrm{~N}\end{array}$ & $\mathrm{Bal}$ \\
\hline $304 \mathrm{~L}$ & $18-20$ & $8-12$ & 0.03 & 2.0 & 1.0 & 0.045 & 0.030 & & $\mathrm{Bal}$ \\
\hline $1018 \mathrm{CS}$ & & & $0.15-0.20$ & $0.60-0.90$ & & 0.040 & 0.1050 & & $\mathrm{Bal}$ \\
\hline 321 & $17-19$ & $9-12$ & 0.08 & .2 .0 & 1.0 & 0.045 & 0.1030 & $5 \times \% \mathrm{Ci}$ & $\mathrm{Bal}$ \\
\hline
\end{tabular}

$a_{\mathrm{Ni}}+\mathrm{Cu} \leq 0.50$. 
Table 3. Chemical Compositions of Coal and Resultant SRC Product Processed During Corrosion Coupon Exposures

\begin{tabular}{|c|c|c|c|c|}
\hline \multirow{3}{*}{ Constituent } & \multicolumn{4}{|c|}{ Analysis, wt \% } \\
\hline & \multicolumn{2}{|c|}{$\begin{array}{l}\text { April 1977-June } 1977 \\
\quad \text { (Emery Coal) }\end{array}$} & \multicolumn{2}{|c|}{$\begin{array}{l}\text { June 1977-Sept. } 1978 \\
\text { (Indiana V Coa1) }\end{array}$} \\
\hline & Feed & SRC & Feed & SRC \\
\hline \multicolumn{5}{|c|}{ Ultimate Analysis } \\
\hline Carbon & $74-76$ & $81-88$ & $66-70$ & $85-87$ \\
\hline Hydrogen & $5.1-5.5$ & $5.1-5.9$ & $4.8-5.0$ & $5.7-6.4$ \\
\hline Nitrogen & $1.0-1.3$ & $1.3-1.8$ & $1.0-1.5$ & $1.9-2.4$ \\
\hline Chlorine & $<0.01-0.12$ & $<0.01-0.06$ & $<0.01$ & $<0.01$ \\
\hline Sulfur & $0.9-1.0$ & $0.38-0.59$ & $3.2-4.1$ & $0.71-0.97$ \\
\hline Ash & $7.9-8.6$ & $1.3-8.9$ & $9.0-12.5$ & $0.10-0.57$ \\
\hline oxygen & $8.3-10.2$ & $2.8-5.3$ & $9.2-1.1 .7$ & $3.9-5.7$ \\
\hline \multicolumn{5}{|c|}{ Forms of Sulfur } \\
\hline Pyritic & $0.19-0.29$ & $<0.01-0.02$ & $1.5-1.9$ & $<0.01-0.22$ \\
\hline Sulfate & $<0.01-0.01$ & $<0.01$ & $0.03-0.04$ & $<0.01-0.22$ \\
\hline Sulfide & $<0.01-0.03$ & $<0.01-0.07$ & $0.01-0.12$ & $<0.01-0.08$ \\
\hline Organic & $0.58-0.82$ & $0.34-0.50$ & $1.3-2.1$ & $0.47-1.2$ \\
\hline \multicolumn{5}{|c|}{ Proximate Analyses } \\
\hline Moisture & $2.5-2.8$ & & $2.7-7.4$ & \\
\hline Ash & $7.9-8.6$ & $1.3-8.9$ & $9.0-12.5$ & $0.10-0.57$ \\
\hline Volatile Macter & $37-42$ & $33-55$ & $35-37$ & $35-50$ \\
\hline Fixed Carbon & $50-56$ & $44-65$ & $47-51$ & $47-65$ \\
\hline
\end{tabular}


varied from run to run since each plant run usually involved some differences in pressure, temperature, residence time, equipment configurations, or other important variables from preceding runs.

After the specimens were removed, they were soaked in a clean organic solvent to remove residual process material and were then brushed to remove loose scale and other deposits. The coupons were shipped to ORNL for weighing and sampling and returned to Wilsonville for reinsertion. After the second exposure, all cleaning and weighing were performed at Wilsonville, and a part of each specimen was shipped to ORNL for examination.' Cross sections 'taken perpendicular to the welds were mounted and polished for metallographic examination. Photomicrographs were taken in the unetched condition of two representative areas after the first exposure; one showing the thickest scale on the specimen and the other showing either the minimum scale thickness observed or a different kind of attack. Electron microprobe analysis was performed on the scale of selected coupons to determine the elemental compositions of the phases present. The probe can detect sulfur directly, but not oxygen. Scales containing only small amounts of or no sulfur are presumed to be primarily oxides. Atter the second exposure a single micrograph was taken of each coupon to document any significant changes.

\section{RESULTS}

The corrosion rate data shown in Table 4 indicate that during the exposure periods examined corrosion was not particularly a problem. Most of the specimens outside the fractionation area had a corrosion rate below $0.01 \mathrm{~mm} /$ year. Even the coupons in the two vessels in the fractionation area $(\mathrm{T}-102$ and $\mathrm{T}-105)$, where severe corrosion has been observed recently, ${ }^{4}$ were relatively unattacked $(<0,25 \mathrm{~mm} /$ year $)$ except for the carbon steel specimens, which exhibited rates of up to $0.83 \mathrm{~mm} /$ year. The corrosion rate data, however, may be somewhat misleading. As can be seen from the micrographs of the samples discussed below, quite a bit of corrosion scale is present on many coupons. Indeed, much of this scale was preserved for the purpose of this examination. As a result, the weight loss data are lower than they would be if all the scale had been removed. 
Table 4. Corrosion Rates Calculated from Weight Change Measurements for Corrosion Coupons Exposed at the Wilsonville SRC Pilot

Plant, 3/77-9/78

\begin{tabular}{|c|c|c|c|}
\hline \multirow[t]{2}{*}{ Vessel } & \multirow[t]{2}{*}{ Material } & \multicolumn{2}{|c|}{$\begin{array}{c}\text { Corrosion Rate, mm/year } \\
\text { (mils/year) }\end{array}$} \\
\hline & & $3 / 77-9 / 77$ & $9 / 77-9 / 78$ \\
\hline$R-101$ & $\begin{array}{l}316 \\
347 \\
410 \\
\text { Carpenter } 20 \mathrm{Cb}-3 \\
304 \\
800 \\
330 \\
22-13-5 \\
26-1\end{array}$ & \begin{tabular}{ll}
0.05 & $(2.1)$ \\
0.00 & $(0.0)$ \\
0.10 & $(3.9)$ \\
0.01 & $(0.4)$ \\
0.00 & $(0.0)$ \\
0.03 & $(1.3)$ \\
0.01 & $(0.3)$ \\
0.00 & $(0.0)$ \\
\multicolumn{1}{c}{$a$}
\end{tabular} & $\begin{array}{l}0.044^{a}(1.4) \\
0.03^{a}(1.1) \\
0.01(0.5) \\
0.04^{a}(1.7) \\
0.01(0.2) \\
0.06^{a}(2.2)\end{array}$ \\
\hline$V-103$ & $\begin{array}{l}26-1 \\
304 \\
316 \\
410 \\
22-13-5\end{array}$ & $\begin{array}{c}{ }^{a} \\
0.02^{a}(0.8) \\
0.02(0.6) \\
0.01^{a}(0.3)\end{array}$ & $\begin{array}{ll}0.00 & (0.0) \\
0.01 & (0.2) \\
0.02 & (0.6) \\
0.03 & (1.0) \\
0.01 & (0.2)\end{array}$ \\
\hline$v-105$ & $\begin{array}{l}\text { Carbon steel } \\
304 \\
410\end{array}$ & $\begin{array}{c}0.02(0.7) \\
a^{a}(0.0)\end{array}$ & $\begin{array}{ll}0.00 & (0.0) \\
0.00 & (0.0) \\
0.00 & (0.0)\end{array}$ \\
\hline$V-111$ & $\begin{array}{l}\text { Carbon stee } 1 \\
304 \\
410\end{array}$ & $\begin{array}{l}0.07(2.9) \\
0.00(0.0) \\
0.00 \quad(0.0)\end{array}$ & $\begin{array}{c}0.01 a^{(0.2)} \\
0.00(0.0)\end{array}$ \\
\hline $\begin{array}{c}\mathrm{T}-102(\mathrm{M1}) \\
\text { (Top } \\
\text { Manway) }\end{array}$ & $\begin{array}{l}\text { Carbon stee } 1 \\
304 \\
410\end{array}$ & $\begin{array}{r}0.06(2.3) \\
0.00(0.0) \\
<0.11(0.1)\end{array}$ & $\begin{array}{ll}0.01 & (0.2) \\
0.00 & (0.0) \\
0.00 & (0.0)\end{array}$ \\
\hline $\begin{array}{c}\mathrm{T}-102(\mathrm{M} 2) \\
\text { (Bottom } \\
\text { Manway) }\end{array}$ & $\begin{array}{l}\text { Carbon steel } \\
304 \\
410\end{array}$ & $\begin{array}{l}0.65(25.7) \\
0.00(0.0) \\
0.01 \quad(0.4)\end{array}$ & $\begin{array}{c}0.64(25.1) \\
a^{a} \\
0.01 \quad(0.2)\end{array}$ \\
\hline
\end{tabular}


Table 4. (Continued)

\begin{tabular}{|c|c|c|c|}
\hline \multirow{2}{*}{ Vessel } & \multirow{2}{*}{ Material } & \multicolumn{2}{|c|}{$\begin{array}{c}\text { Corrosion Rate, mm/year } \\
\text { (mils/year) }\end{array}$} \\
\hline & & $3 / 77-9 / 77$ & $9 / 77-9 / 78$ \\
\hline $\begin{array}{c}\mathrm{T}-105(\mathrm{M} 1) \\
\text { ( Top } \\
\text { Manway) }\end{array}$ & $\begin{array}{l}316 \\
\text { Carpenter } 20 \mathrm{Cb}-3 \\
304 \\
321 \\
330 \\
410 \\
\text { Carbon steel } \\
800\end{array}$ & $\begin{array}{l}0.00(0.0) \\
0.03(1.2) \\
0.00(0.0) \\
0.00(0.0) \\
0.00(0.0) \\
0.01(0.2) \\
0.05(2.1) \\
0.01(0.2)\end{array}$ & $\begin{array}{ll}0.00 & (0.0) \\
0.00 & (0.0) \\
0.00 & (0.0) \\
0.00 & (0.0) \\
0.00 & (0.0) \\
0.00 & (0.0) \\
0.03 & (1.3) \\
0.00 & (0.0)\end{array}$ \\
\hline $\begin{array}{r}\mathrm{T}-105(\mathrm{M} 2) \\
\text { (Midd1e } \\
\text { Manway) }\end{array}$ & $\begin{array}{l}316 \\
304 \\
321 \\
410 \\
\text { Carbon steel } \\
800\end{array}$ & $\begin{array}{l}0.18(7.0) \\
0.18(7.2) \\
0.14(5.6) \\
0.21(8.4) \\
0.23(9.1) \\
0.27(10.5)\end{array}$ & $\begin{array}{ll}0.13 & (5.2) \\
0.04 & (1.4) \\
0.03 & (1.0) \\
0.06 & (2.4) \\
0.08 & (3.1) \\
0.03 & (1.3)\end{array}$ \\
\hline $\begin{array}{r}\mathrm{T}-105(\mathrm{M} 3) \\
\text { (Bottom } \\
\text { Manway) }\end{array}$ & $\begin{array}{l}316 \\
304 \\
321 \\
410 \\
\text { Carbon steel } \\
000\end{array}$ & $\begin{array}{l}0.01(0.0) \\
0.00(0.0) \\
0.03(1.1) \\
0.13(5.3) \\
0.77(30.5) \\
0.02(0.8)\end{array}$ & $\begin{array}{c}a \\
a \\
0.05(1.8) \\
0.83(32.6) \\
0.05(2.1)\end{array}$ \\
\hline$v-178$ & $\begin{array}{l}316 \\
304 \\
321 \\
410 \\
\text { Carbon steel } \\
800\end{array}$ & $\begin{aligned} 0.00 & (0.0) \\
0.01 & (0.2) \\
0.01 & (0.3) \\
0.01 & (0.2) \\
0.12 & (4.7) \\
0.01 & (0.1)\end{aligned}$ & $\begin{array}{l}0.0{ }^{\prime \prime}(0.0) \\
0.00(0.0) \\
0.00(0) \\
0.00(0.0) \\
0.07(2.6) \\
0.00(0.0)\end{array}$ \\
\hline
\end{tabular}

uspecimen gained weight. 


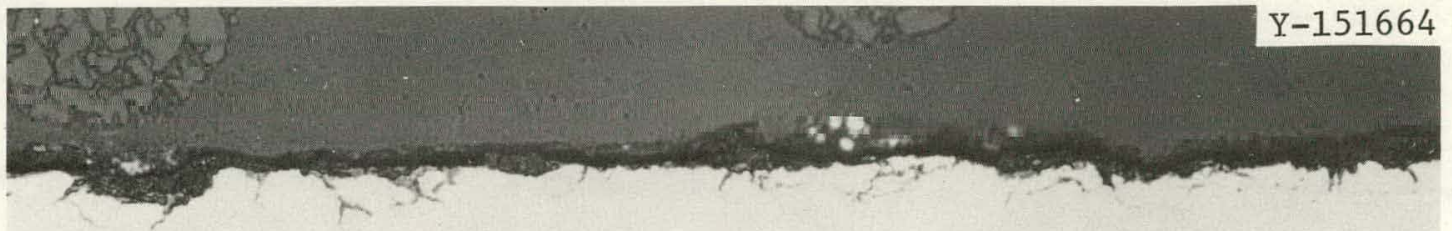

(a)

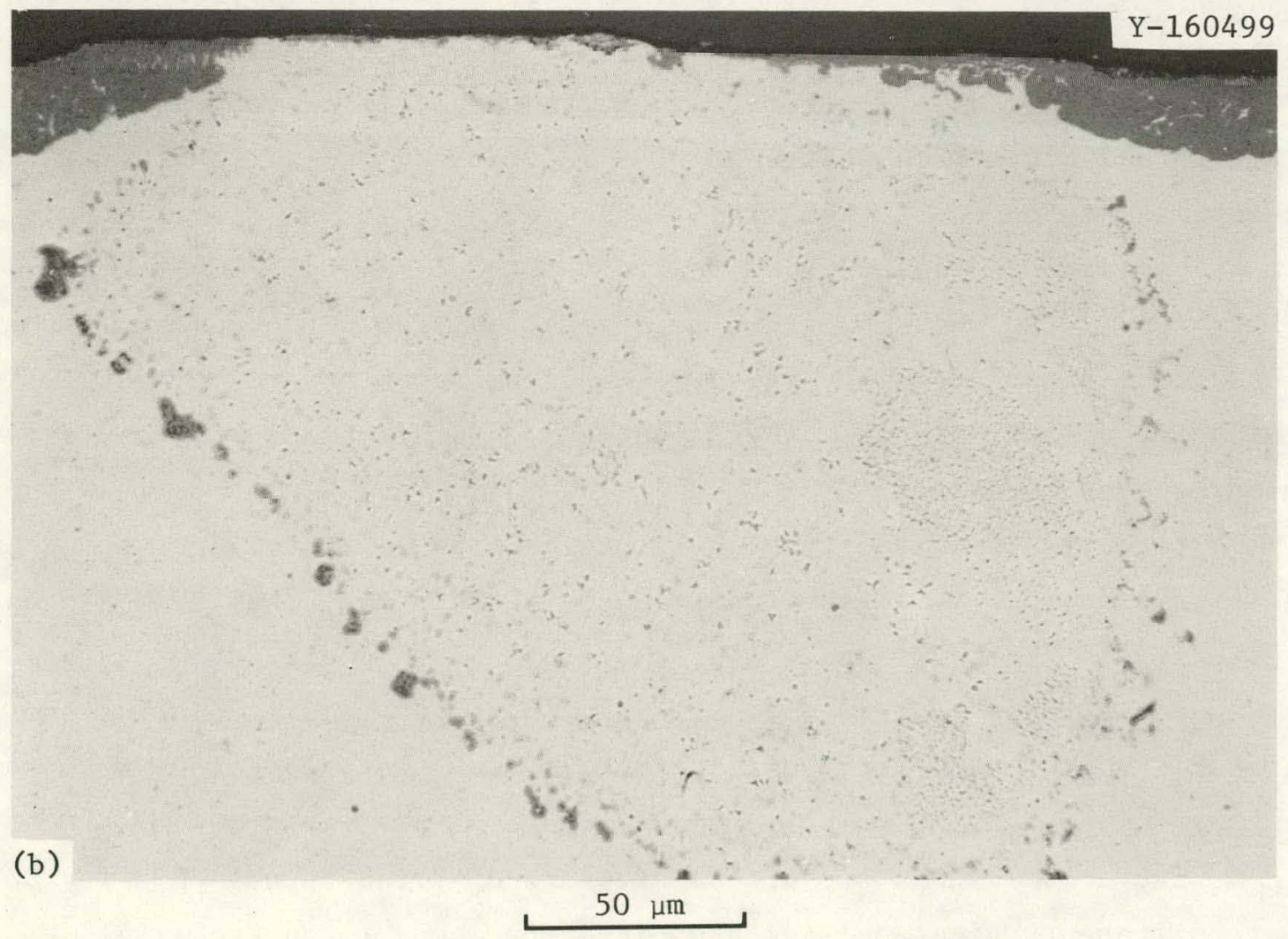

Fig. 3. Type 316 Stainless Steel Specimen Exposed for (a) 4015 Operating Hours and (b) an Additional $5730 \mathrm{~h}$ at the Wilsonville SRC Pilot plant in the R-101 Dissolver. 
We believe, however, even with complete scale removal, that the corrosion rates would not have been significantly higher. Since the purpose of this report is to discuss the scale characteristics, corrosion rate data will not be discussed further.

$$
\text { R-101 Dissn1ver }
$$

Photomicrographs of specimens from the R-101 Dissolver are shown in the following figures. The type 316 stainless steel (Fig. 3) shows surface scale and subsurface attack less than $25 \mu \mathrm{m}$ ( 1 mil) thick; note the slight intergranular attack ill Fiy, 3(A) and the subsurtacc corrosion products in the welded region shown in Fig. 3(b). The type 347 stainless steel shows the same sort of attack as the type 316 stainless steel with slight intergranular attack [Fig. 4(a)] and with a dual-layer scale [Fig. 4(b)] about $70 \mu \mathrm{m}$ thick with subsurface penetration.

The type 410 stainless steel (Fig. 5) has a multilayered srale, which is the thickest found on any of the dissolver specimens, ranging from 0.025 to $0.28 \mathrm{~mm}(1-11 \mathrm{mils})$. The outer layer is very irregular [Fig. 5(a)] with cracks throughout. The cracking and variability in scale thickness may be due to spalling of the scale or to the cleaning process. An irregular outer layer is shown also on the Carpenter $20 \mathrm{Cb}-3$ section [FIy. 6(a)] with what appcar to be several pliases in the deposit. The subsurface attack is also irregular, and the deposits are of medium thickness relative to the other specimens. Some imbedded process stream material can be seen.

The deposits on the type 304 stainless stccl (Fig. 7) are amuly the most interesting. Like the type 410 stainless steel, they show a grcat variation in thickness and appear as a multiphase scale adhering to a very irregular surface [Fig. 7(a)]. Figure 7(b) shows metallic inclusions imbedded in the dendritic scale structure near the weld, along with some subsurface attack.

Figure $8(a)$ shows subsurface attack and surface scale on alloy 800 with different appearances; these differences may be due to exfoliation or partial scaling followed by reexposure. The alloy 330 (Fig. 9) shows a darker deposit on the outer surface near the weld in Fig. 9(b) and some subsurface penetration. The deposit may be process stream material. 


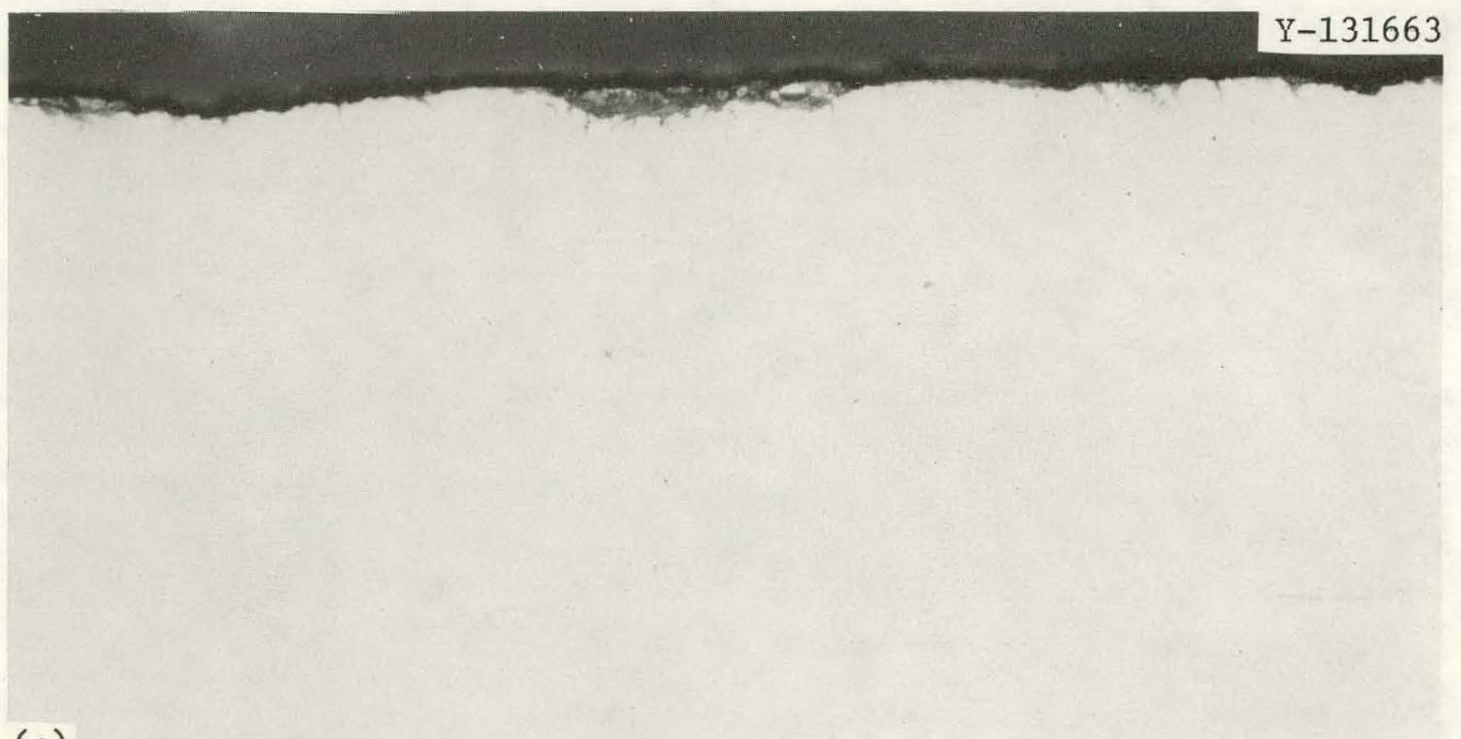

(a)

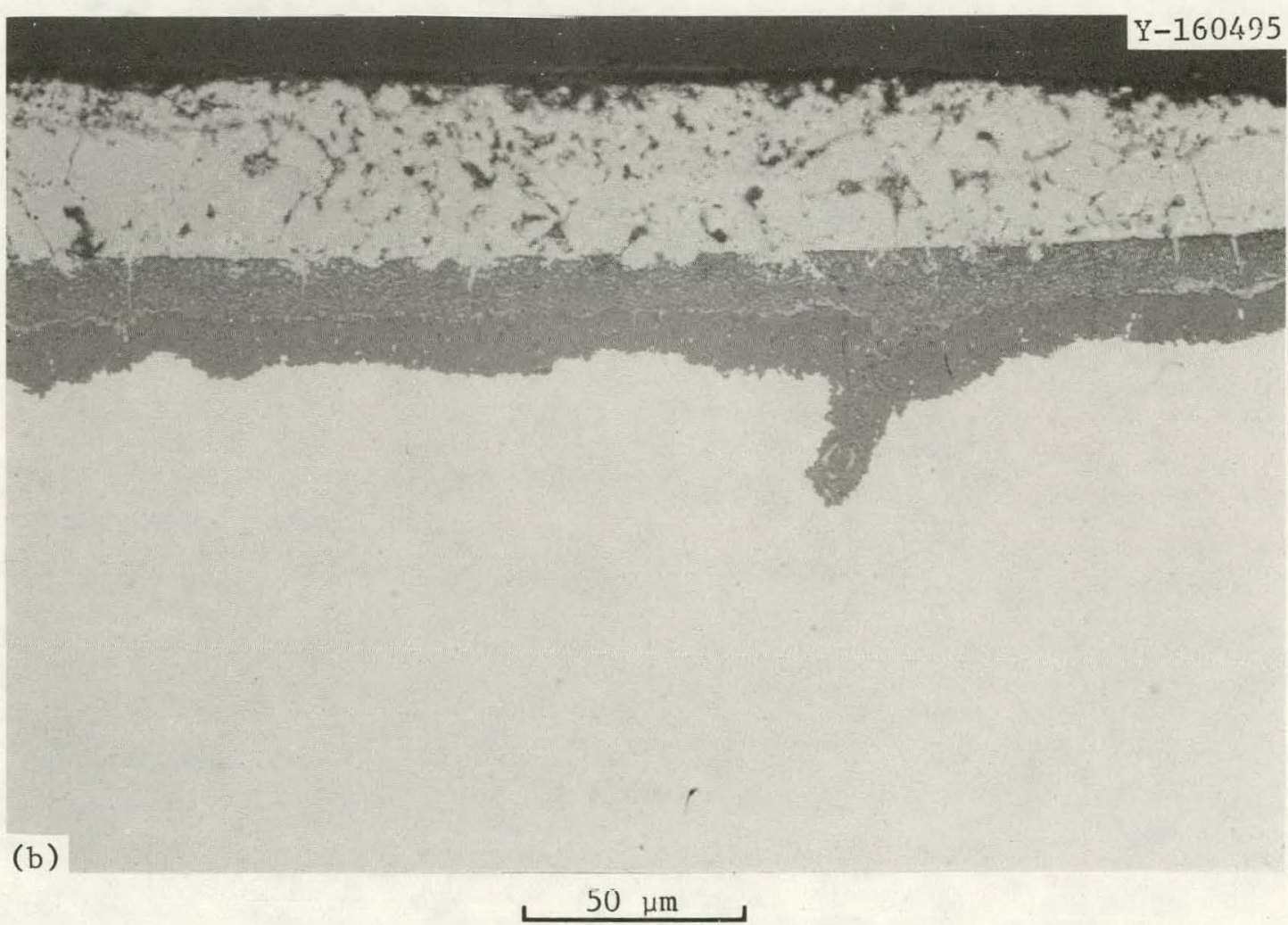

Fig. 4. Type 347 Stainless Steel Specimen Exposed for (a) 4015 Operating Hours and (b) an Additional $5730 \mathrm{~h}$ at the Wilsonville SRC Pilot Plant in the R-101 Dissolver. 

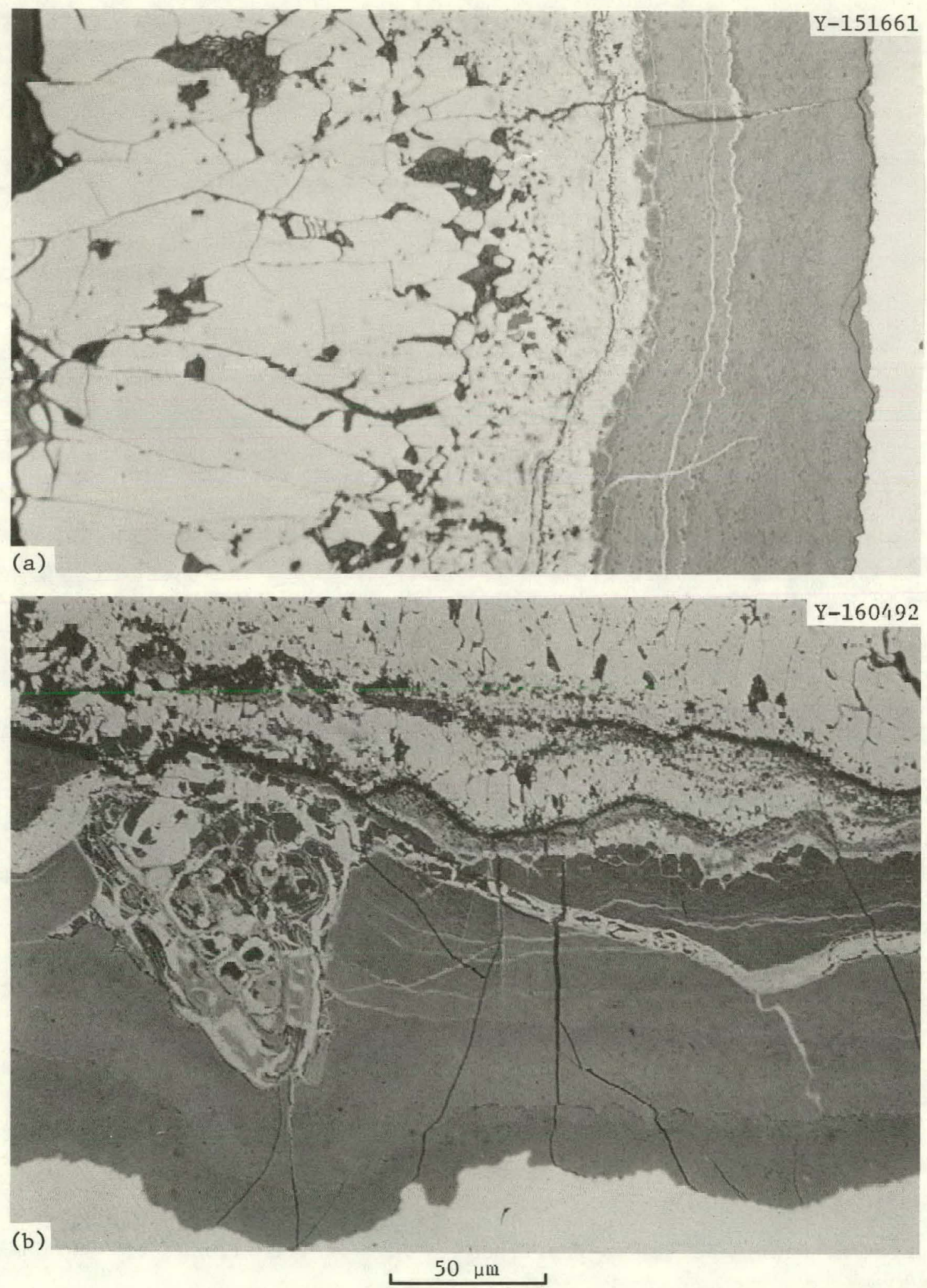

Fig. 5. Type 410 Stainless Steel Specimen Exposed for (a) 4015 Operating Hours and (b) an Additional $5730 \mathrm{~h}$ at the Wilsonville SRC Pilot Plant in the R-101 Dissolver. 

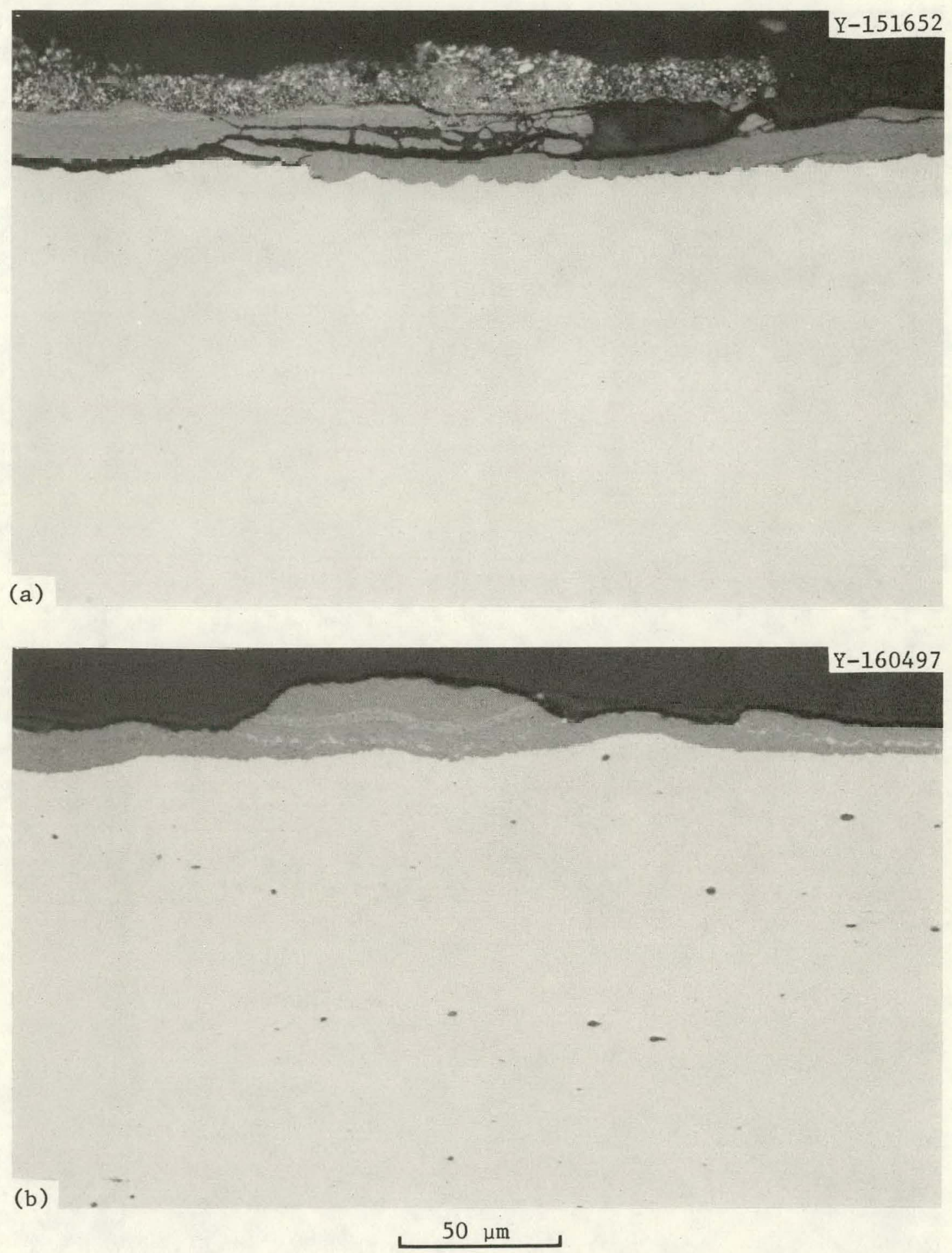

Fig. 6. Carpenter 20 Cb-3 Specimen Exposed for (a) 4015 0perating Hours and (b) an Additional $5730 \mathrm{~h}$ at the Wilsonville SRC Pilot Plant in the R-101 Dissolver. 

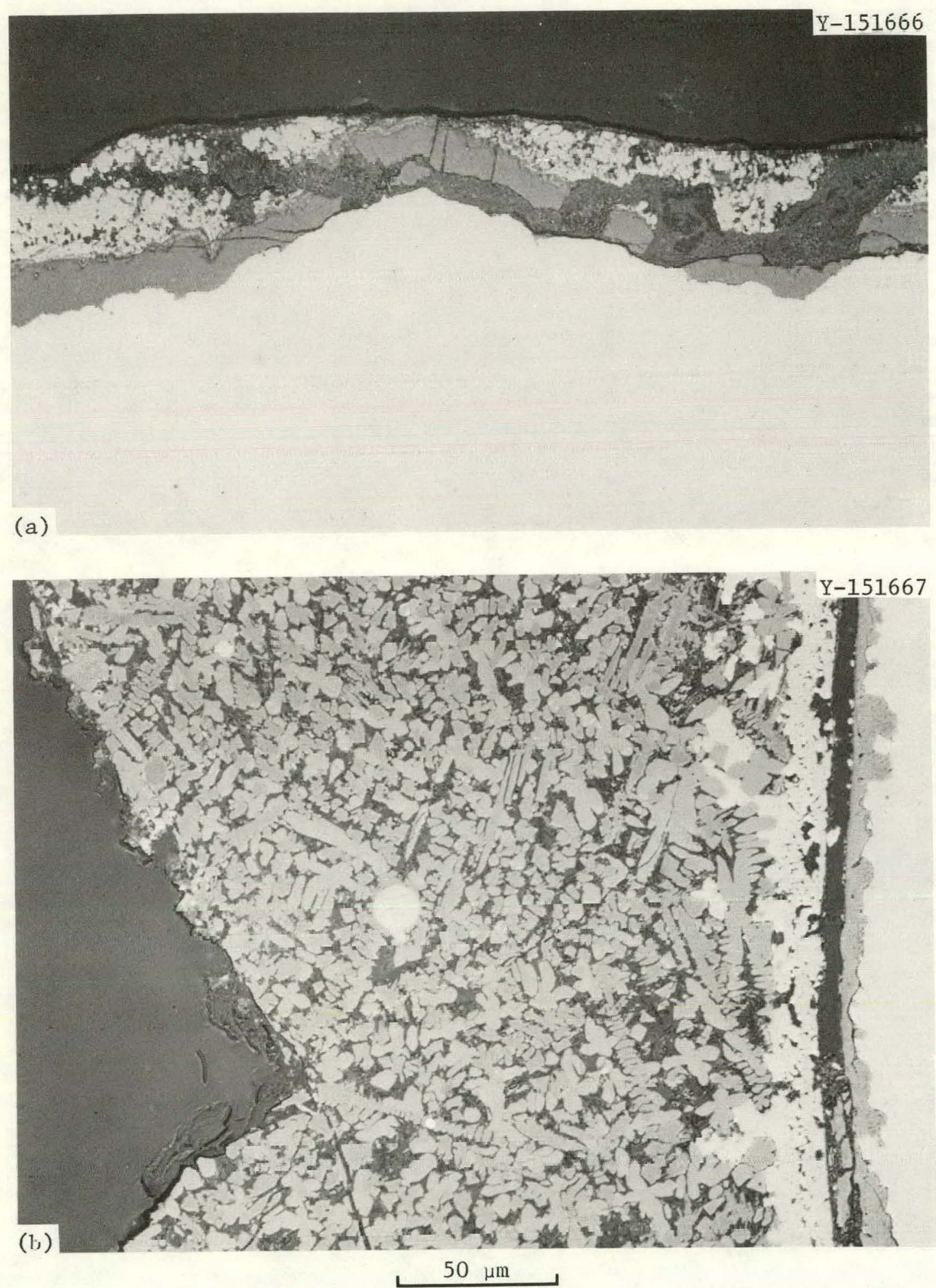

Fig. 7. Type 304 Stainless Steel Specimen Exposed for 4015 Operating Hours at the Wilsonville SRC Pilot Plant in the R-101 Dissolver. The specimen displayed similar subsurface penetration with less surface scale (probably removed during cleaning) after an additional exposure of $5730 \mathrm{~h}$. 


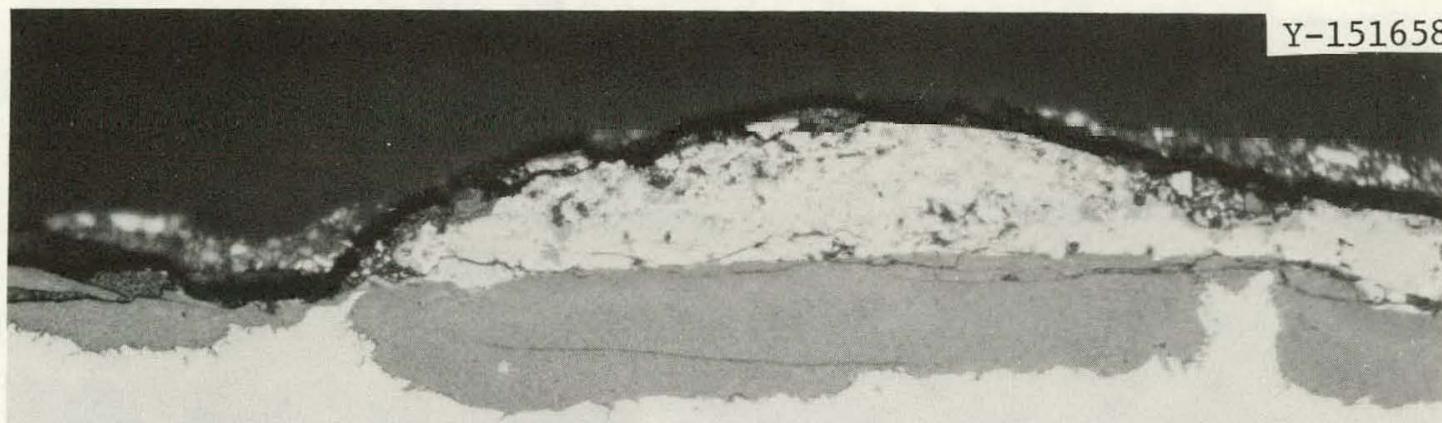

(a)

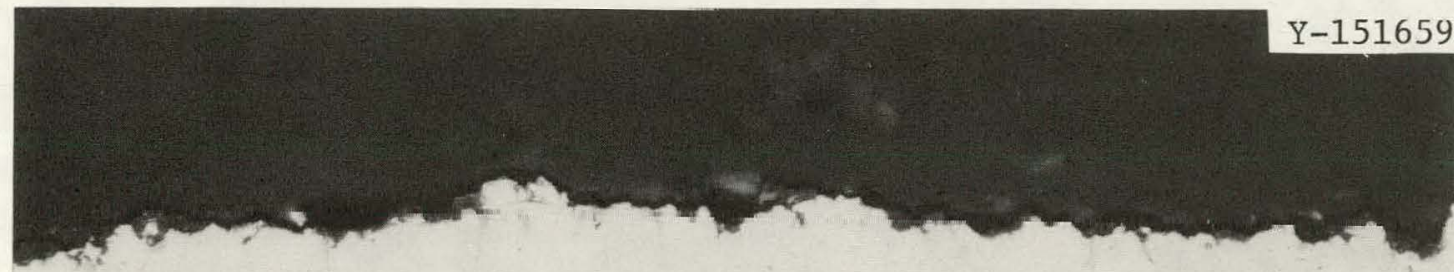

(b)

Fig. 8. Alloy 800 Specimen Exposed for 4015 Operating Hours at the Wilsonville SRC Pilot Plant in the R-101 Dissolver. After the second exposure of 5730 operating hours the extent of subsurface corrosion products had increased. 

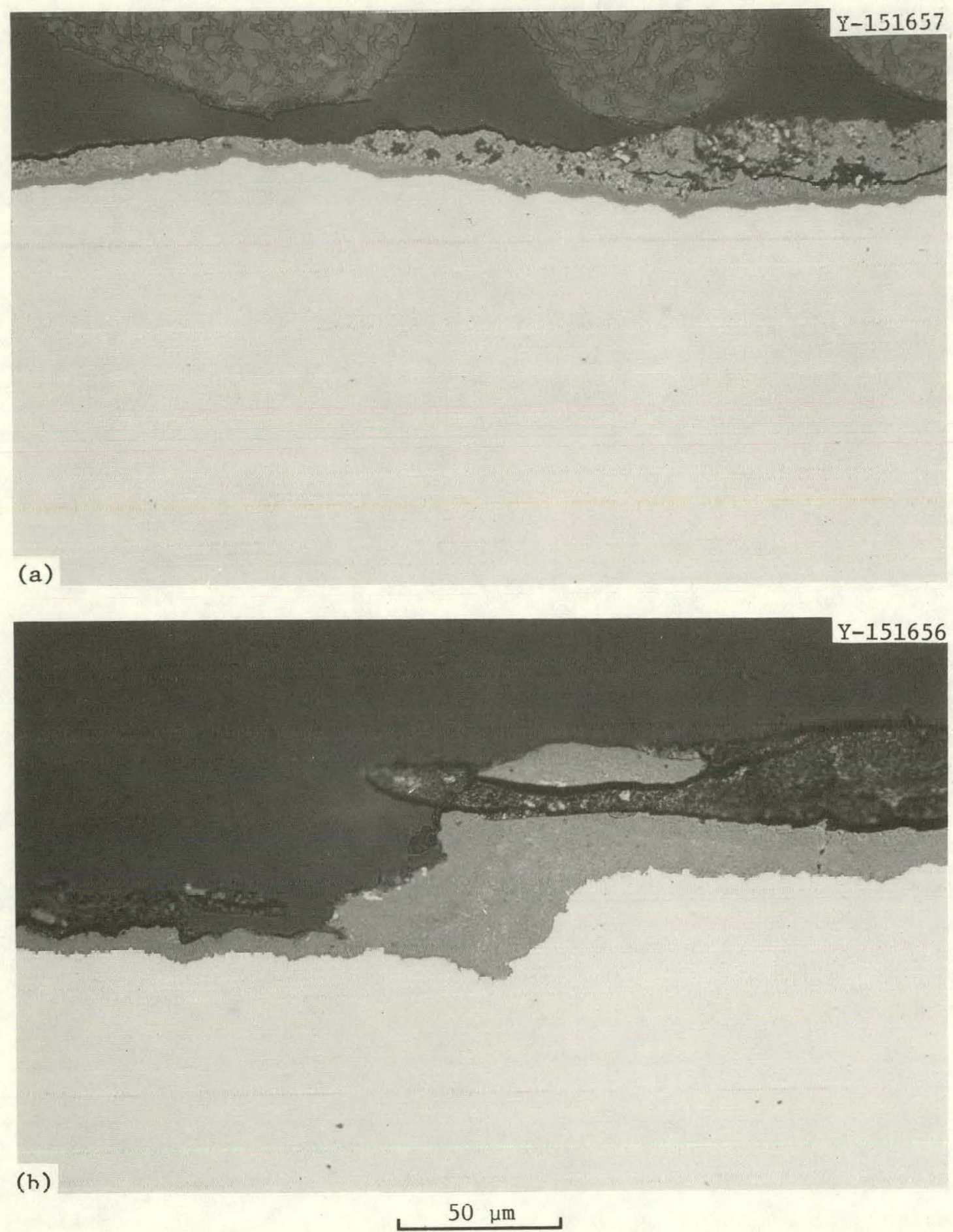

Fig. 9. Alloy 330 Specimen Exposed for 4015 Operating Hours at the Wilsonville SRC Pilot Plant in the R-101 Dissolver. After an additional $5730 \mathrm{~h}$ the specimen displayed the same general characteristics. 
Figure 10 (a) shows the interface between base metal and weld metal in the alloy 22-13-5. Some subsurface attack is noted after the second exposure [Fig. 10(b)], but the scale is thinner than on many of the dissolver specimens. The $26 \mathrm{Cr}-1 \mathrm{Mo}$ (Fig. 11) also shows evidence of subsurface corrosion products [Fig. 11(b)]. Note also the metallic inclusions from the process stream imbedded in the surface scale in Fig. 11(a), which probably account for the weight gain during exposure.

Microprobe analyses were performed on four of the coupons after the first exposure in the dissolver: types 304, 347, and 410 stainless steel and alloy 800. Figure 12 shows the analysis of the type 347 stainless steel. Area B [Fig. 12(c)] is an inner layer of scale, found to contain mostly chromium and iron with some sulfur and silicon. The outer layer appears to be sulfide, predominantly iron sulfide with some nickel sulfide. The presence of nickel is somewhat unexpected, since it is not present in the inner layer.

The composition of the scale on the alloy 800 (Fig. 13) shows some similarity to that observed for the type 347 stainless steel. The inner deposit is primarily chromium, iron, and sulfur with no nickel [Fig. 13(c)], yet the outer layer is predominantly nickel sulfide [Fig. 13(d)].

The presence of sulfides is quite evident in the type 410 stainless steel, as shown in Fig. 14. The inner scale is a somewhat homogeneous sulfide of iron and chromium [Fig. 14(c)] with stringers of primarily iron sulfide [Fig. 14(d)]. The outer layer is completely iron sulfide [Fig. 14(e)].

The complex scale on the type 304 stainless steel is analyzed in Fig. 15. The gray area that appears to be a subsurface deposit contains some sulfide [Fig. 15(c)], but the adjacent light gray area is all iron sulfide with no chromium present [Fig. 15(d)]. The outer surface contains dendrites of calcium-titanium in a matrix that contains calcium, silicon, titanium, and manganese [Fig. 15(e) and (f)]. These elements may be from the process stream or may be oxide spatter from the covered electrode used in welding. 

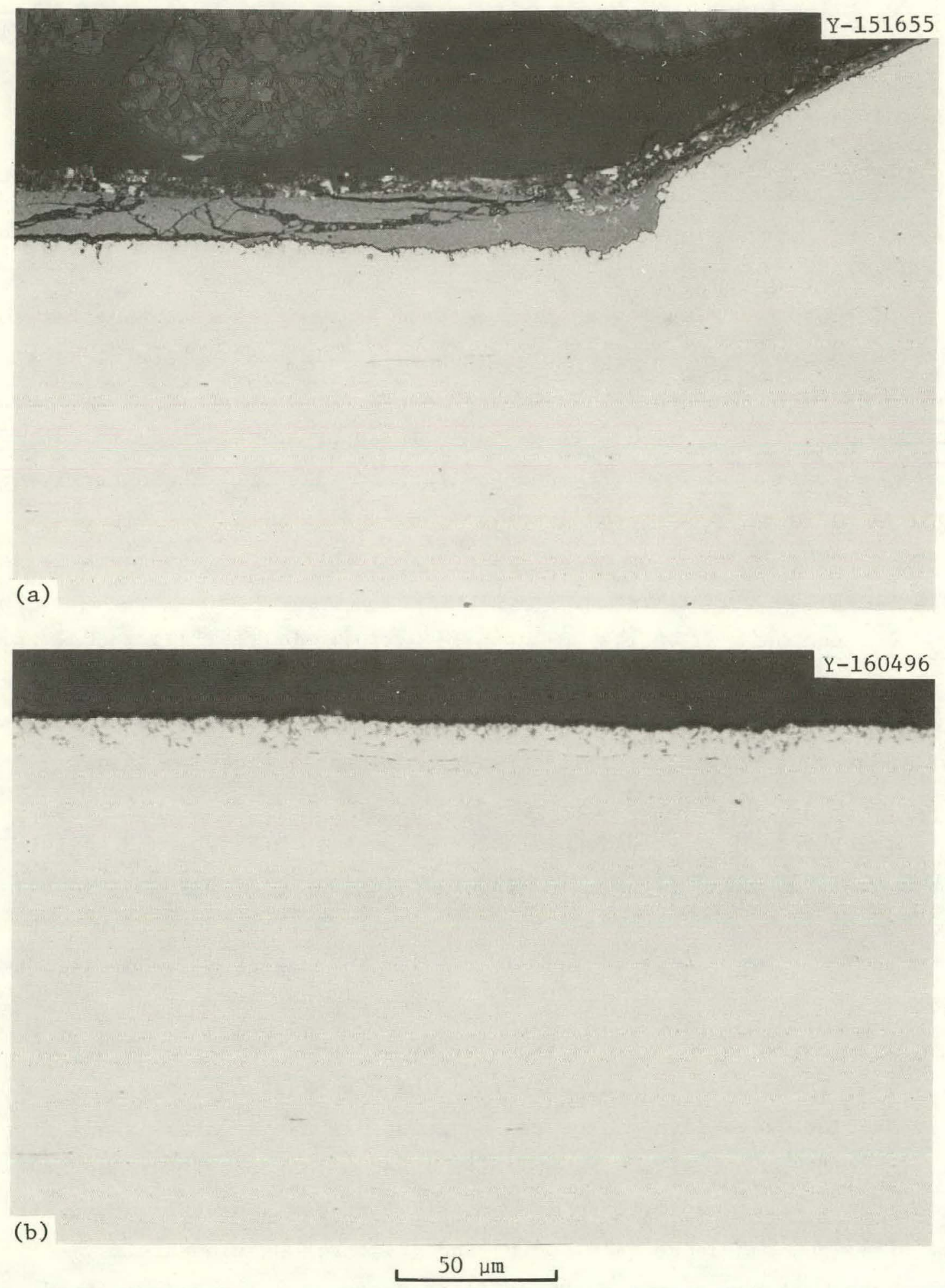

Fig. 10. Alloy 22-13-5 Spec1men Exposed for (a) 4015 Uperating Hours and (b) an Additional $5730 \mathrm{~h}$ at the Wilsonville SRC Pilot Plant in the R-101 Dissolver. 


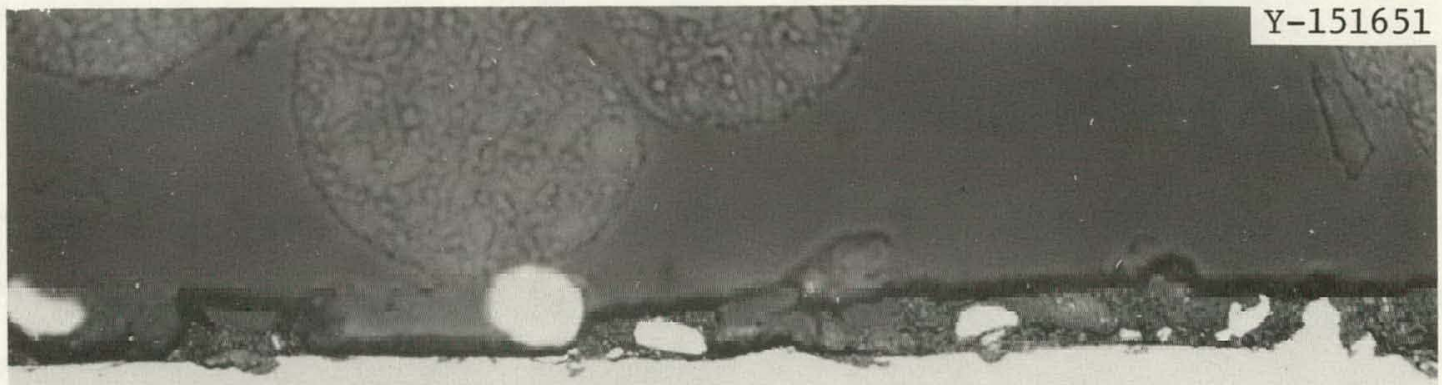

(a)

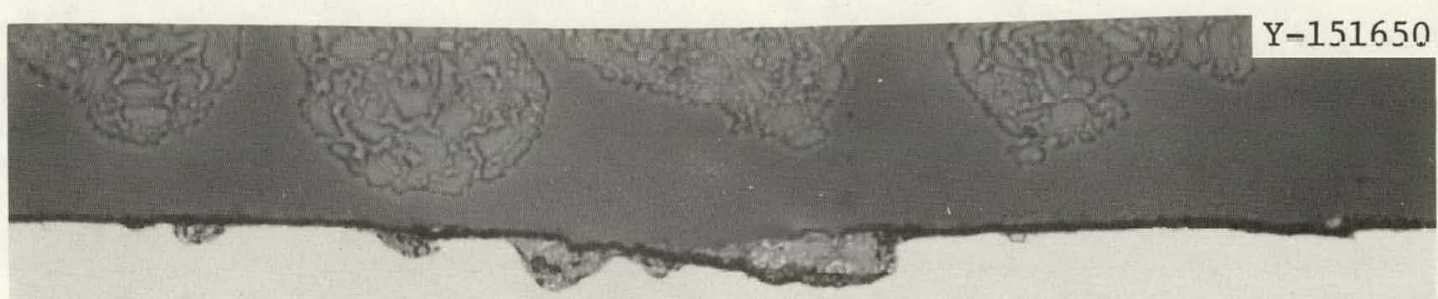

(b)

Fig. 11. Specimen of $26 \mathrm{Cr}-1$ Mo Steel Exposed for 4015 Operating Hours at Wilsonville SRC Pilot Plant in the R-101 Dissolver. 
(a)

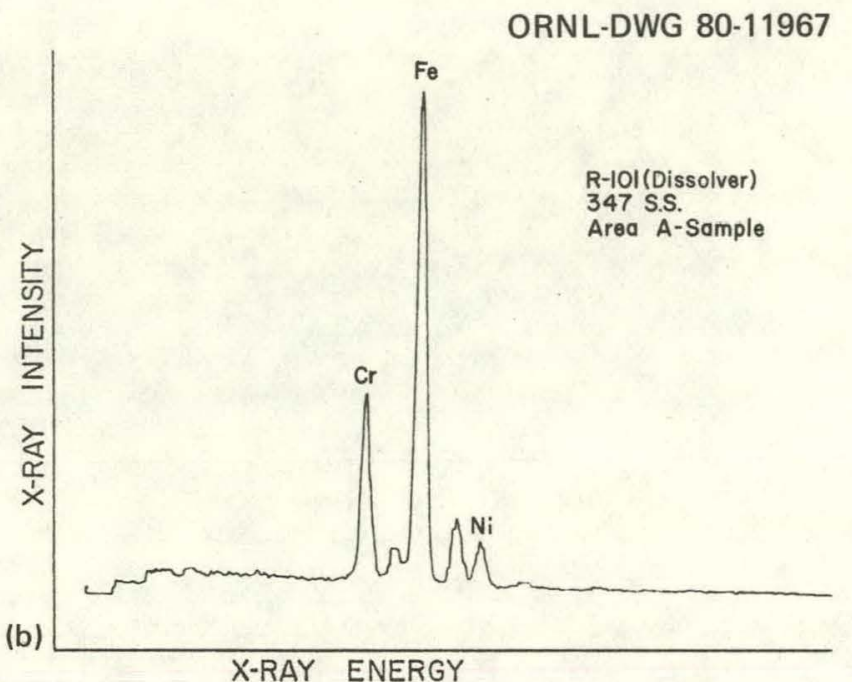

Fig. 12. Microprobe Analysis of Type 347 Stainless Steel Specimen After Exposure in the R-101 Dissolver.
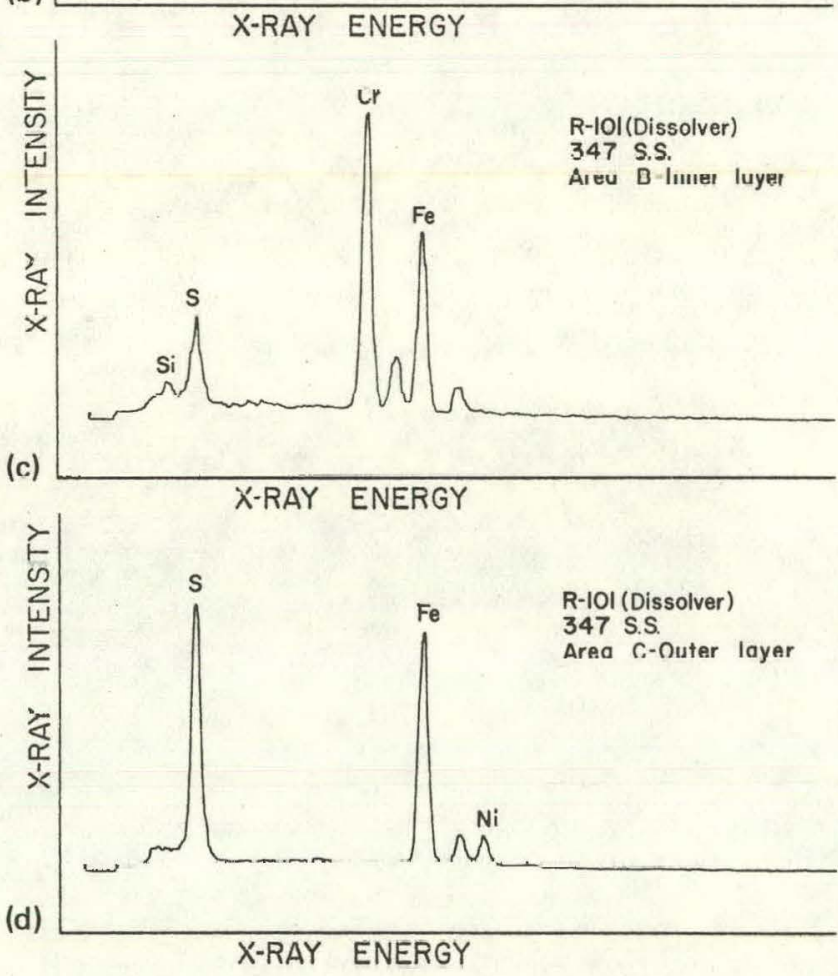
ORNL-DWG 80-11968

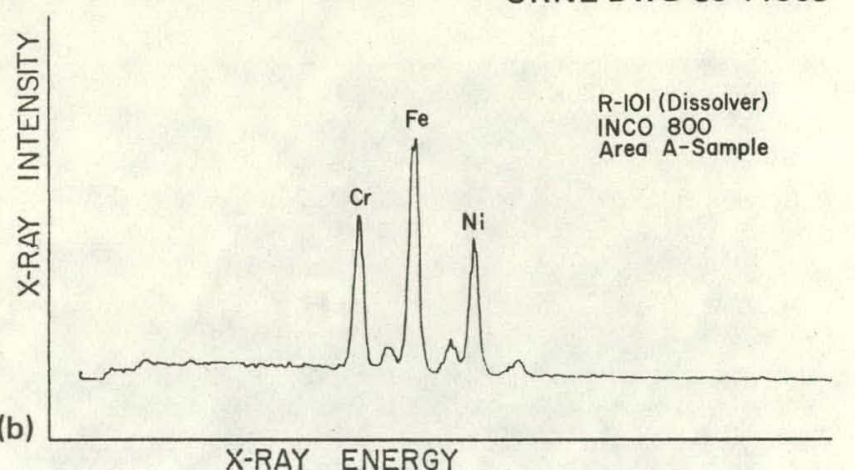

(a)

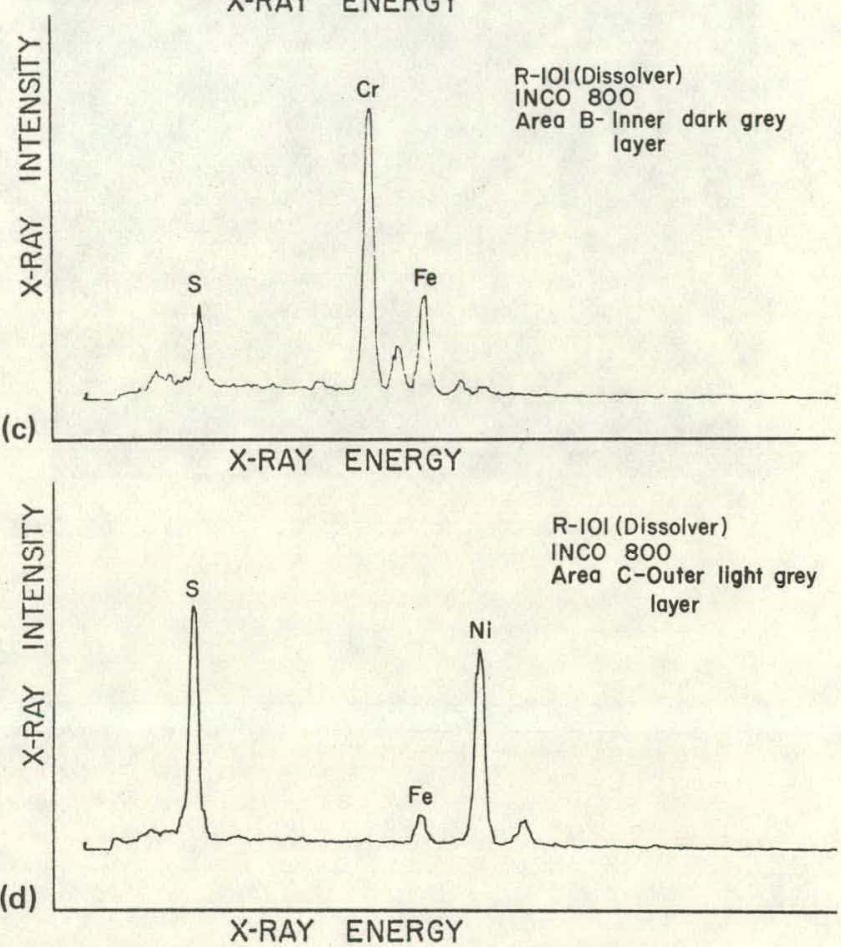




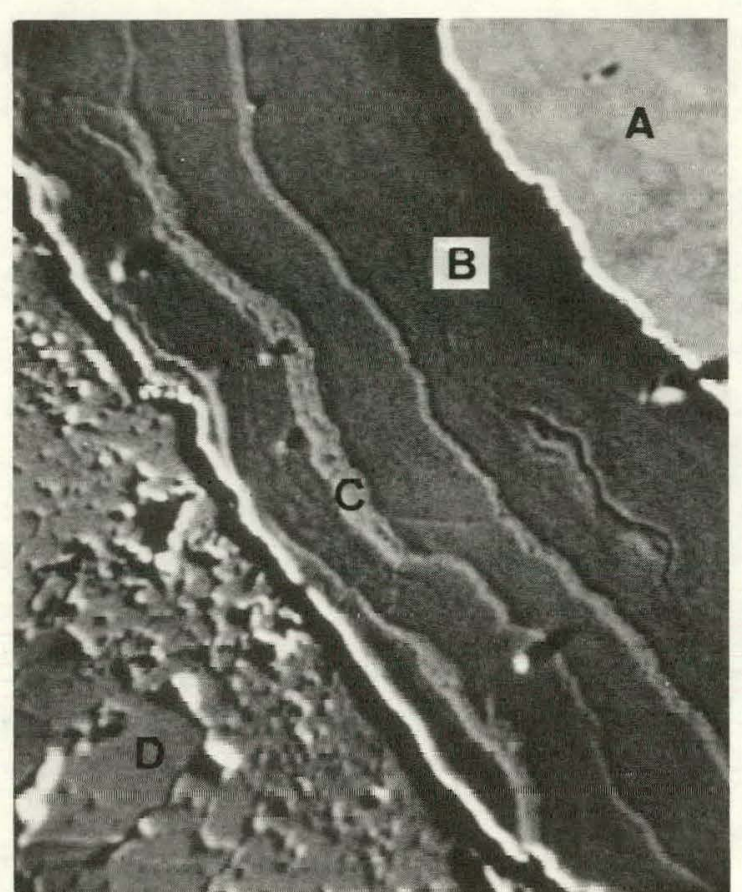

(a)
Fig. 14. Microprobe Analysis of Type 410 Stainless Steel Specimen After Exposure in the R-101 Dissolver.
ORNL-DWG 80-11969
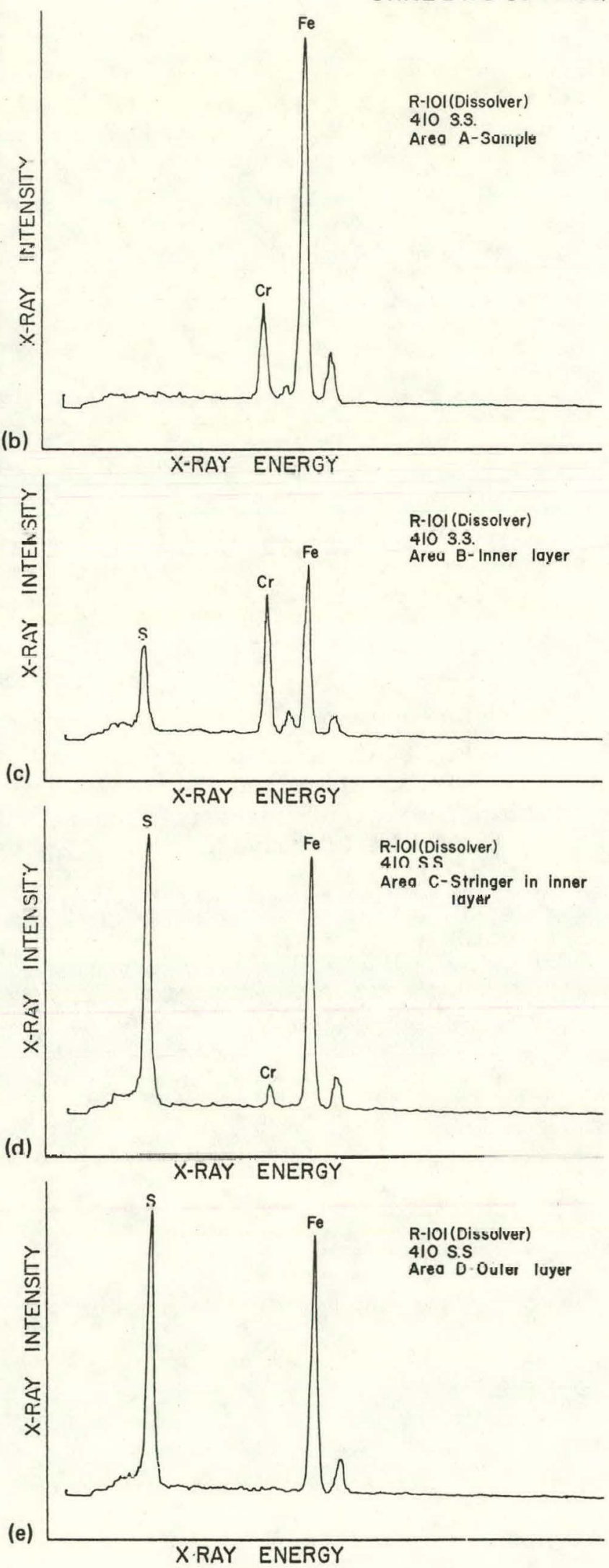

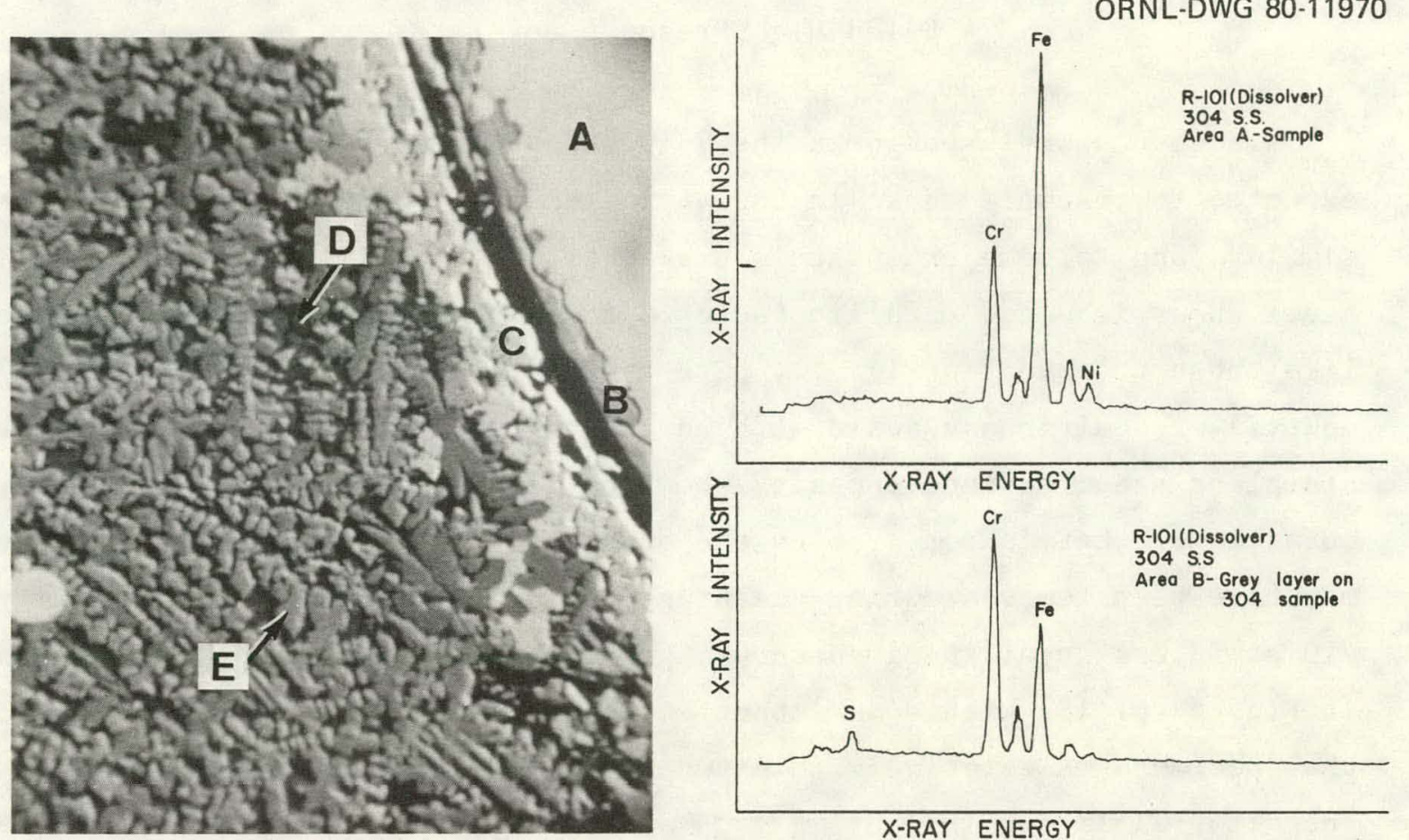

Fig. 15. Microprobe Analysis of Type 304 Stainless Steel Specimen Shown in Fig. 7(b) After Exposure in the $\mathrm{R}-101$ Dissolver.
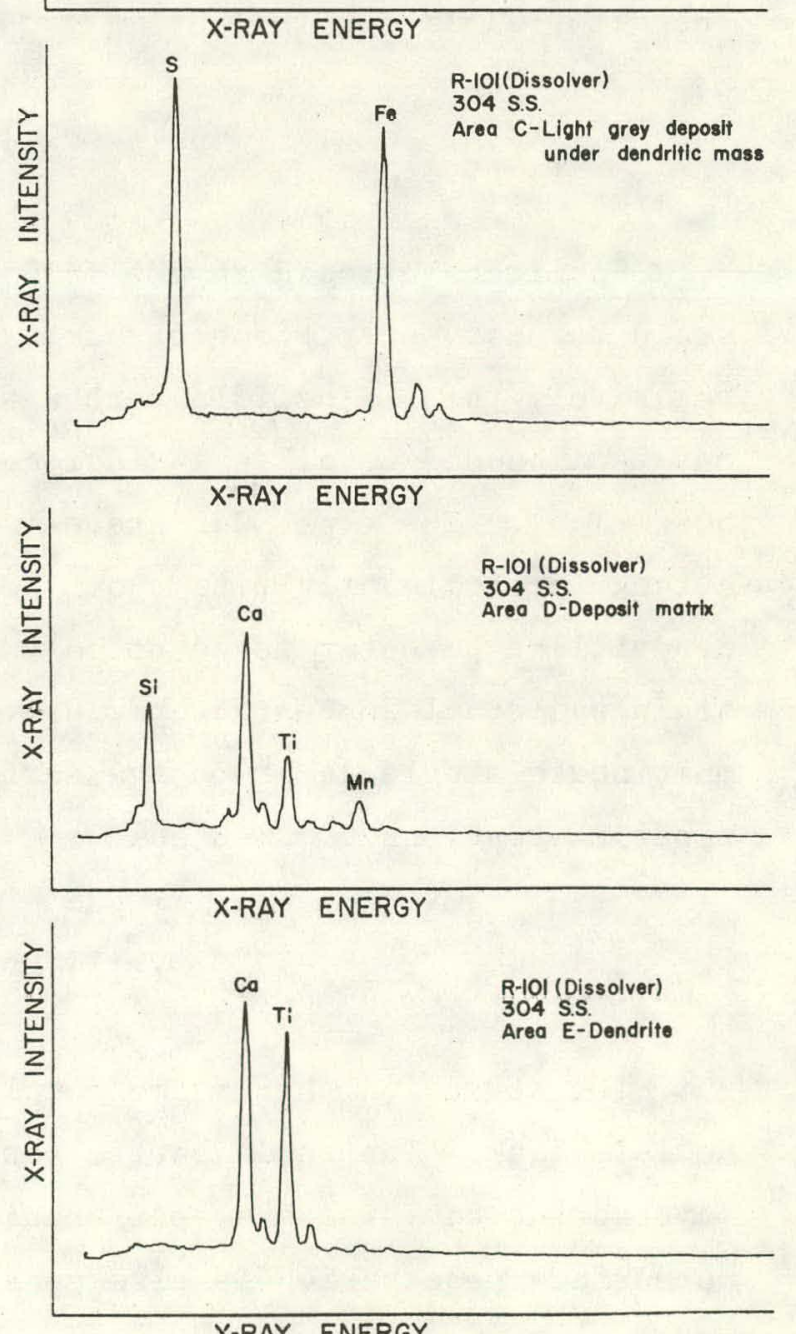

X-RAY ENERGY 
V-103 High Pressure Separator

Those coupons exposed in the V-103 High Pressure Separator would be expected to resemble those in the dissolver since process conditions are similar, and to some extent this expectation is fulfilled. The $26 \mathrm{Cr}-1 \mathrm{Mo}$ steel shows imbedded metallic inclusions and subsurface corrosion products like those observed in Fig. 11. The type 304L stainless steel contains a multilayer, multiphase scale with an outer dendritic layer. The type 316 stainless steel surface deposits show the largest difference, with an outer layer that is not seen on the dissolver coupons; however, this layer may have been removed during cleaning of the dissolver specimen. The type 410 stainless steel specimen shows the same multistructured layers shown in Fig. 5 ( $\mathrm{p}$. 18) with some subsurface penetration in another location on the specimen. A relatively thin two-layer scale was observed again for the alloy 22-13-5.

\section{V-105 Solvent Decanter}

Specimens exposed in the V-105 Solvent Decanter exhibited mostly grain boundary or pitting attack; surface scales and deposits were relatively thin. The 1018 carbon steel shows a multilayer scale with what may be imbedded metallic inclusions and stringer-type penetrations up to $50 \mu \mathrm{m}$ long. The type 304L stainless steel shows noticeable subsurface attack (predominantly pits about $100 \mu \mathrm{m}$ deep) but no evidence of the thick dendritic-type outer scale noted previously. The attack of the type 410 stainless steel is characterized by many imbedded inclusions in a multiphase single layer on the surface and subsurface pits and stringertype penetrations $30 \mu \mathrm{m}$ deep.

\section{V-111 Reclaim Tank}

The attack on these same metals is quite different in the V-111 Reclaim Tank. The scale on the carbon steel (Fig. 16) is not distinctly layered but contains many different phases and some metallic particles. Subsurface penetration is also apparent [Fig. 16(b)] to a depth of about 

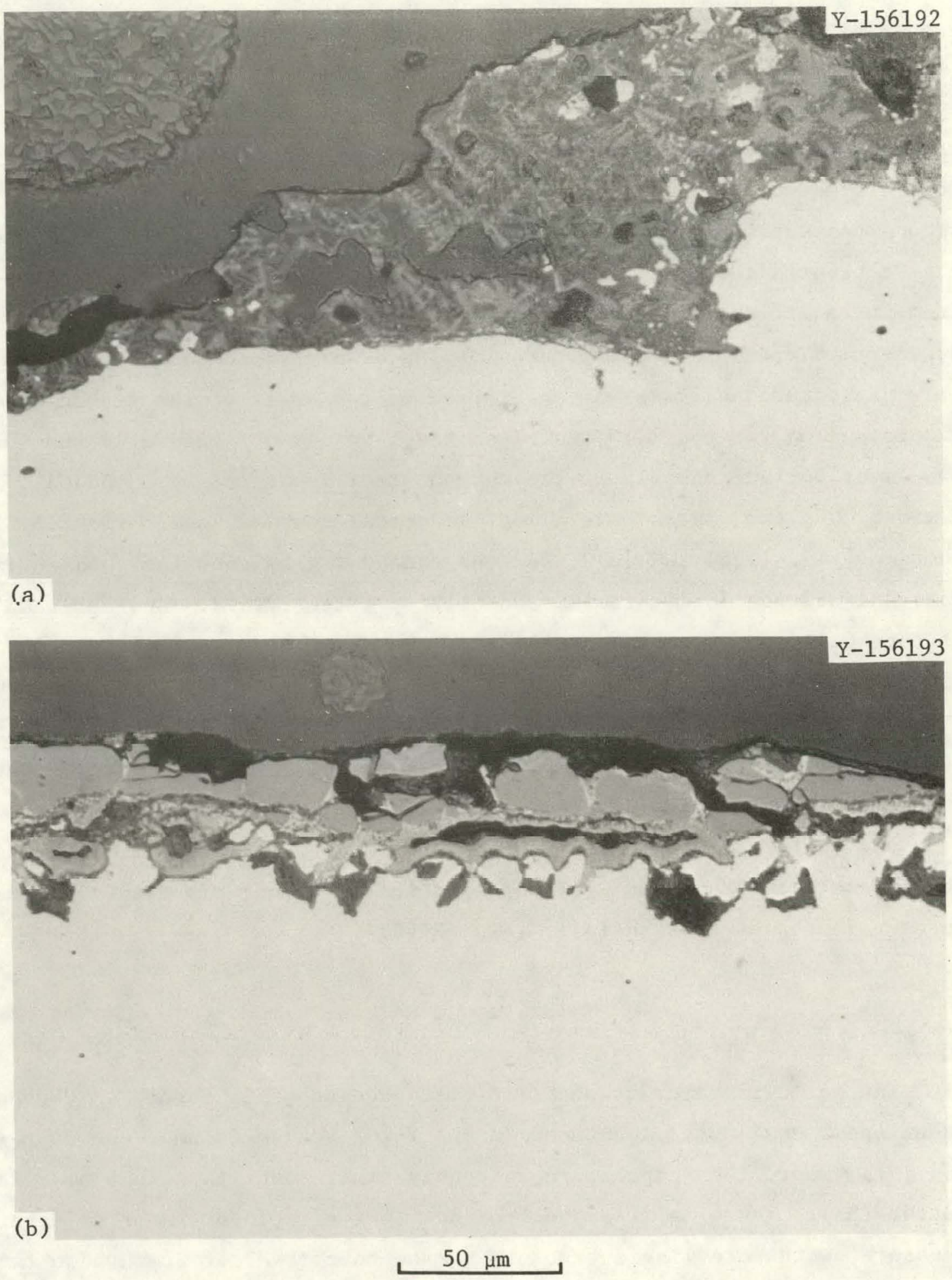

Fig. 16. Specimen of 1018 Carbon Steel Exposed for 4015 Operating Hours at the Wilsonville SRC Pilot Plant in the V-111 Reclaim Tank. After an additional $5730 \mathrm{~h}$ of exposure time the specimen exhibited a two-layer scale. 
$30 \mu \mathrm{m}$ below the existing surface. The type $304 \mathrm{~L}$ stainless steel has a different scale appearance (Fig. 17) when compared with the R-101 (type 304) and V-103 specimens; the scale is still multilayer but penetrates the surface more and contains inclusions not observed previously for this material. Intergranular penetrations were observed after the second exposure [Fig. 17(b)]. Figure 18 shows the extent of subsurface penetration in the type 410 stainless steel. Needle-like cracks extend from the multilayer scale. The subsurface penetration extended even further after the second exposure forming a layered corrosion product. Microprobe analyses were performed on two areas of the carbon steel sample and on the type 410 stainless steel specimen. Figure 19 shows a two-layer surface deposit on the carbon steel separated by a banded region. The two layers have almost identical compositions, primarily iron sulfide [Fig. 19(c) and (e)], but the banded region contains substantially less sulfur with some chromium and silicon [Fig. 19(d)]. Another view of the scale on the carbon steel (Fig. 20) displays a pock-marked gray deposit containing $\mathrm{Fe}, \mathrm{Si}, \mathrm{Mn}, \mathrm{Ti}$, and $\mathrm{Al}$, completely different from that observed in Fig. 19. These elements are present in trace quantities in the process streams or may be present as a result of weld spatter. The reaction product on the type 410 stainless steel (Fig. 21) is primarily iron and sulfur with a small amount of chromium [Fig. 21(c)]. As the scale penetrates the sample, the proportion of chromium present in the deposit increases substantially [Fig. 21(d)].

\section{T-102 Vacuum Column}

The following micrographs illustrate the deposits formed on carbon steel specimens in two locations in the T-102 Vacuum Column, one near the top (MI), where the temperature is considerably lower than that near the bottom (M2). There is also a difference in the ratio of vapor to liquid exposure, with more liquid exposure at the bottom (M2). From these two differences alone, one would expect the scale to be somewhat different on the two specimens, with the most damage occurring under the hightemperature liquid phase conditions. The amount of scale and depth of penetration are indeed different in the two locations in a comparison 


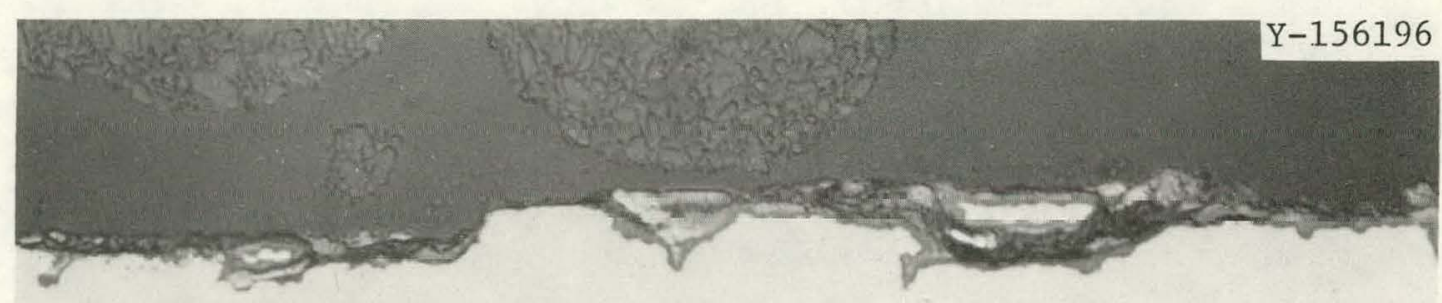

(a)

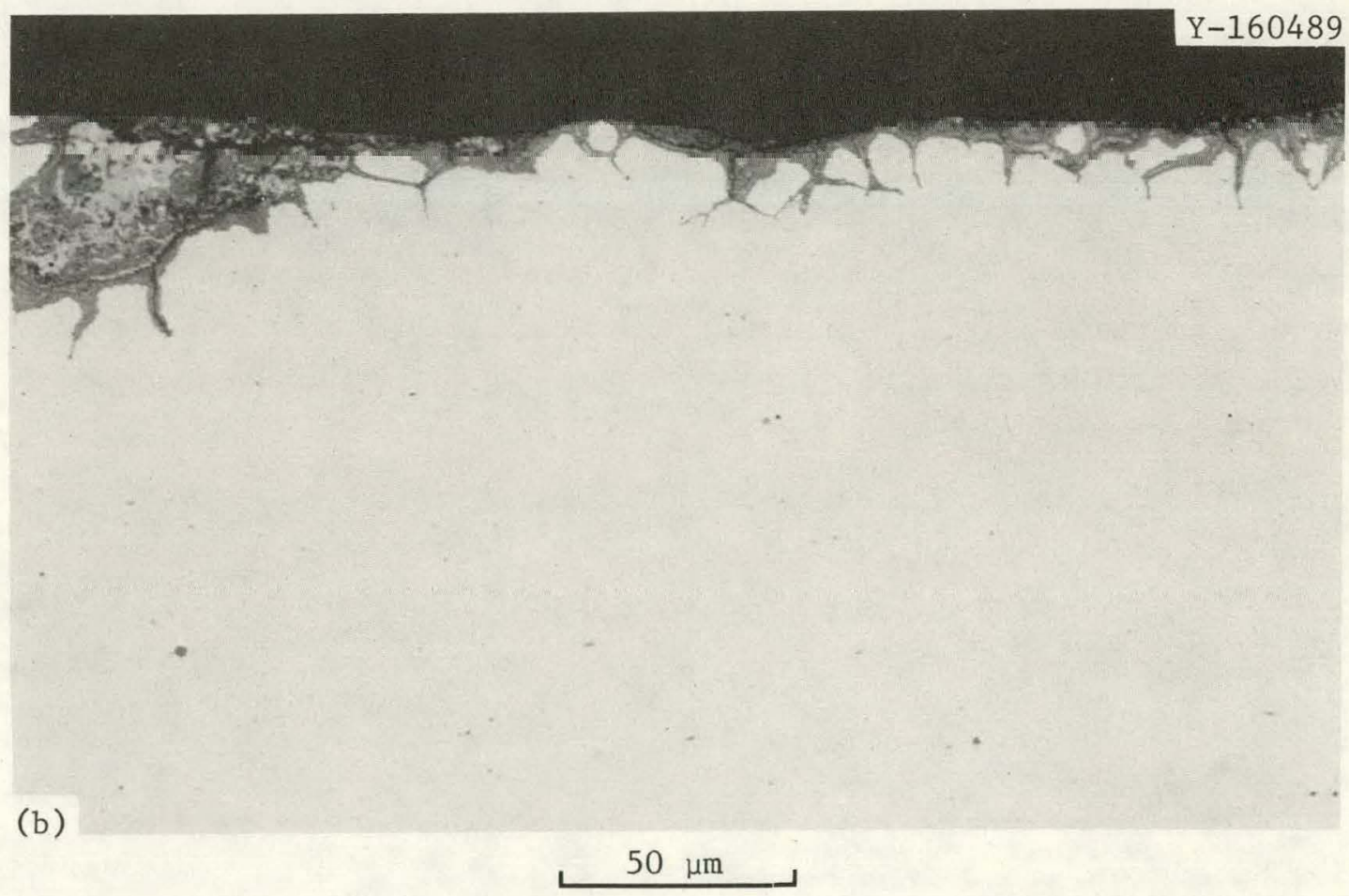

Fig. 17. Type 304L Stainless Steel Specimen Exposed for (a) 4015 Operating Hours and (b) an Additional $5730 \mathrm{~h}$ at the Wilsonville SRC Pilot Plant in the V-111 Reclaim Tank. 

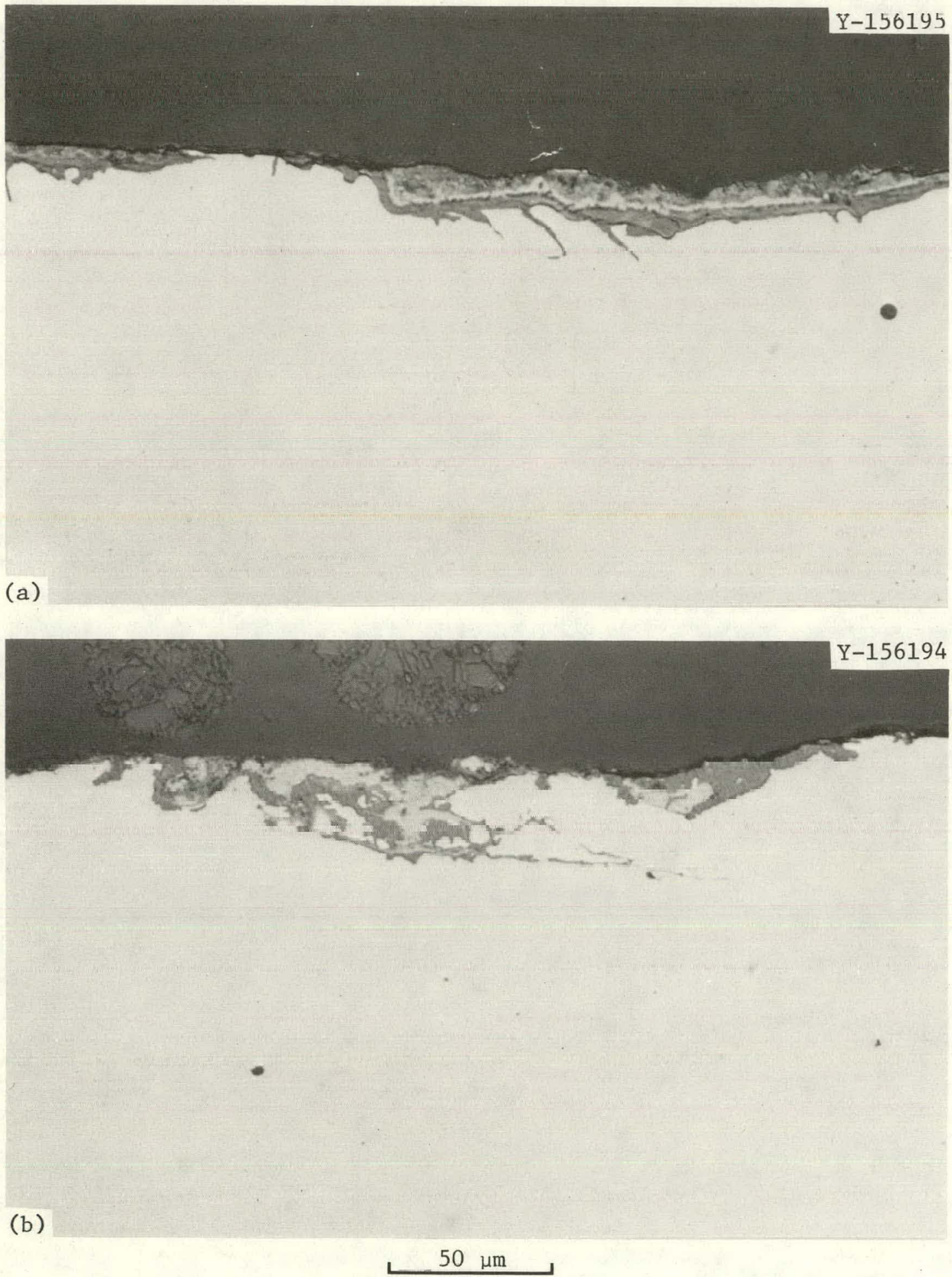

Fig. 18. Type 410 Stainless Steel Specimen Exposed for 4015 Operating Hours at the Wilsonville SRC Pilot Plant in the V-111 Reclaim Tank. Subsurface penetration increased during the second exposure period of $5730 \mathrm{~h}$. 

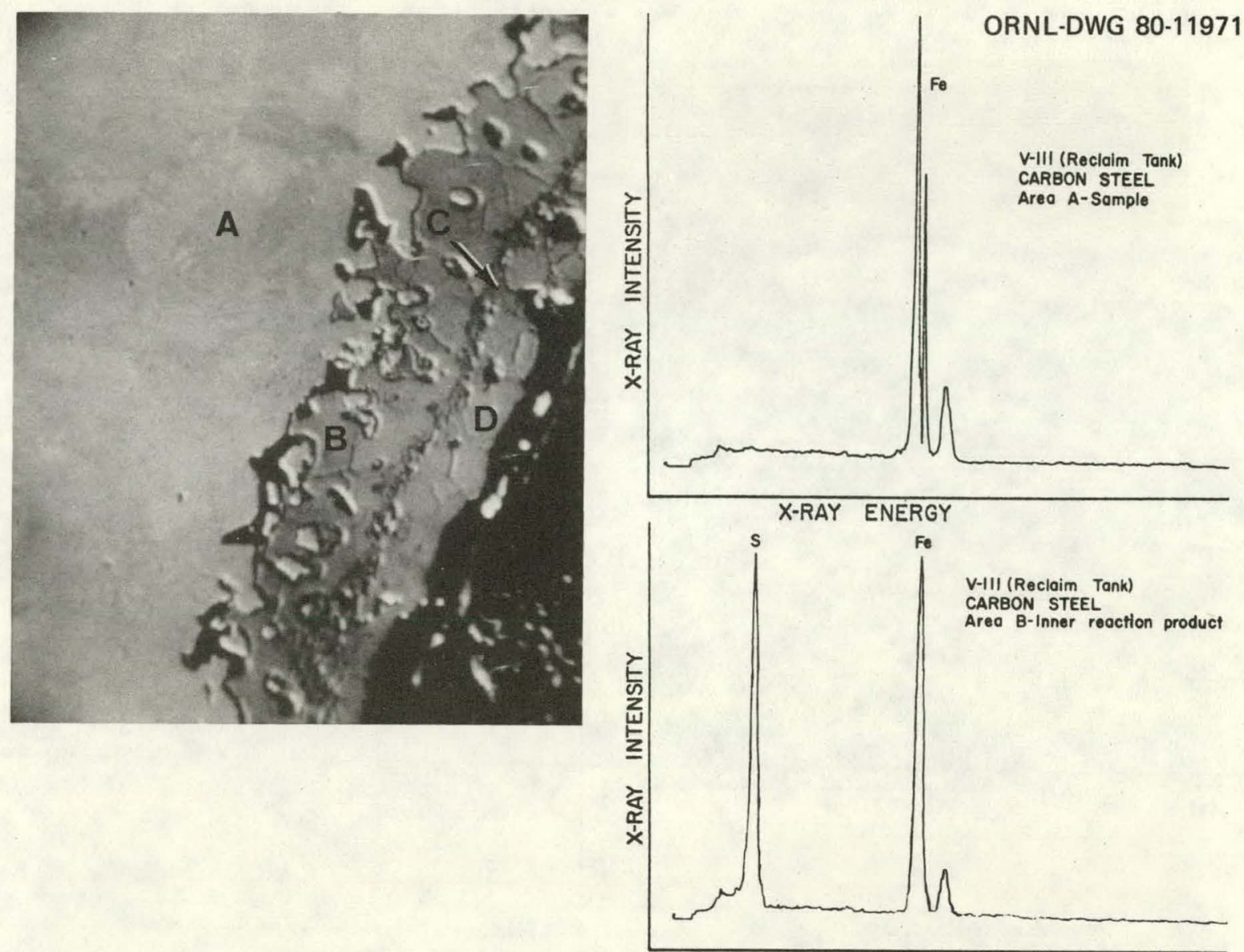

Fig. 19. Microprobe Analysis of 1018 Carbon Steel Sample Shown in Fig. 16(b) After Exposure in the V-111 Reclaim Tank.

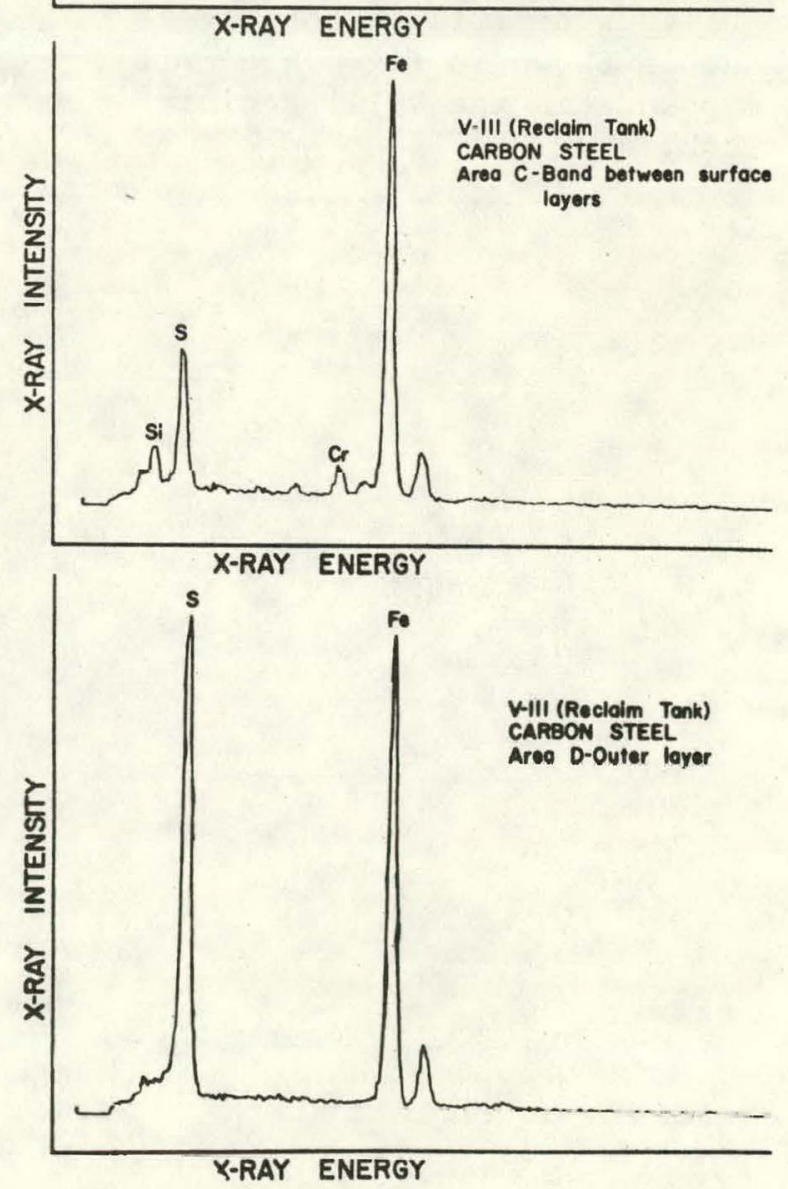




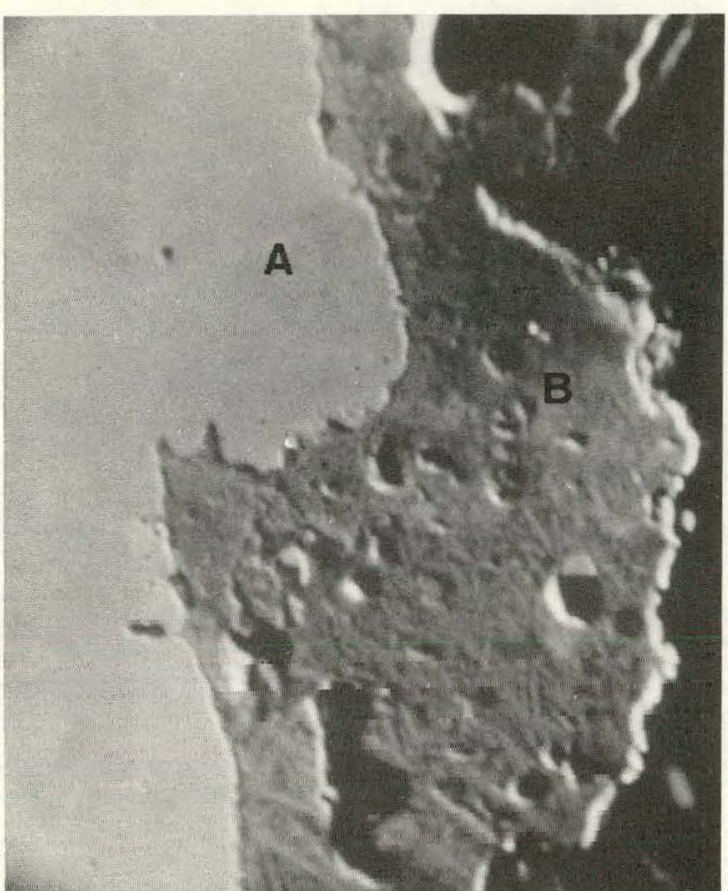

(a)

Fig. 20. Microprobe Analysis of 1018 Carbon Steel Sample Shown in Fig. 16(a) After Exposure in the V-111 Reclaim Tank.

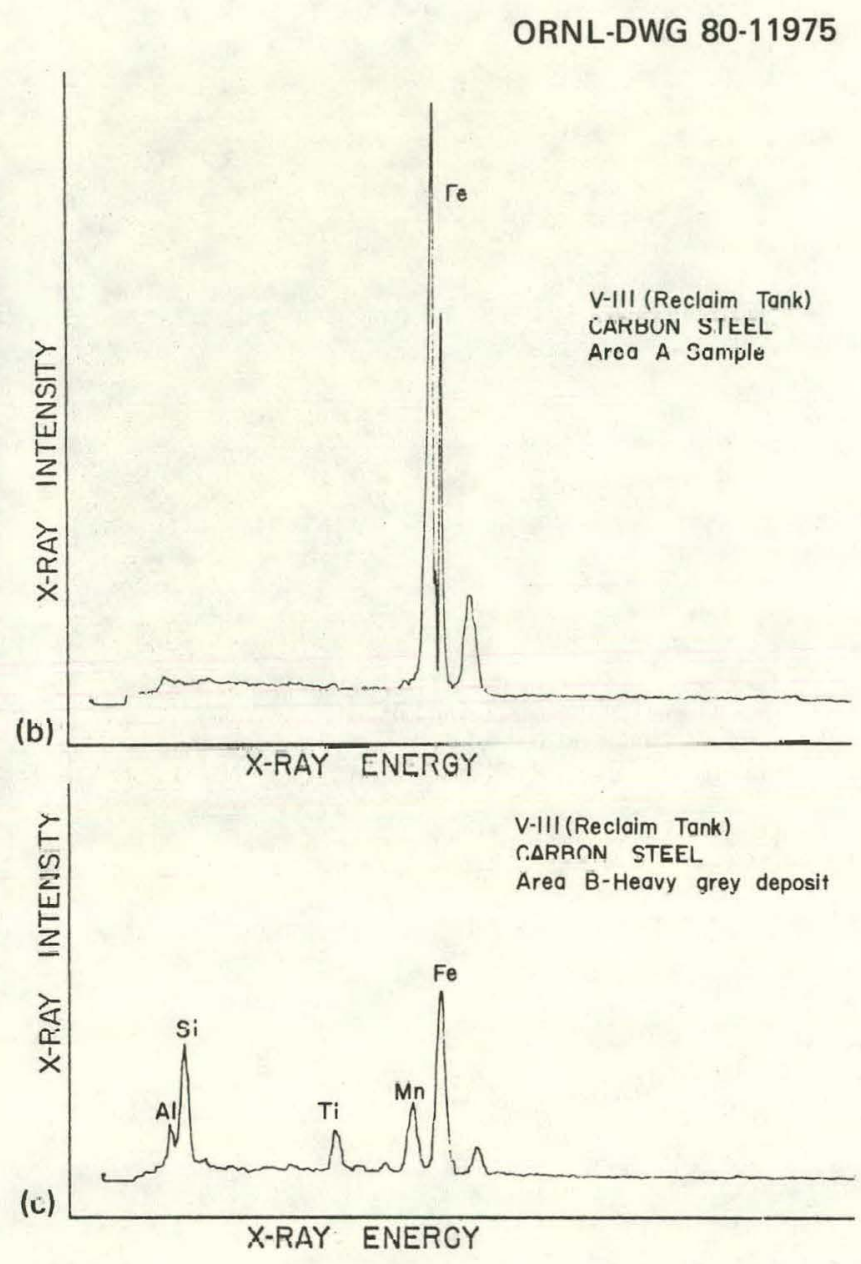




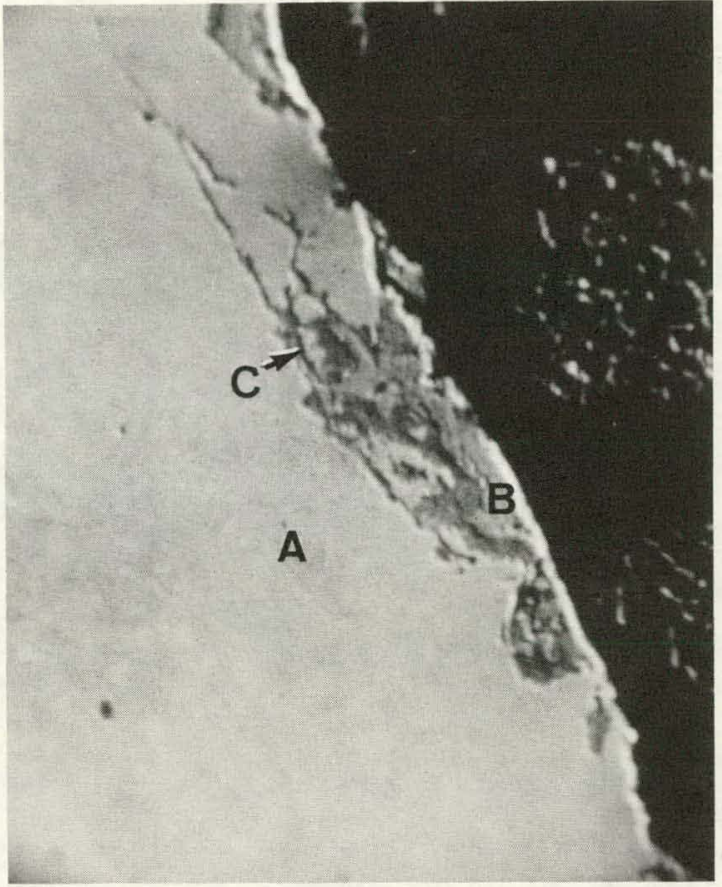

(a)

Fig. 21. Microprobe Analysis of Type 410 Stainless Steel Sample Shown in Fig. 18(b) After Exposure in the $\mathrm{V}-111$ Reclaim Tank.

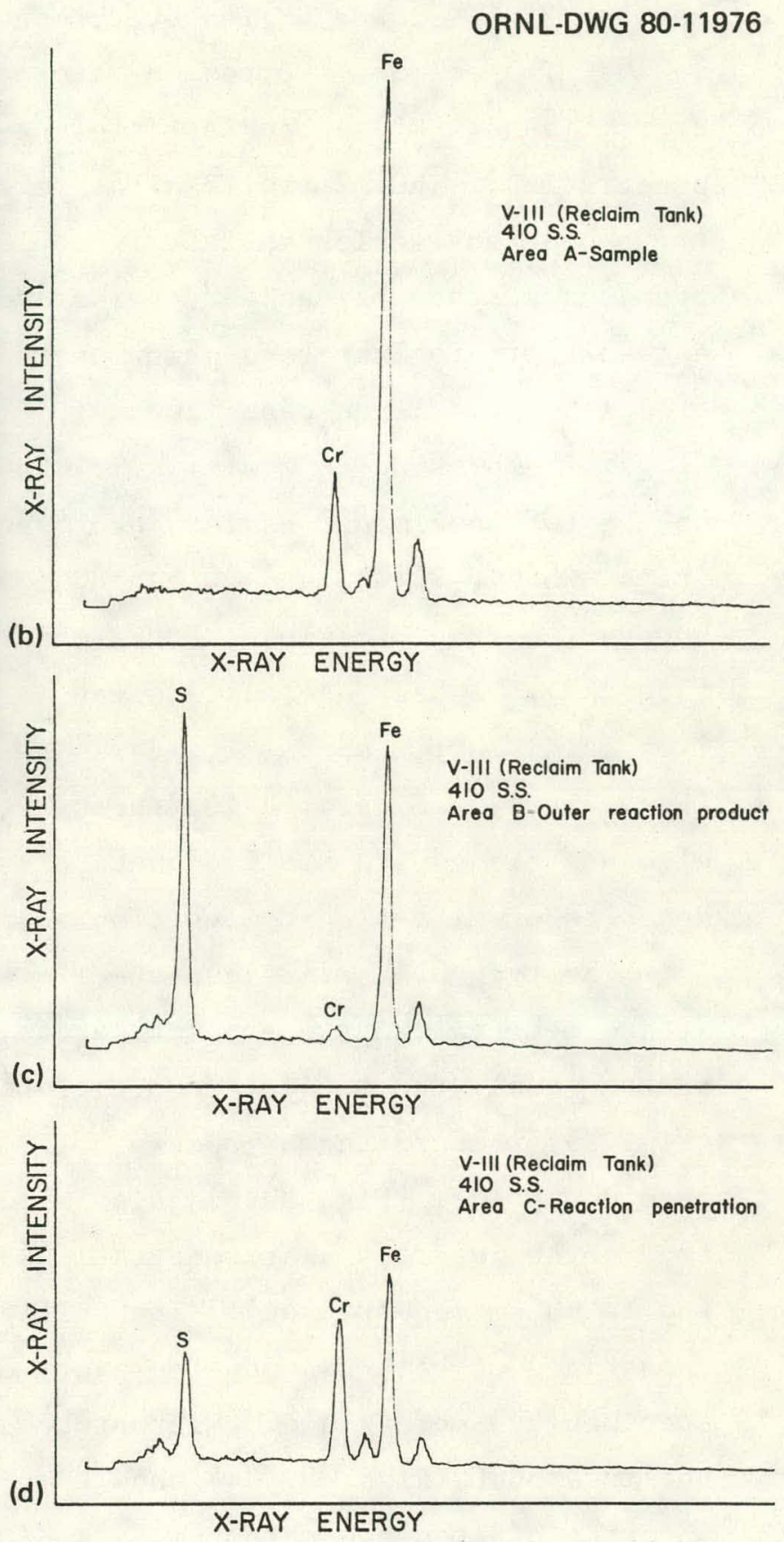


between Figs. 22 and 23; however, more subsurface damage and scale appear on the Ml specimen. Corrosion rate data for the two locations, however, are the same. Of particular interest is the relative degree of subsurface penetration. The M2 specimen has very little damage from penetration, but the subsurface scales in the Ml sample are multiphase and not only extend from the surface but appear as isolated pockets [Fig. 22(a)], possibly as a result of droplets condensing on the coupons. After the second exposure, the pitting is as deep as $130 \mu \mathrm{m}$ (Fig. 24). The microprobe analyses (Figs. 25-28) show some similarity in composition of the surface deposits on the two specimens, as both are hypothesized to contain iron oxide [Figs. 25(c), 26(e), and 28(c) and (d)]. The scale is much more complex, however, on the M1 sample, both subsurface [Fig. 25(d)] and on the surface (Fig. 27). Subsurface sulfidation is shown in Figs. 25 and 26 below the iron oxide matrix containing dark areas with silicon and manganese [Fig. 26(c)]. In Fig. 27(c) through (f) varying amounts of these same elements along with small amounts of sulfur or titanium create complex deposits of differing composition and morphology.

The type 304L stainless steel also exhibits comparable differences in attack between the two exposure areas in the vacuum column. As in the carbon steel, the subsurface penetration found is deeper in the Ml sample (Fig. 2y) than in the M2 specimen (Fig. 30). The M1 specimen after the second exposure [Fig. 2y(b)] displayed pits containing corrosion products from which intergranular penetrations into the base metal were observed (up to $60 \mu \mathrm{m}$ penetration). The multiphase surface scale has the same appearance on both coupons; however, unlike the carbon steel, the M2 specimen has more scale. Microprobe analyses of the reaction products on the type 304L (Figs. 31-34) show that the scale in most cases is probably an oxide of iron and chromium. In Fig. 31 the oxide on the Ml sample includes minor amounts of silicon, titanium, or manganese. The oxide also constitutes the M1 specimen subsurface reaction product (Fig. 32). A chromium-iron oxide also forms the corrosion deposit on the hightemperature specimen in one area of the sample (Fig. 33); however, the deposit on the other area of the M2 sample (Fig. 34) is a sulfide. Again note that nickel is not present in the innermost layer but is in the other two. The sulfide is much more predominant below the outer layer (as it was on the carbon steel sample), while the sample probably exhibits oxidation on the outer surface. 

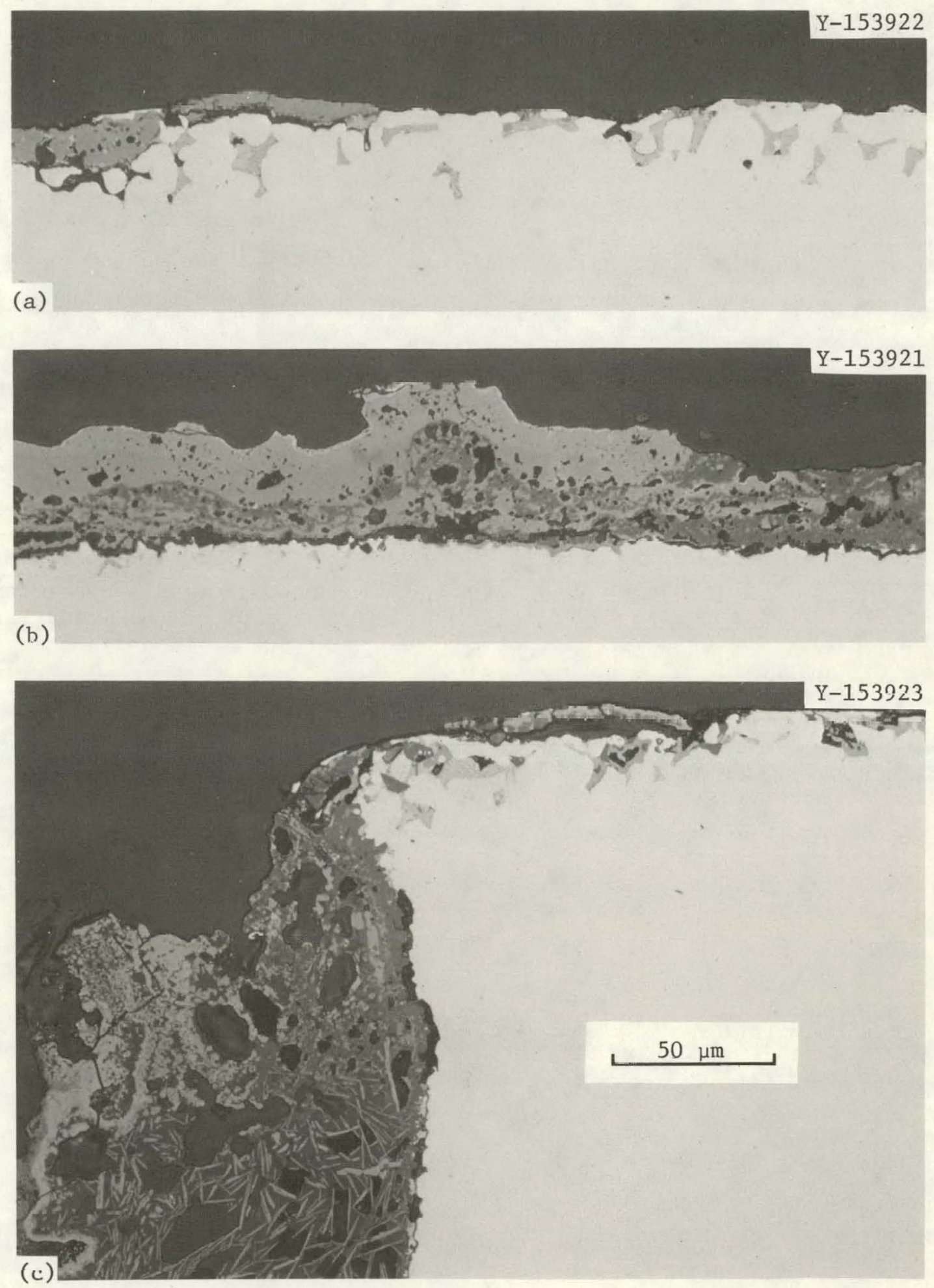

Fig. 22. Specimen of 1018 Carbon Steel Exposed for 4015 Operating Hours at the Wilsonville SRC Pilot Plant in the Top of the T-102 Vacuum Column (M1). 


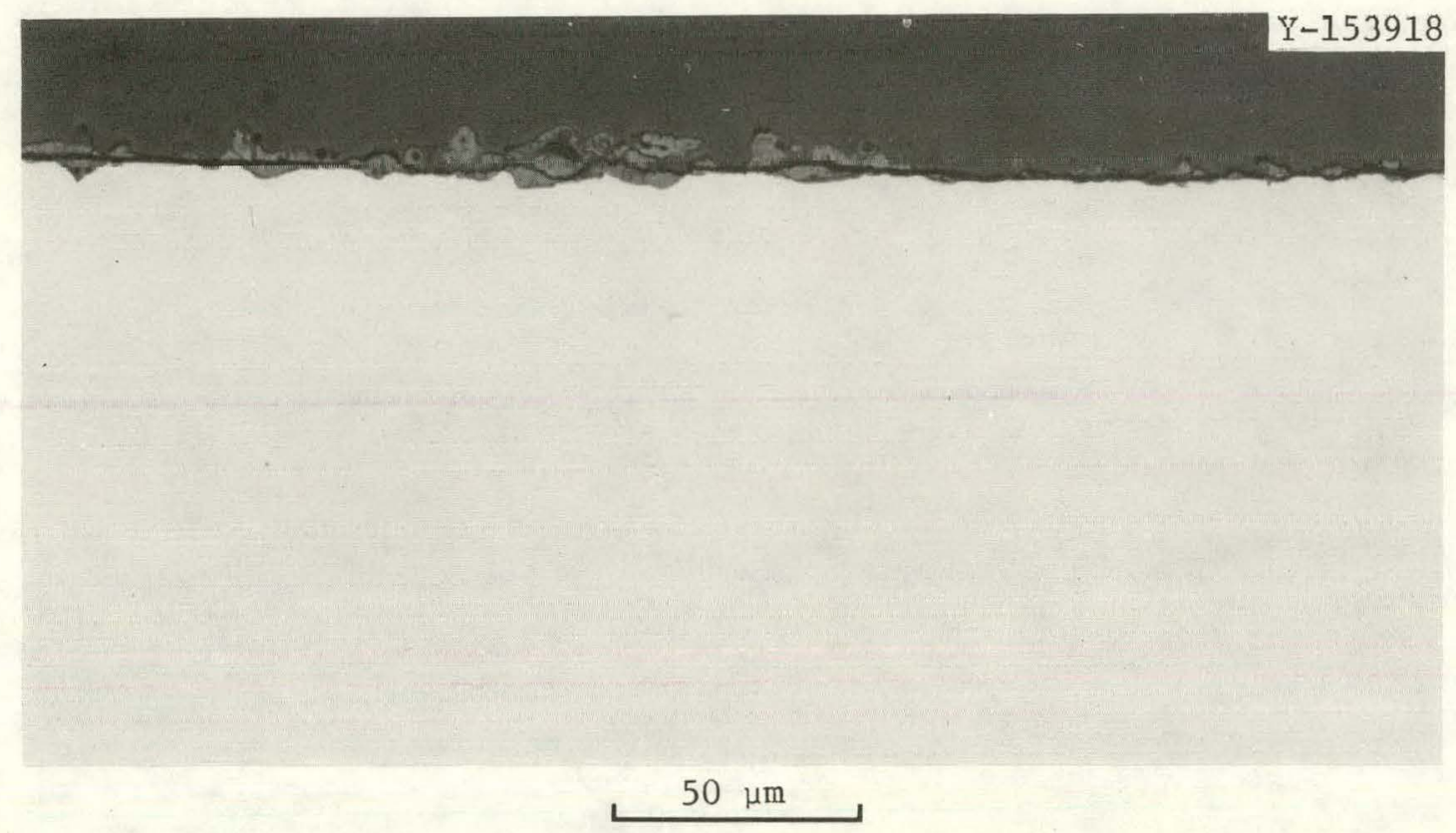

Fig. 23. Specimen of 1018 Carbon Steel Exposed for 4015 Operating Hours at the Wilsonville SRC Pilot Plant in the Bottom of the T-102 Vacuum Column (M2). The specimen did not change appearance noticeably after accruing an additional exposure time of $5730 \mathrm{~h}$.

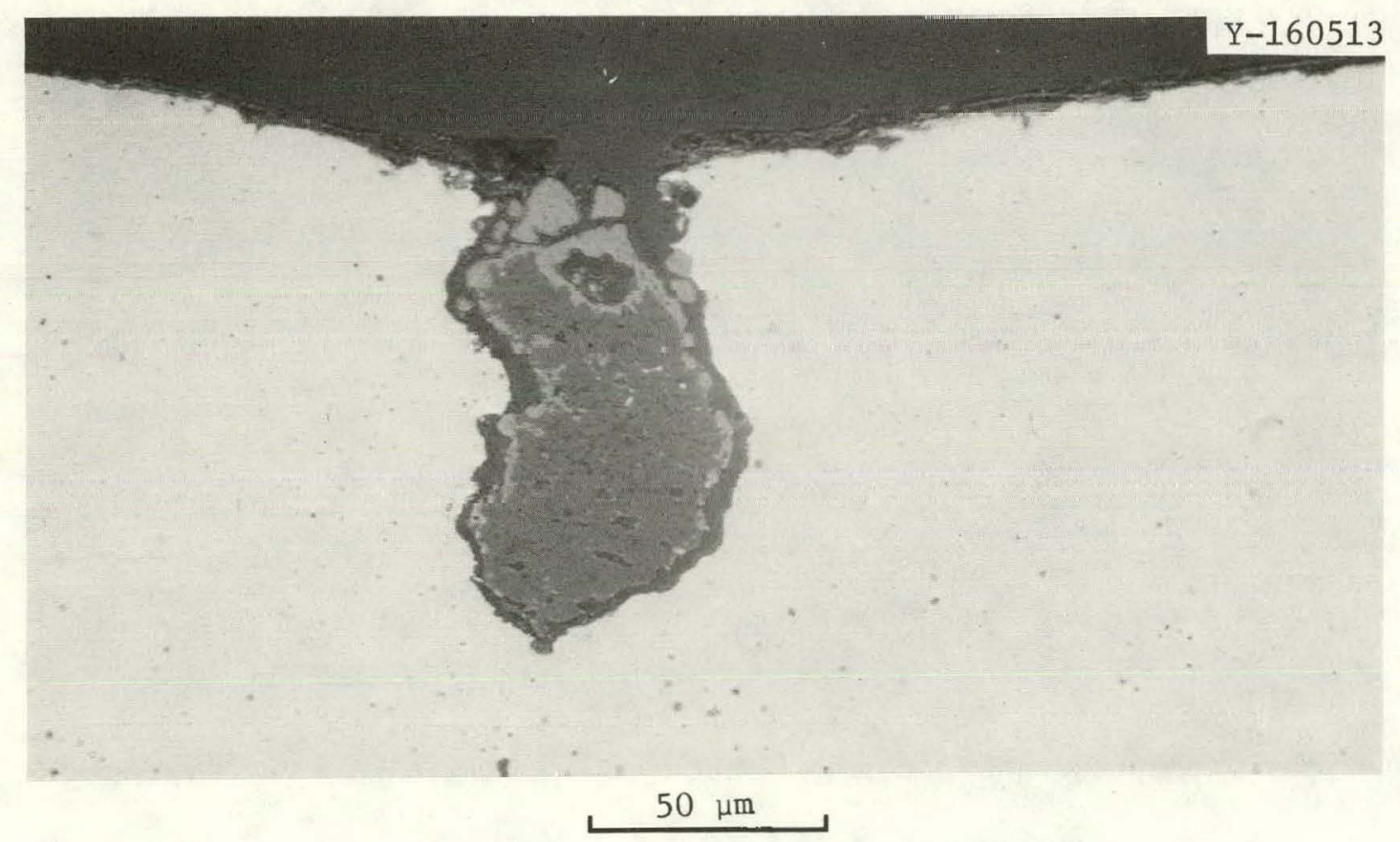

Fig. 24. Specimen of 1018 Carbon Steel Exposed for 9745 Operating Hours at the Wilsonville SRC Pilot Plant in the Top of the T-102 Vacuum Column (M1). 


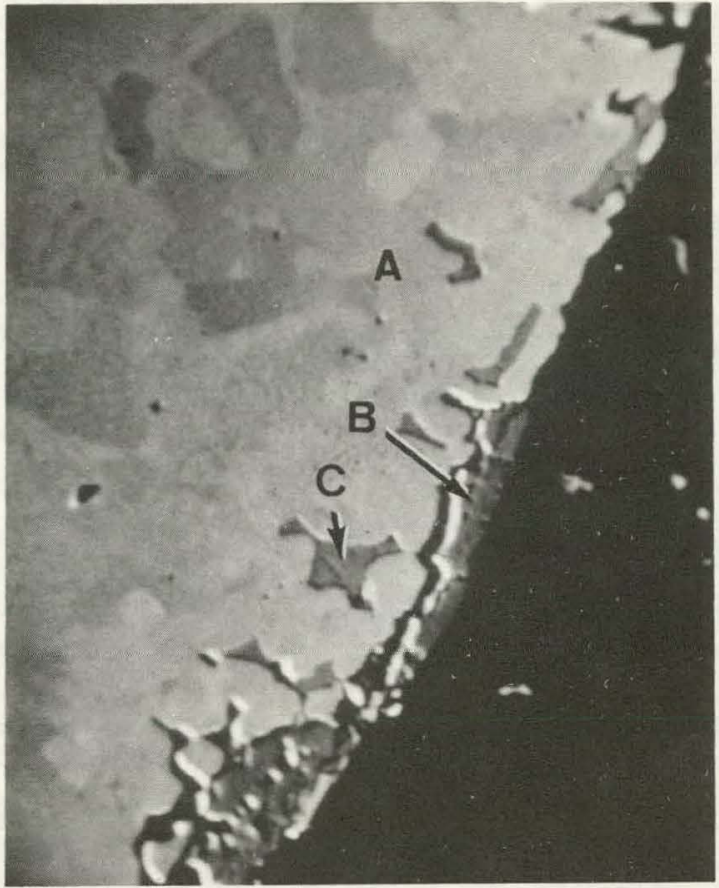

(a)

Fig. 25. Microprobe Analysis of 1018 Carbon Steel Sample Shown in Fig. 22(a) After Exposure in the Top of the T-102 Vacuum Column (M1).

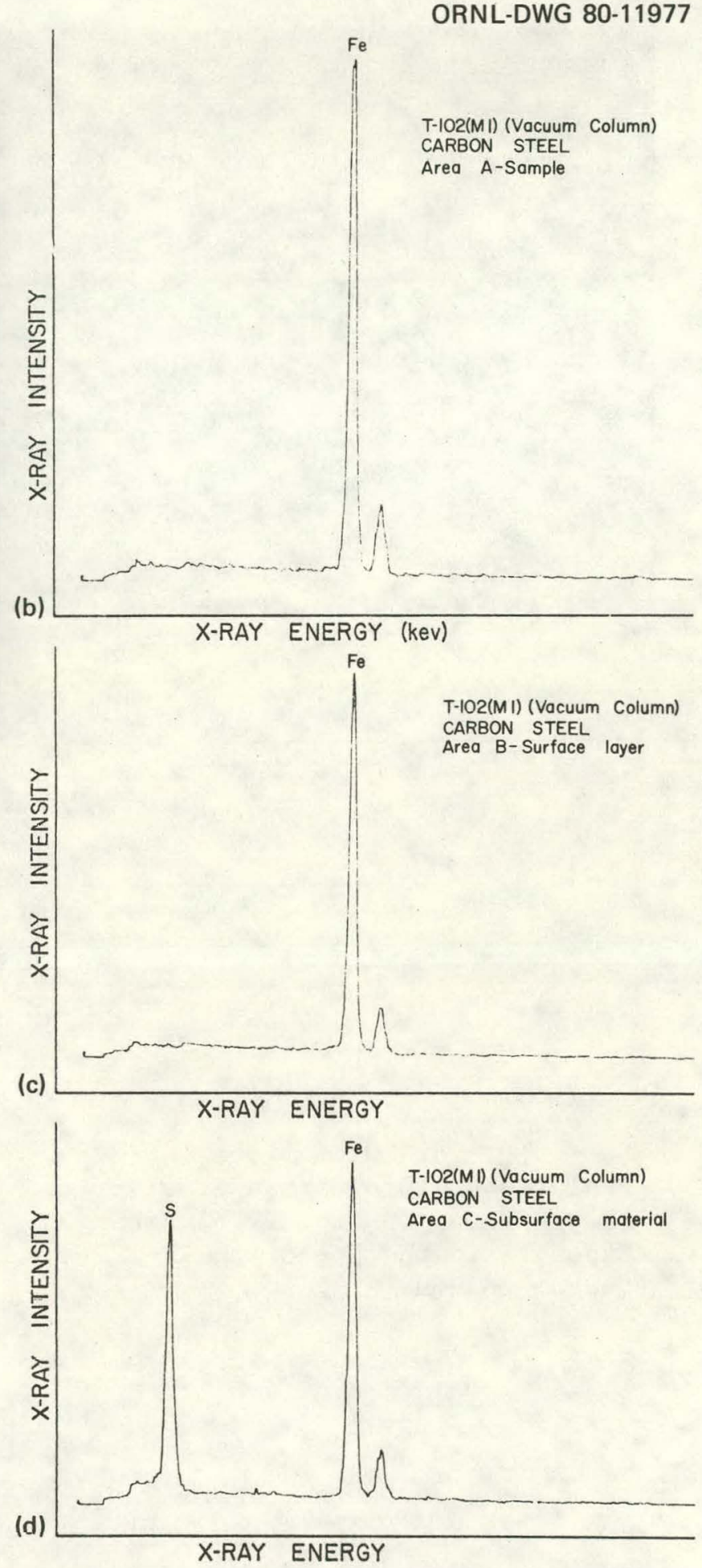




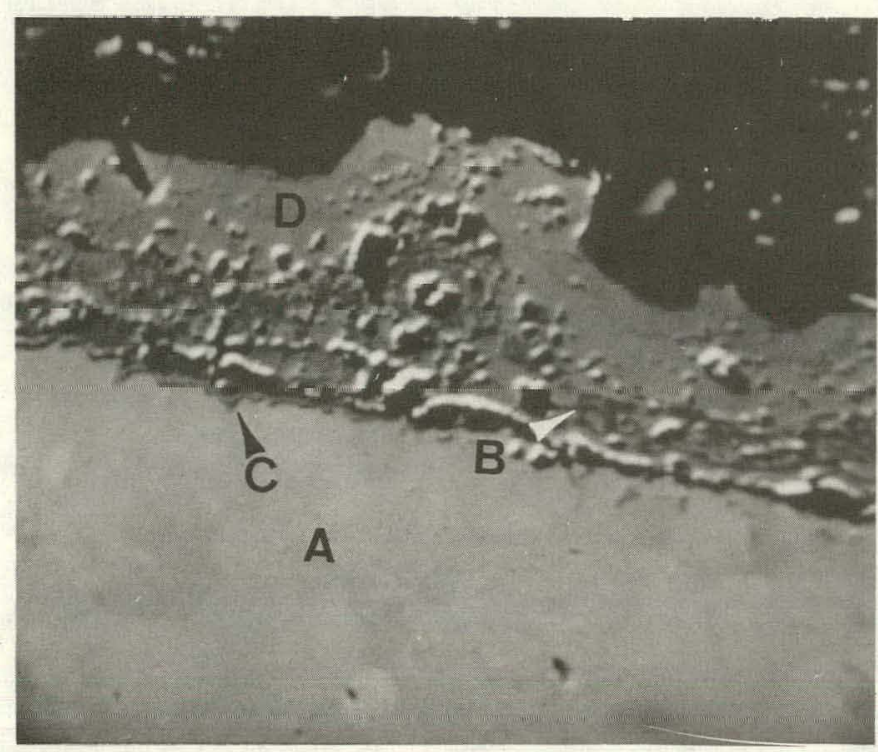

(a)

Fig. 26. Microprobe Analysis of 1018 Carbon Steel Sample Shown in Fig. 22(b) After Exposure in the Top of the T-102 Vacuum Column (M1).
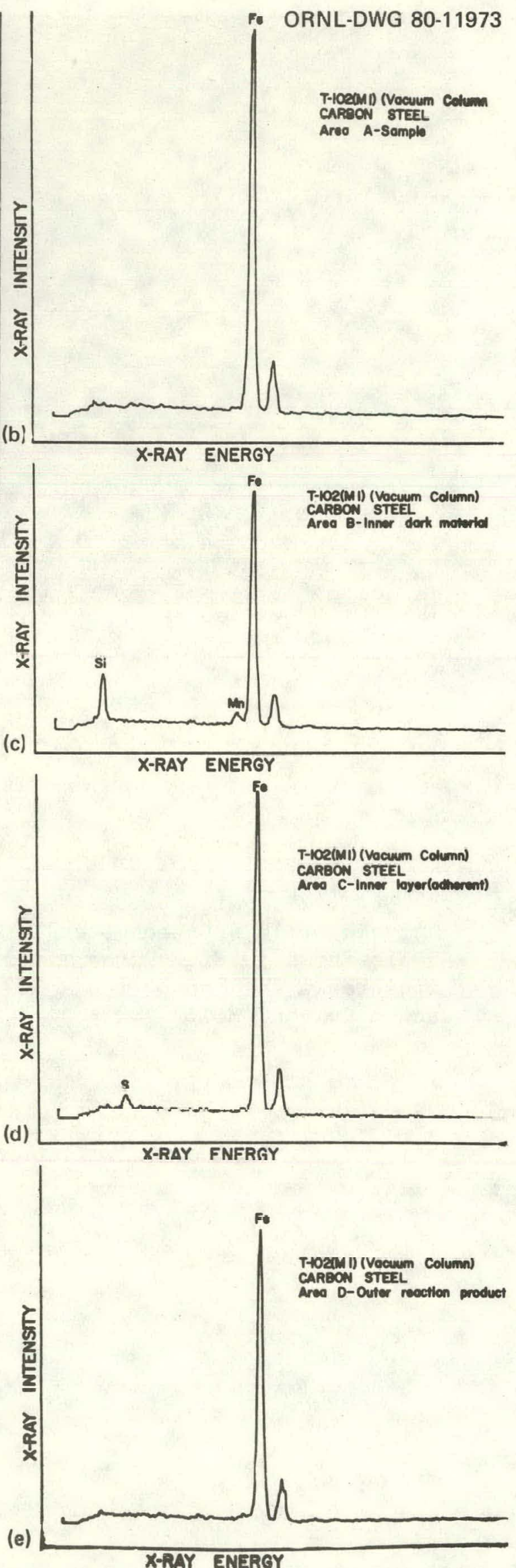


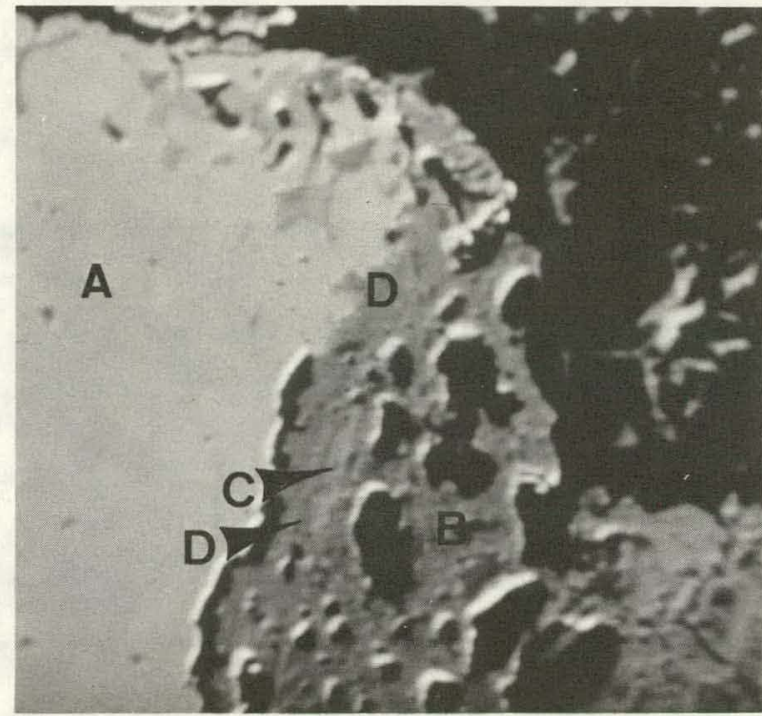

(a)

Fig. 27. Microprobe Analysis of 1018 Carbon Stee1 Sample Shown in Fig. 22(c) After Exposure in the Top of the T-102 Vacuum Column (M1).
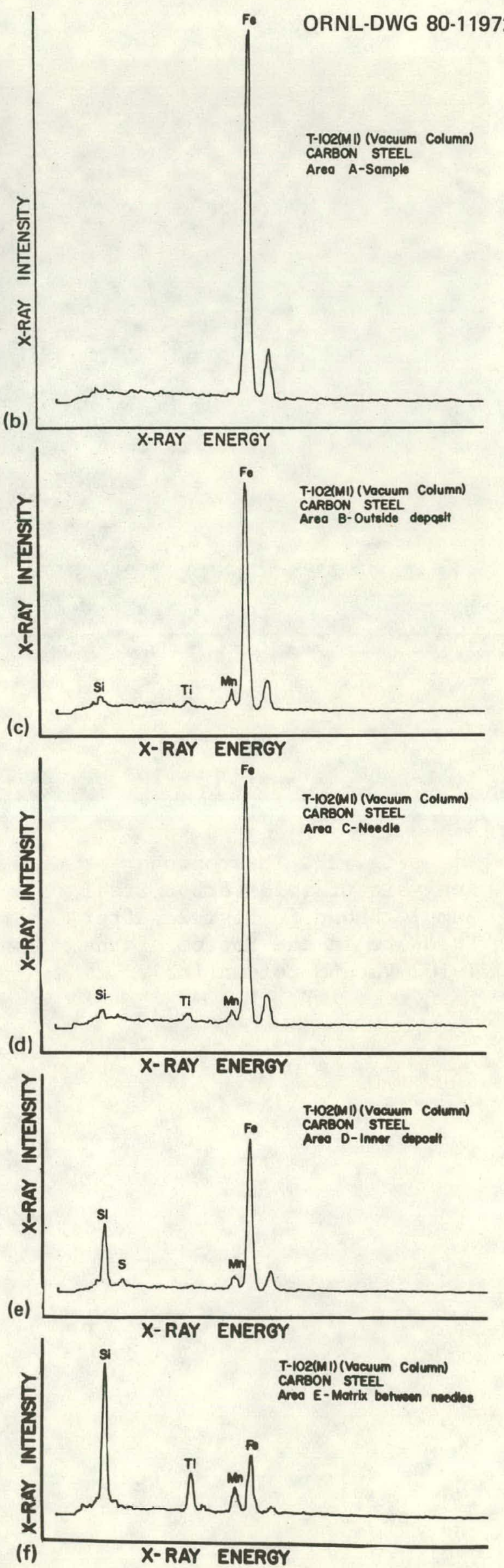


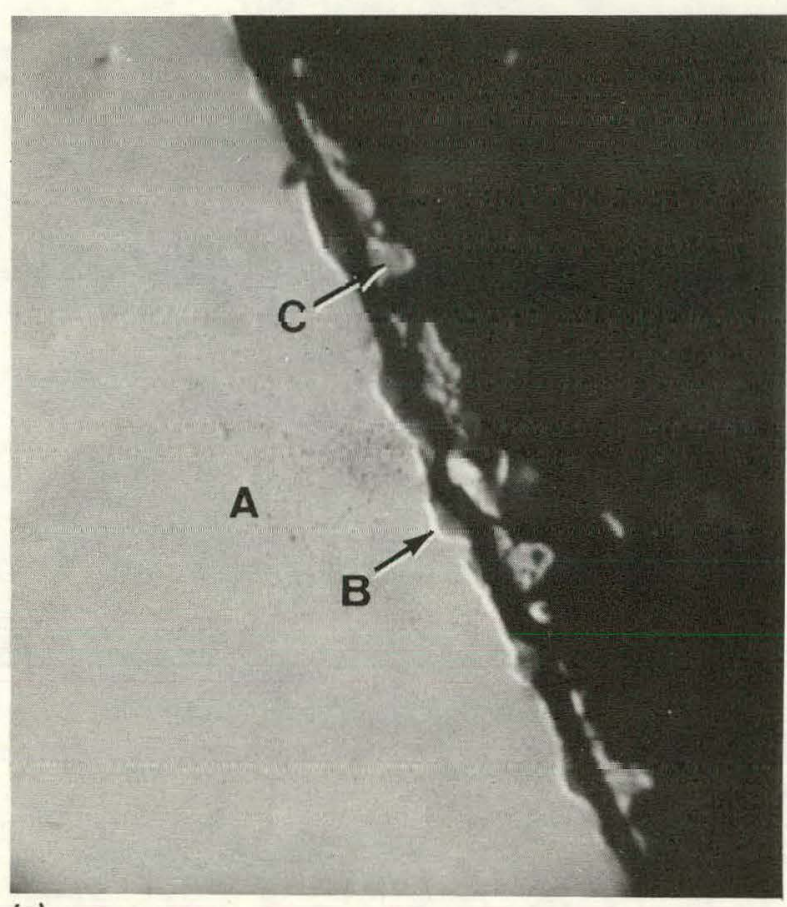

(a)

F1g. 28. M1croprobe Analysis of 1018 Carbon Stee1 Sample Shown in Fig. 23 After Exposure in the Bottom of the T-102 Vacuum Column (M2).
ORNL-DWG 80-11974

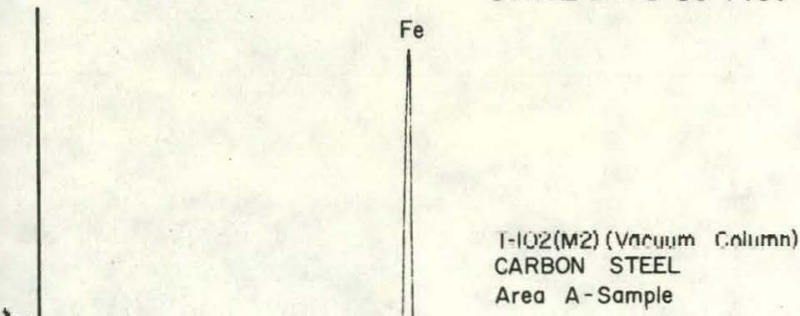

(b)

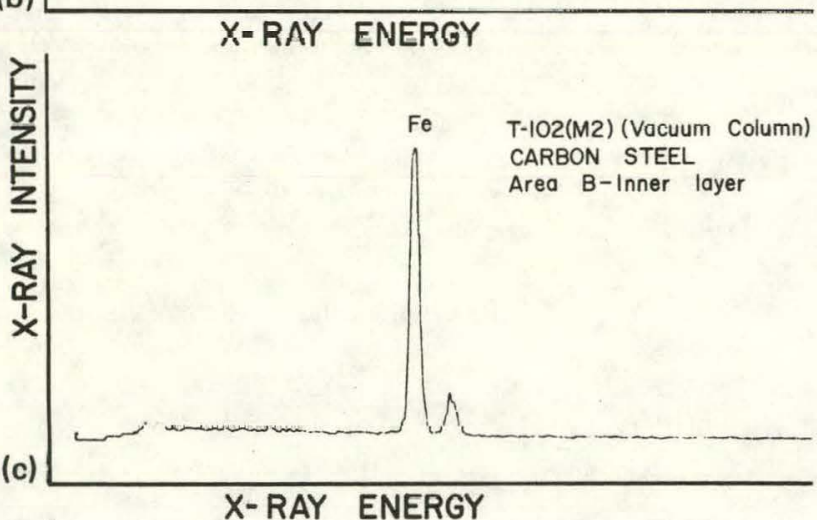

点

(d)

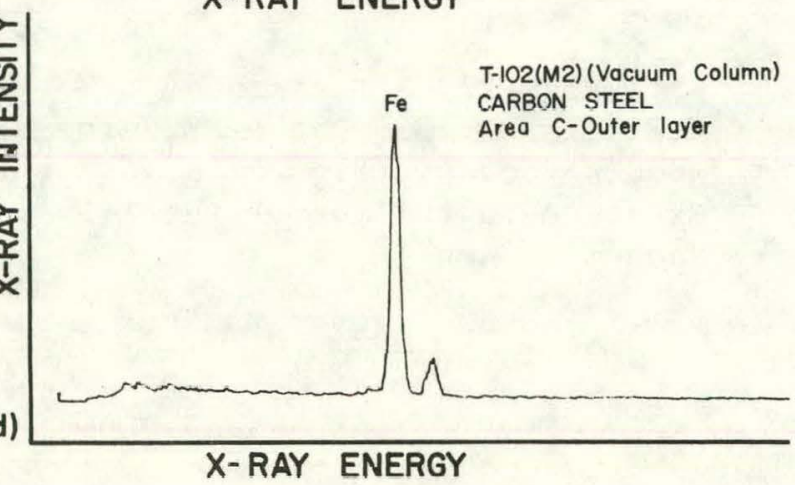




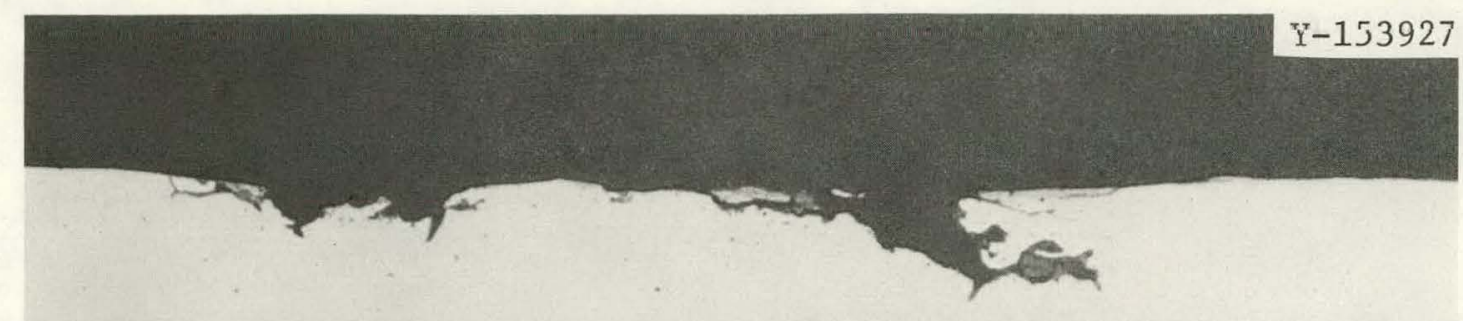

(a)

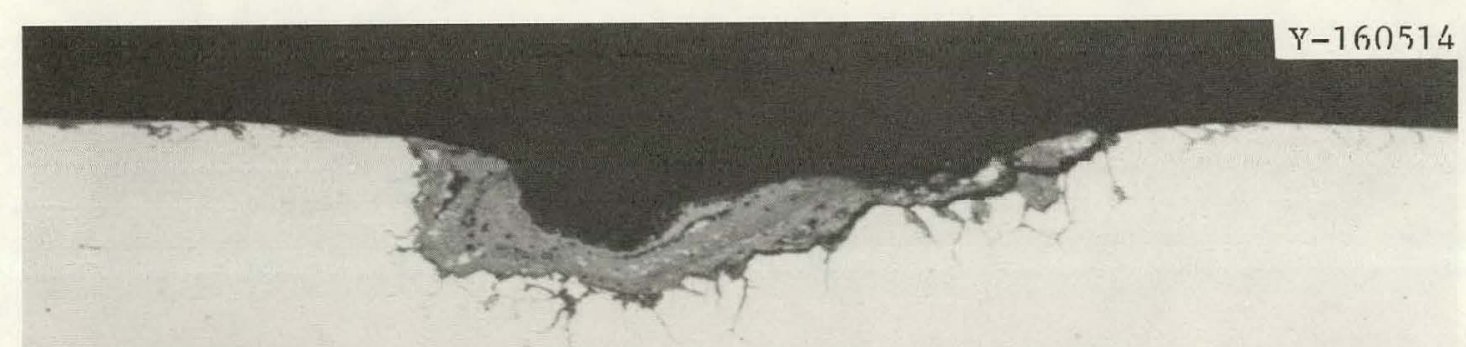

(b)

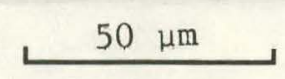

Fig. 29. Type 304L Stainless Steel Specimen Exposed for (a) 4015 Operating Hours and (a) an Additional $5730 \mathrm{~h}$ at the Wilsonville SRC Pilot Plant in the Top of the T-102 Vacuum Column (M1). 


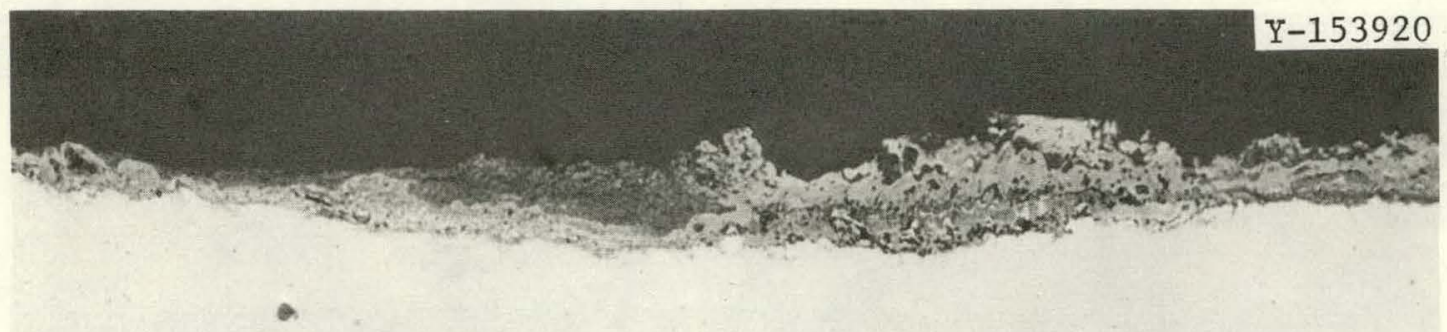

(a)

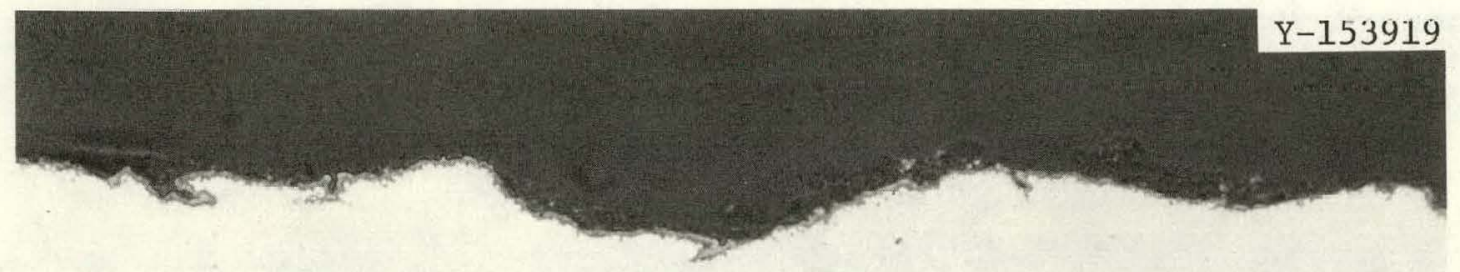

(b)

Fig. 30. Type 304L Stainless Steel Specimen Exposed for 4015 Operating Hours at the Wilsonville SRC Pilot Plant in the Bottom of the T-102 Vacuum Column (M2). 

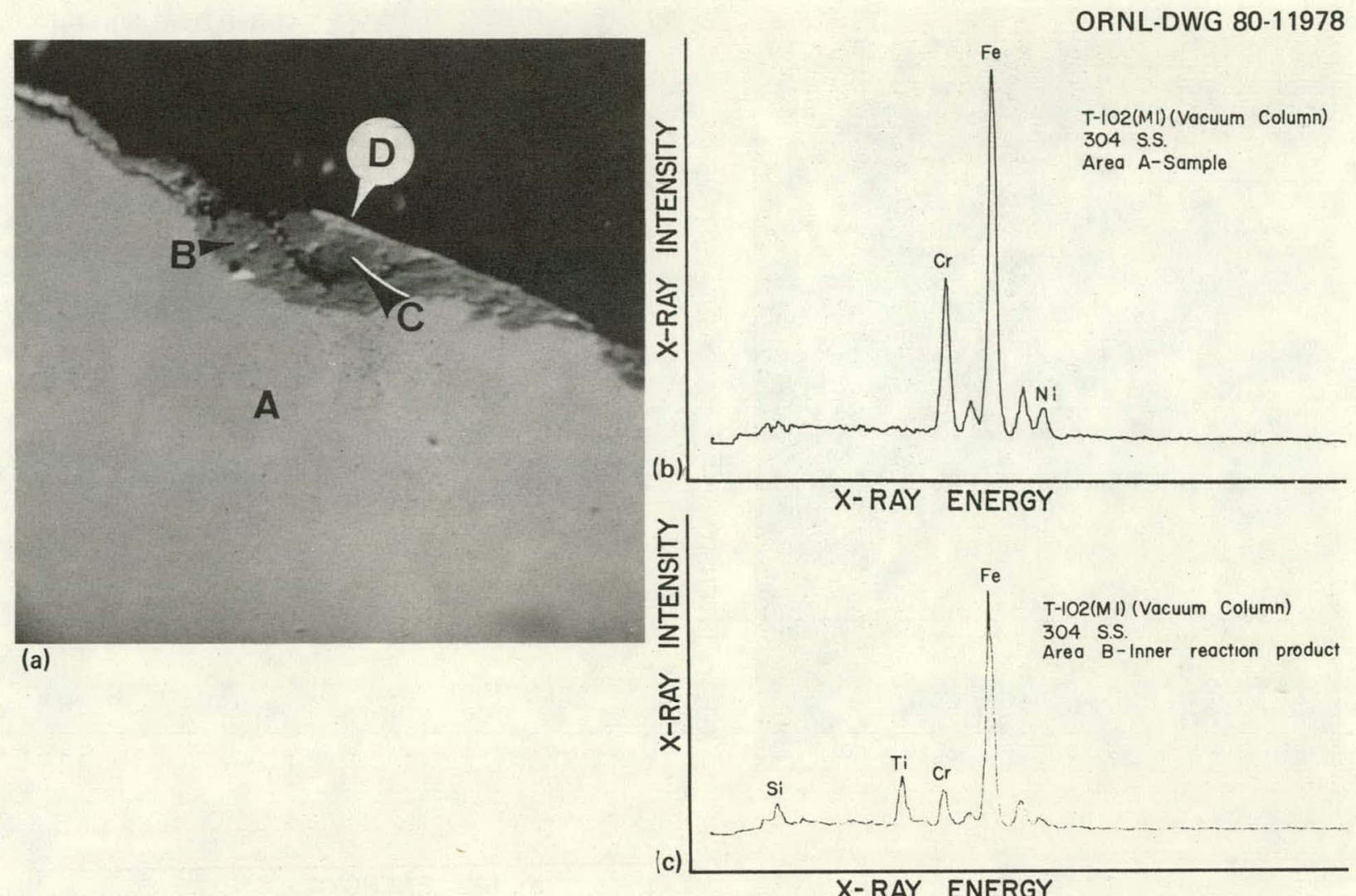

Fig. 31. Microprobe Analysis of Type 304L Stainless Steel Sample After Exposure in the Top of the T-102 Vacuum Column (M1).

(d)

(c)

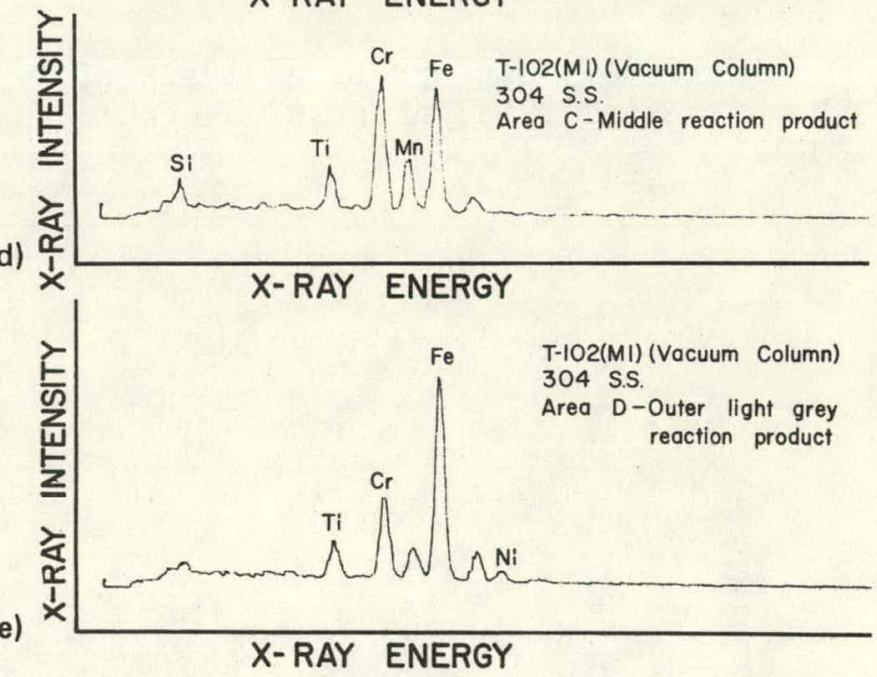




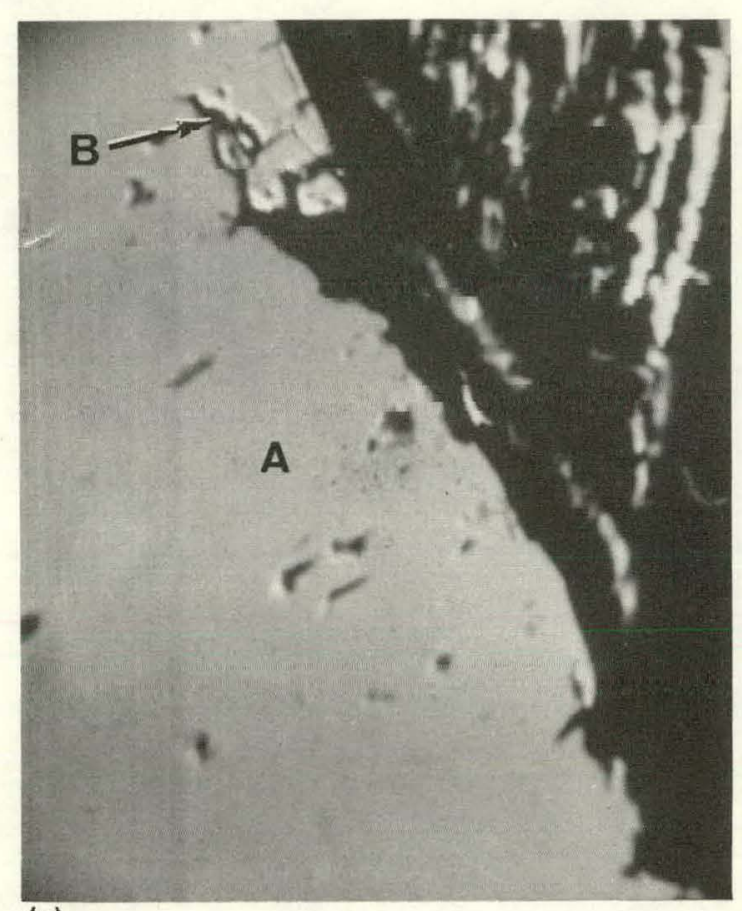

(a)

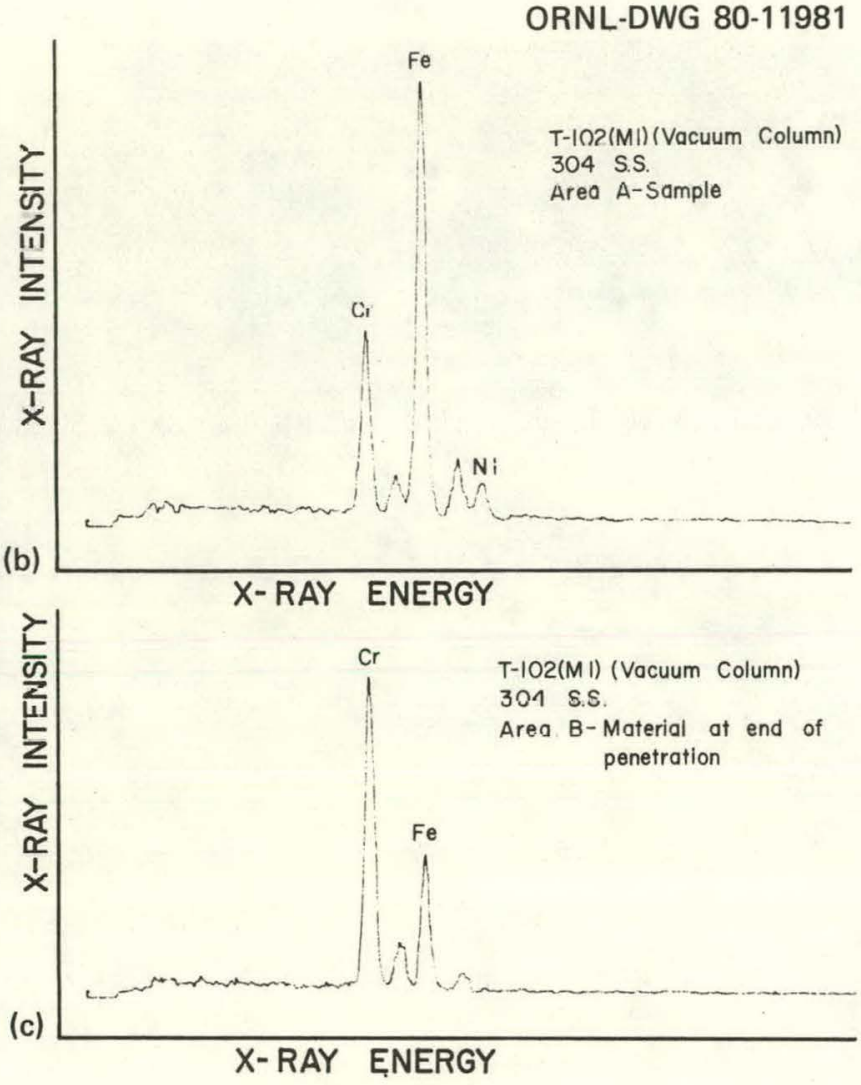

Fig. 32. Microprobe Analysis of Type 304L Stainless Steel Specimen Shown in Fig. 29(a) Atter Exposure in the Top of the T-102 Vacuum Column (M1). 
ORNL-DWG 80-11983

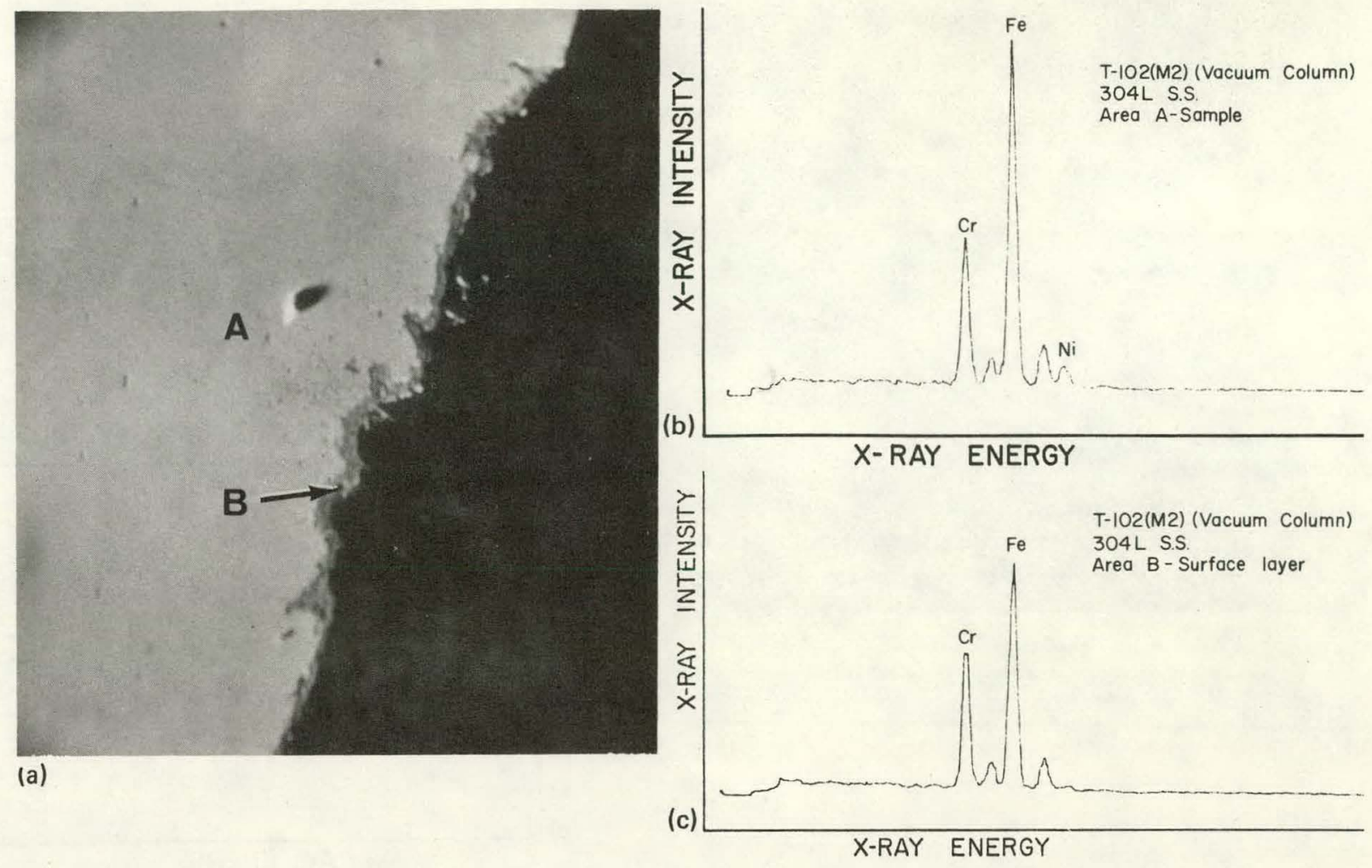

Fig. 33. Microprobe Analysis of Type 304L Stainless Steel Sample Shown in Fig. 30(b) After Exposure in the Bottom of the T-102 Vacuum Column (M2). 


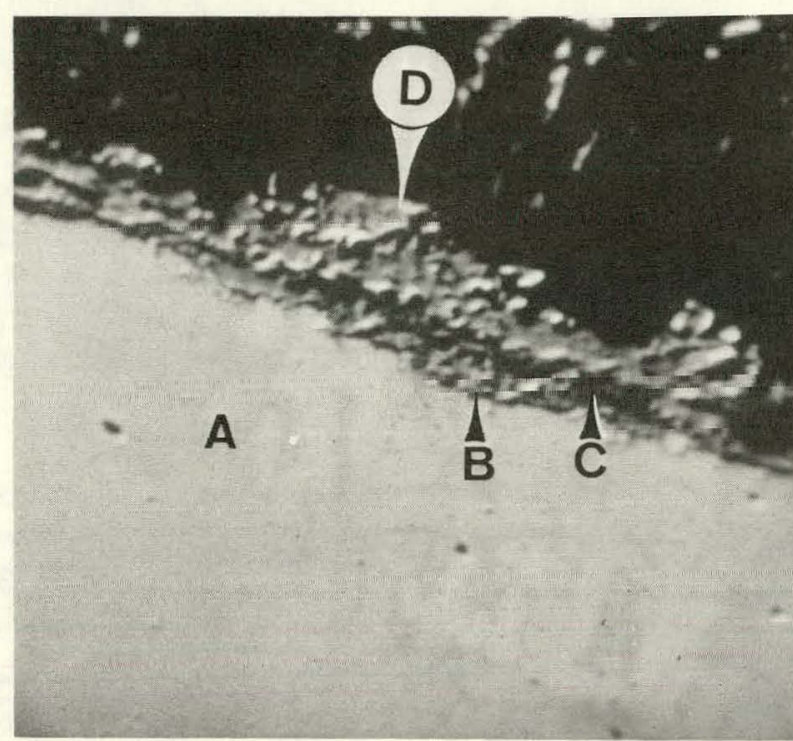

(a)

Fiy. 34. Microprobe Analysis of Type 304L Stainless Steel Sample Shown in Fig. 30(a) After Exposure in the Bottom of the T-102 Vacuum Column (M2).
ORNL-DWG 80-11982
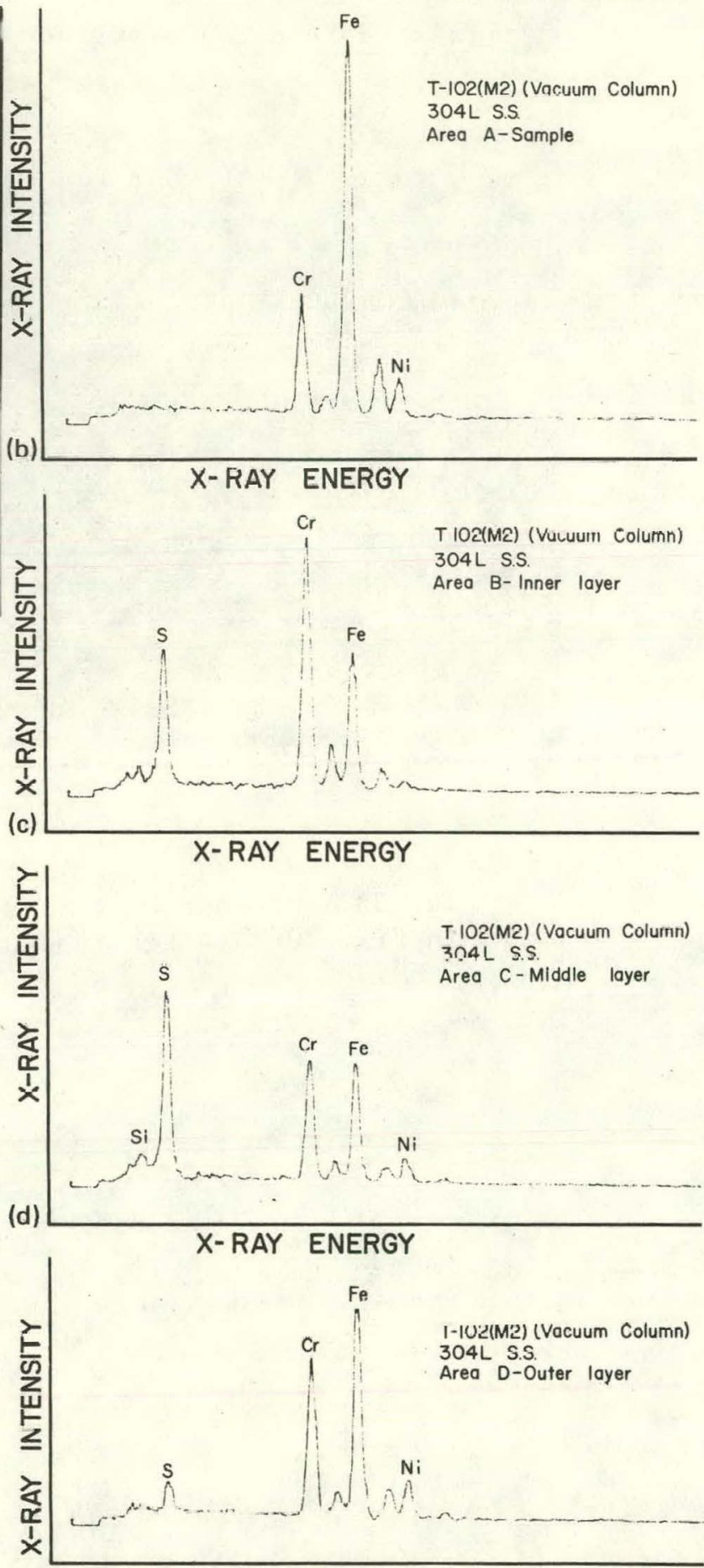

(e) X-RAY ENERGY 
The type 410 stainless steel exposed to the Vacuum Column environment (Figs. 35 and 36) displays predominantly subsurface scale with some dendritic growth containing many small metallic inclusions [Fig. 35(b)]. An irregular surface layer is present on both the M1 [Fig. 35(a)] and M2 [Fig. 36(a)] samples; and, unlike in the previous coupons discussed, the subsurface attack is about the same in the M1 as in the M2 specimens. We observed stringers similar to those found on the type 410 specimen exposed in the V-111 Reclaim Tank (Fig. 18, p. 34). Figure 35(b) was taken near the weld, showing the dendritic deposits below the original surface. These deposits are revealed by microprobe analysis to be primarily titanium, possibly oxide, with varying amounts of $\mathrm{Si}, \mathrm{Ca}, \mathrm{Cr}, \mathrm{Mn}$, and $\mathrm{K}$ also present in the Ml scale (Fig. 37). Again, these elements may occur as a result of spatter from the welding operation. The outer layer at another location contains these elements with some calcium and iron also [Fig. 38(e)]. The inner layer and surface penetrations are discovered to be possible oxides of chromium and iron [Fig. 38(c) and (d)]. On the M2 specimen the same titanium plus other element oxide layer is also present as a dendritic deposit [Fig. 39(d)] but is accompanied by a band of iron sulfide with some chromium [Fig. 39(c)]. Another location on the sample showed sulfidation on the inner subsurface layer [Fig. 40(c)], and the outer layer is a possible oxide of iron and chromium [Fig. 40(d)] similar to that observed in Fig. 38 .

\section{T-105 Fractionation Column}

Since the temperature range in the T-105 Fractionation Column lies between the two extremes of the T-102 Vacuum Column and the contents are similar, one would expect to find a similar type of corrosion behavior with increasing deposits and decreasing subsurface penetration as the temperature increases (M1 to M2 to M3, respectively). Figures 41 through 48 are photomicrographs of the coupons exposed to the lowest temperature $\left(221-232^{\circ} \mathrm{C}\right)$ in the column (M1). In general, the surfaces of the specimens are relatively clean, particularly the type 316 stainless steel (Fig. 41), type 304L (Fig. 43), and alloy 800 [Fig. 48(a)]. The corrosion rate of the Ml specimens was less than $0.01 \mathrm{~mm} /$ year for most specimens, the lowest 

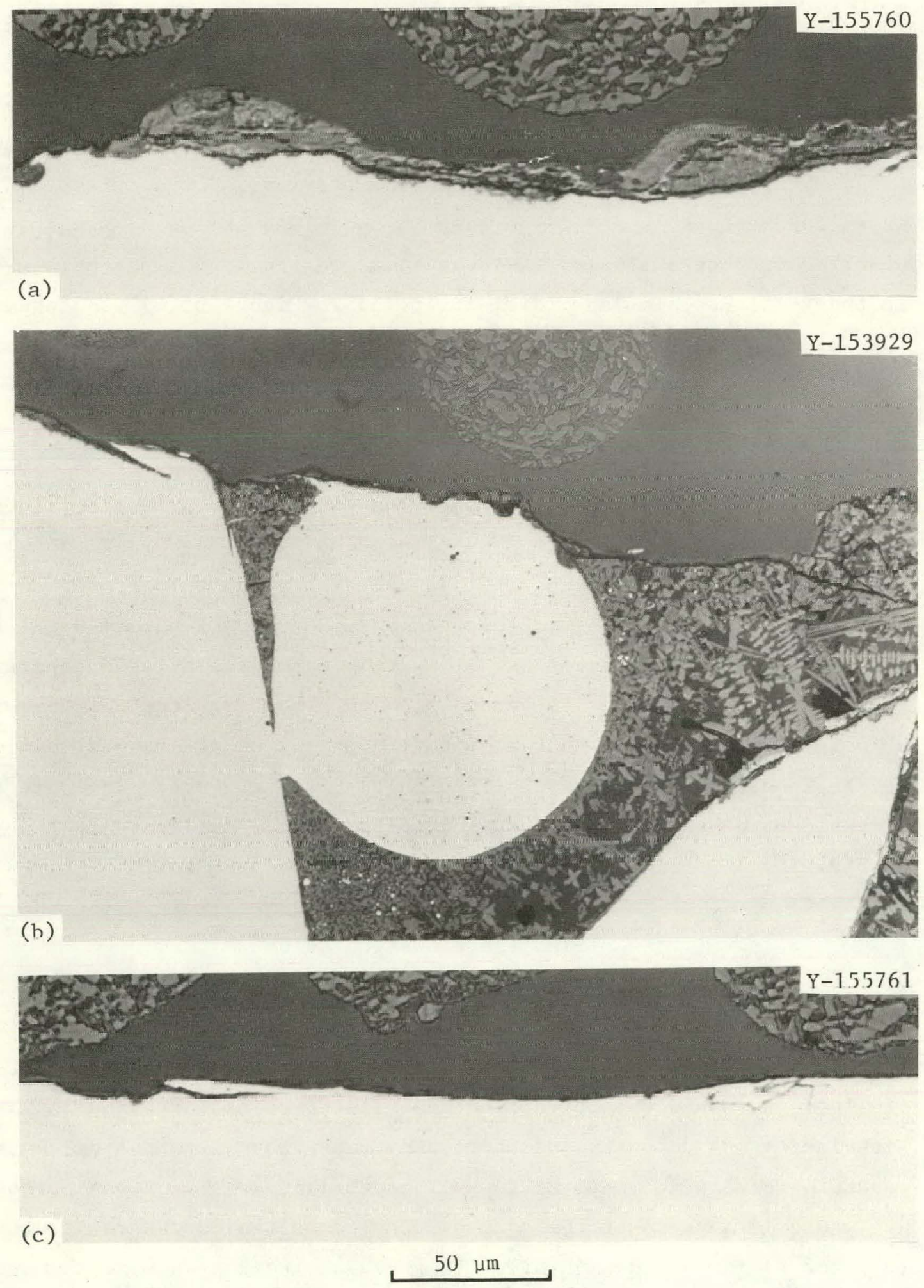

Fig. 35. Type 410 Stainless Steel Specimen Exposed for 4015 operating Hours at the Wilsonville SRC Pilot Plant in the Top of the T-102 Vacuum Column (M1). 


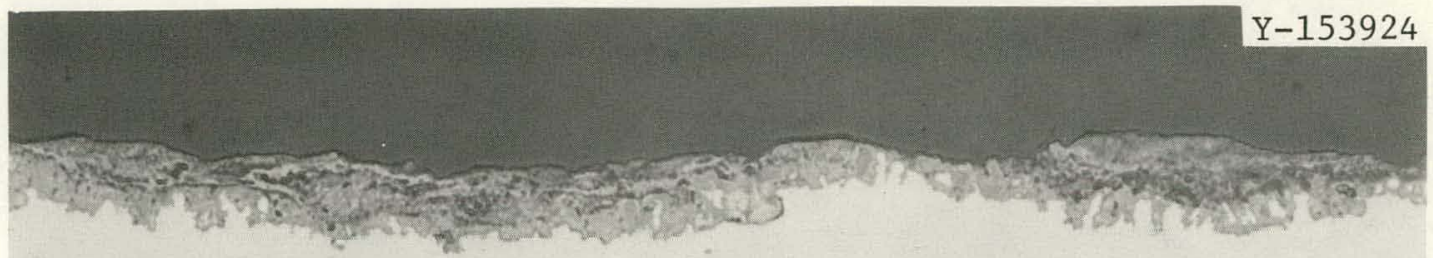

(a)

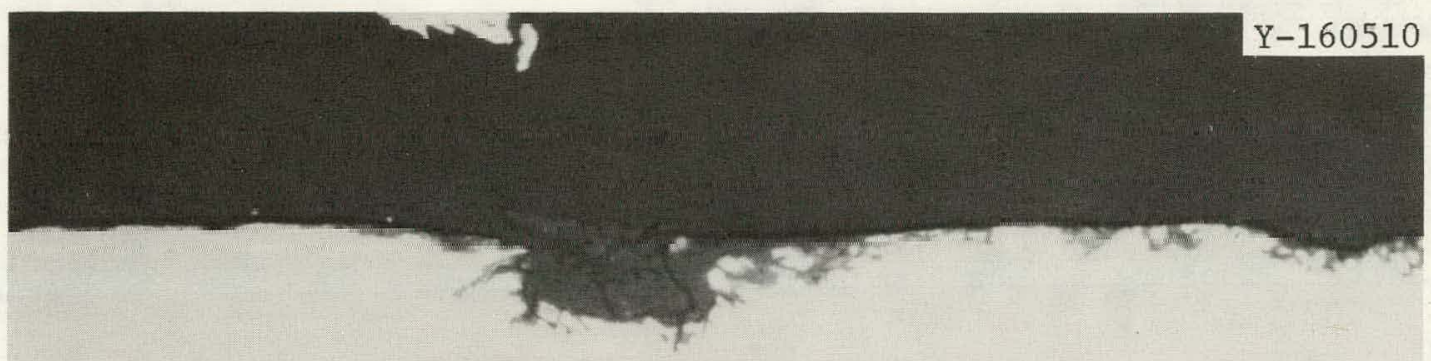

(b)

Fig. 36. Type 410 Stainless Steel Specimen Exposed for (a) 4015 Operating Hours and (b) an Additional $5730 \mathrm{~h}$ at the Wilsonville SRC Pilot Plant in the Bottom of the T-102 Vacuum Column (M2). 


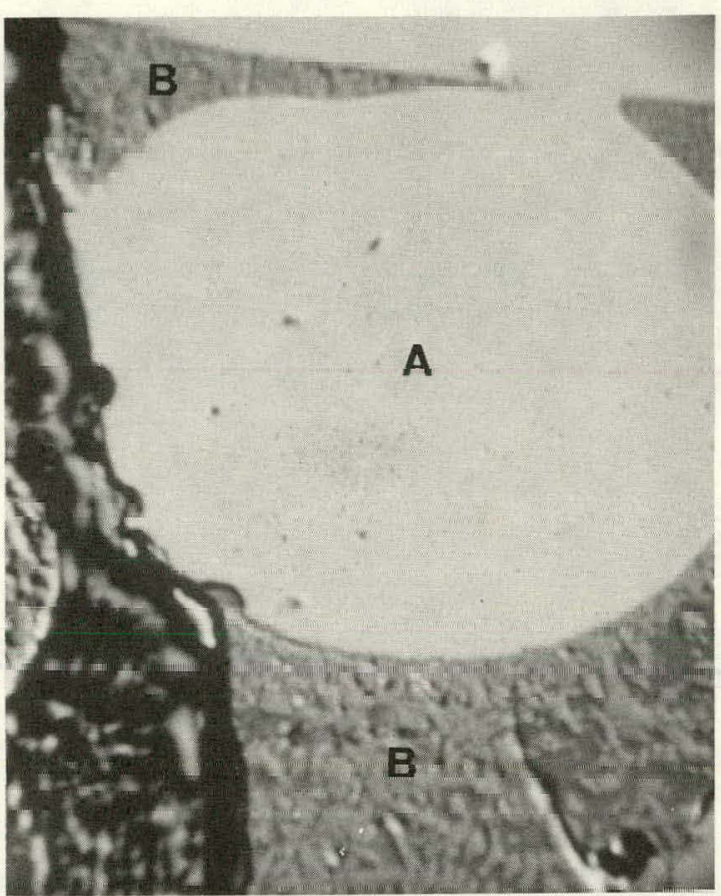

(a)

Fig. 37. Microprobe Analysis of Type 410 Stainless Steel Sample Shown in Fig. 35(b) After Exposure in the Top of the T-10'2 Vacuum Column (MI).
ORNL-DWG 80-11979

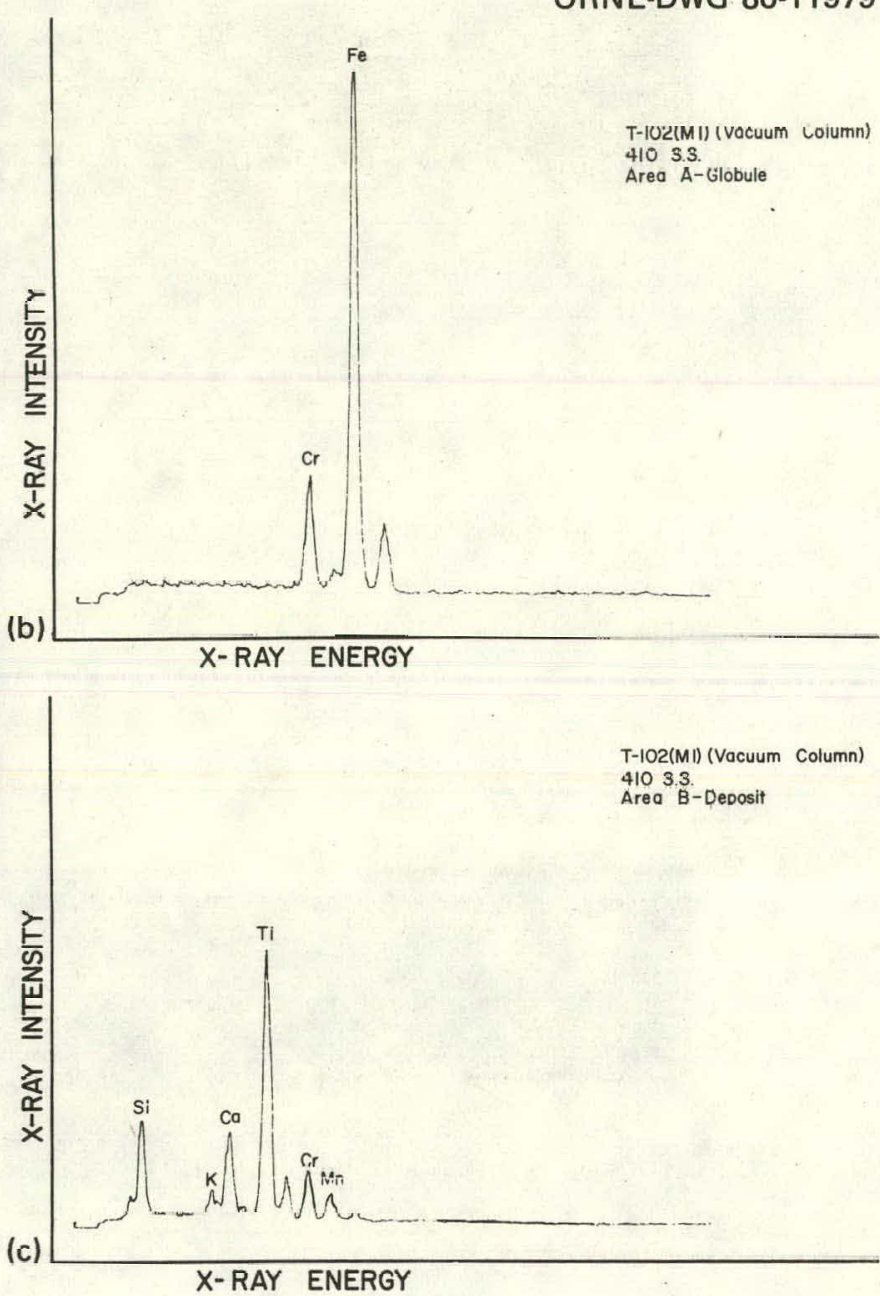



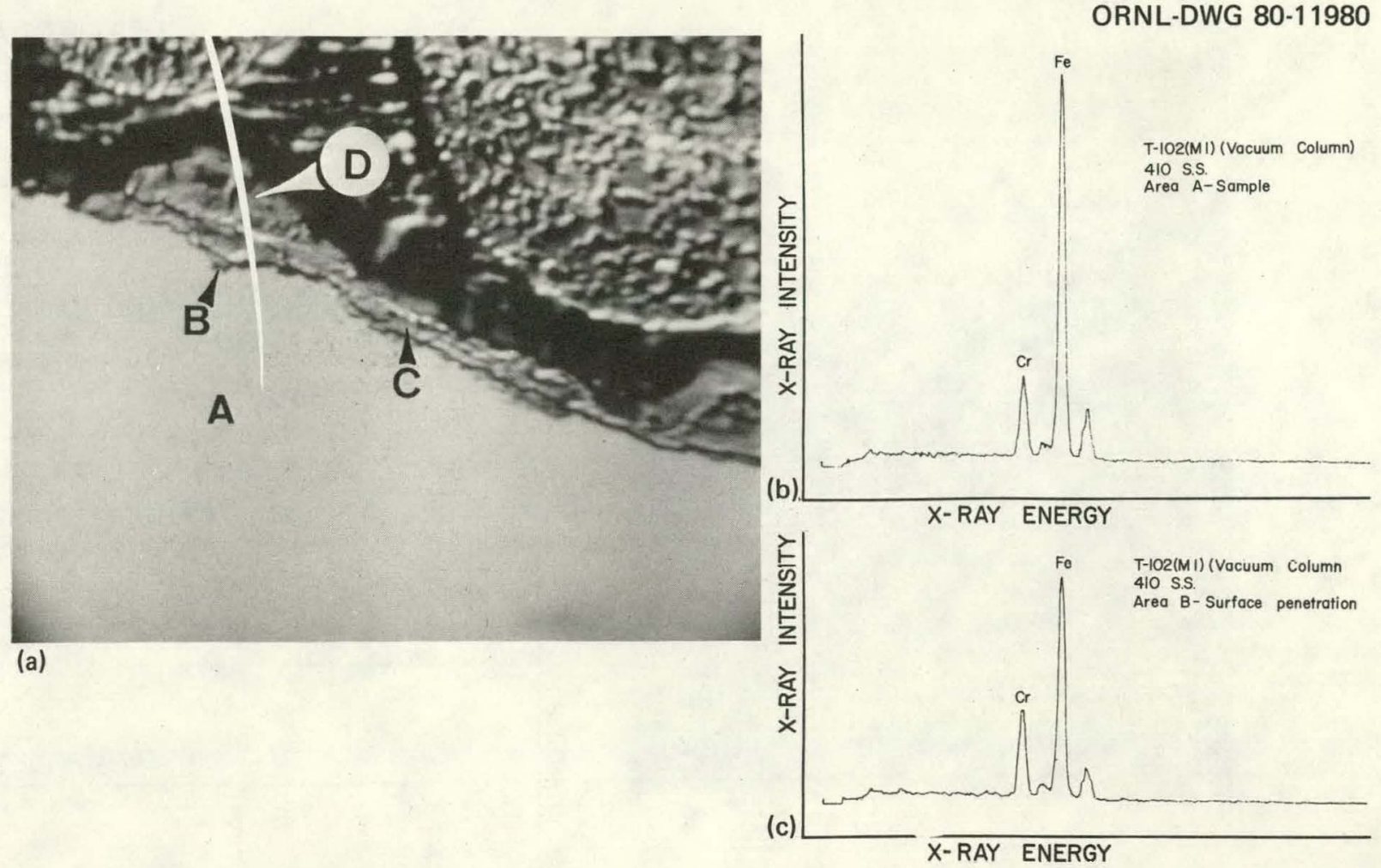

Fig. 38. Microprobe Analysis of Type 410 Stainless Steel Sample Shown in Fig. 35(a) After Exposure in the Top of the $\mathrm{T}-102$ Vacuum Column (M1).

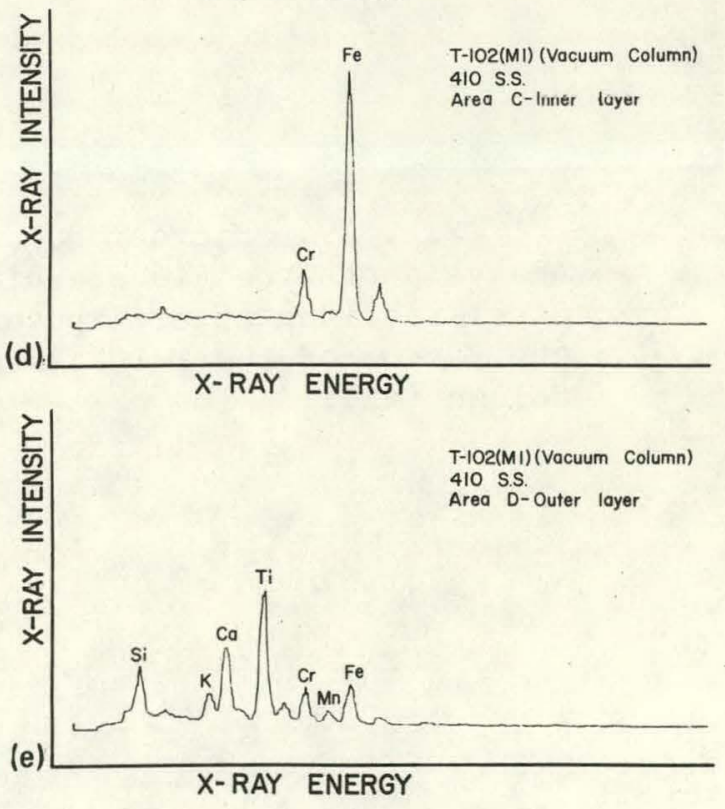




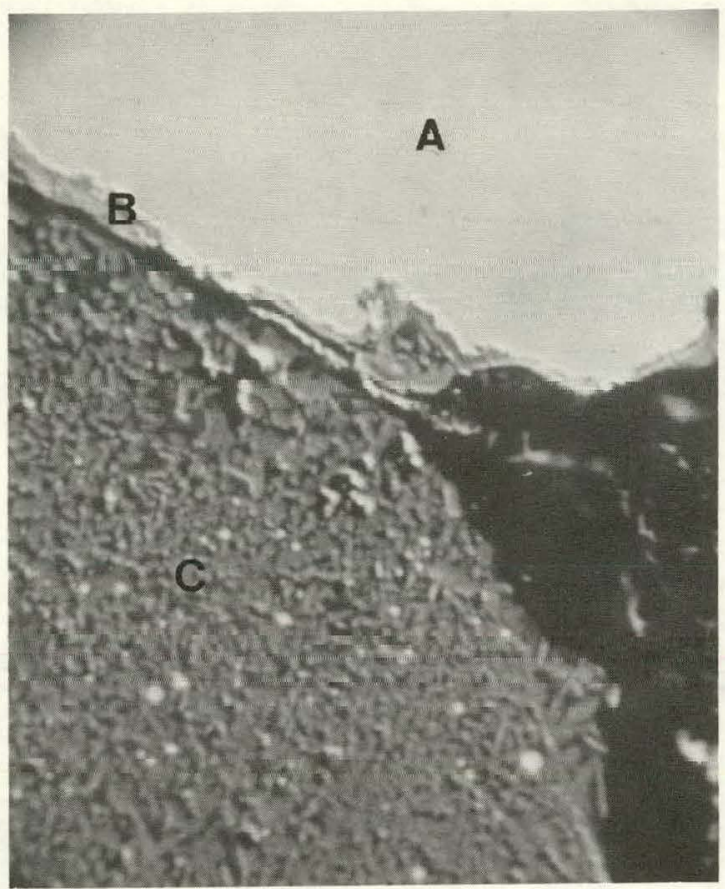

(a)

Fig. 39. Microprobe Analysis of Type 410 Stainless Steel Specimen After Exposure in the Bottom of the T-102 Vacuum Column (M2).
ORNL-DWG 80-11984

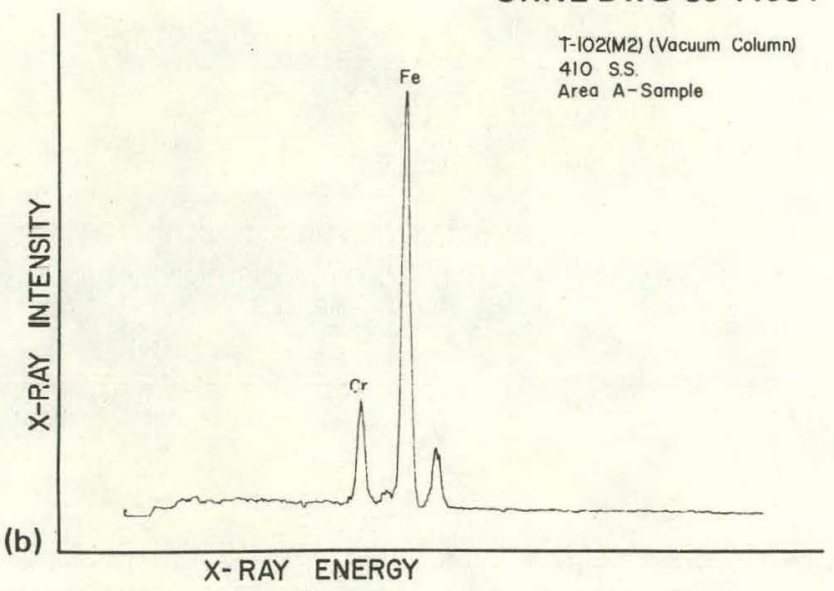

(c)

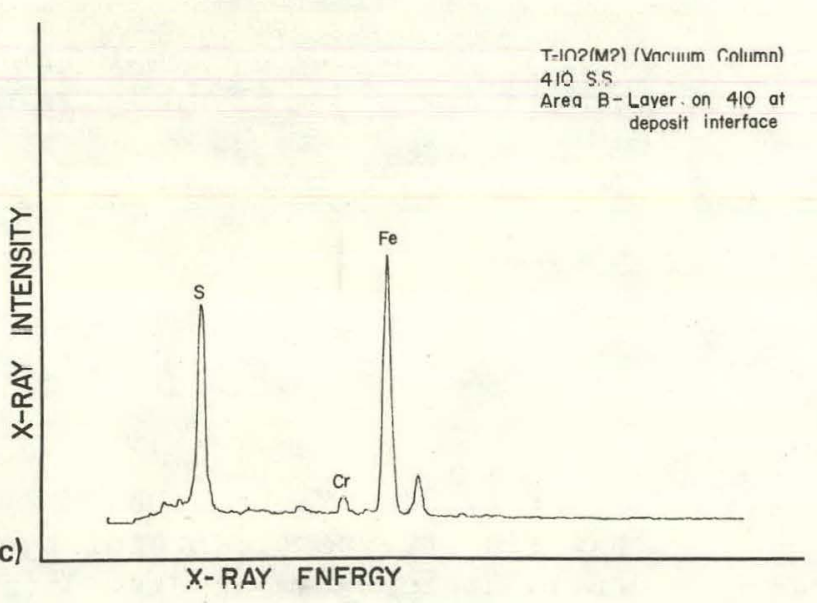

T-102(M2) (Vocuum Column)

410 S.S

Area C-Deposit

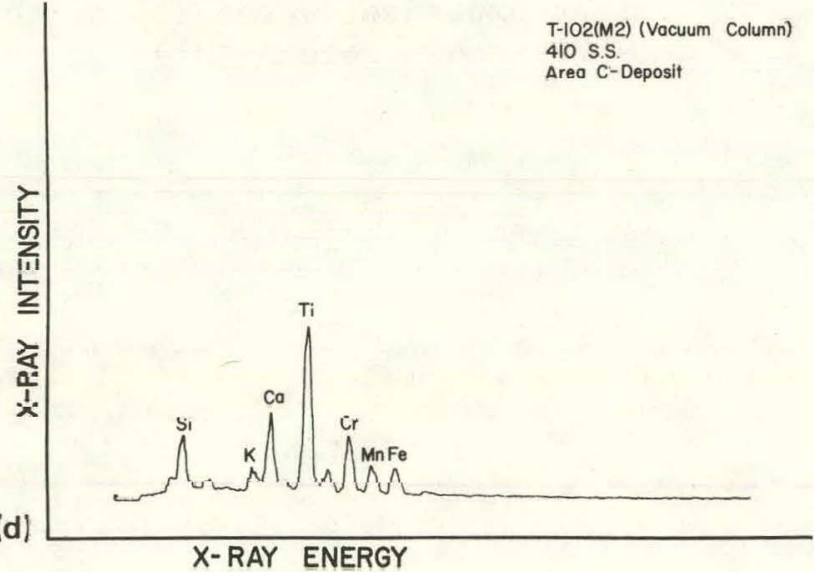




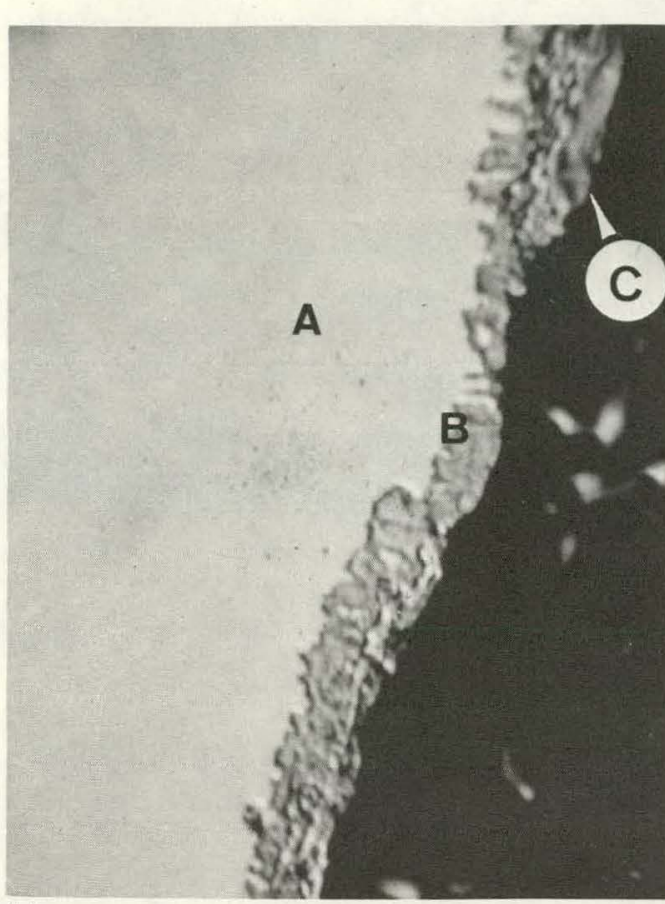

(a)

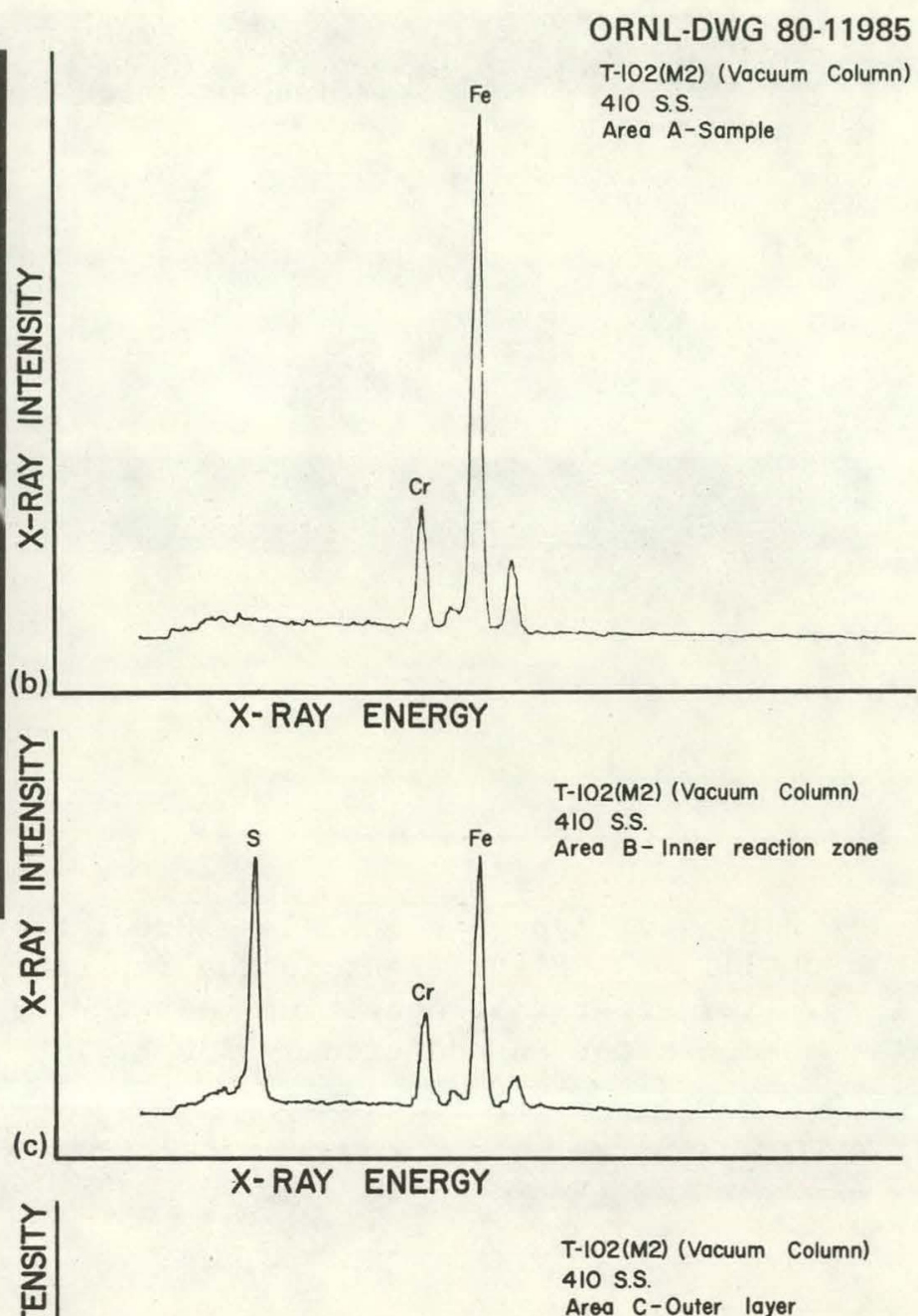

Fig. 40. Microprobe Analysis of Type 410 Stainless Steel Sample Shown in Fig. 36(a) After Exposure in the Top of the T-102 Vacuum Column (M2).

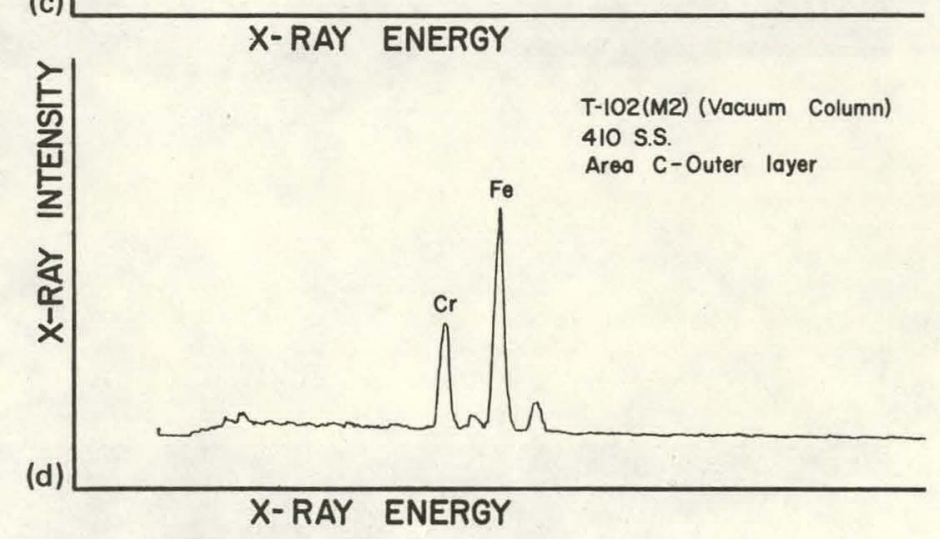



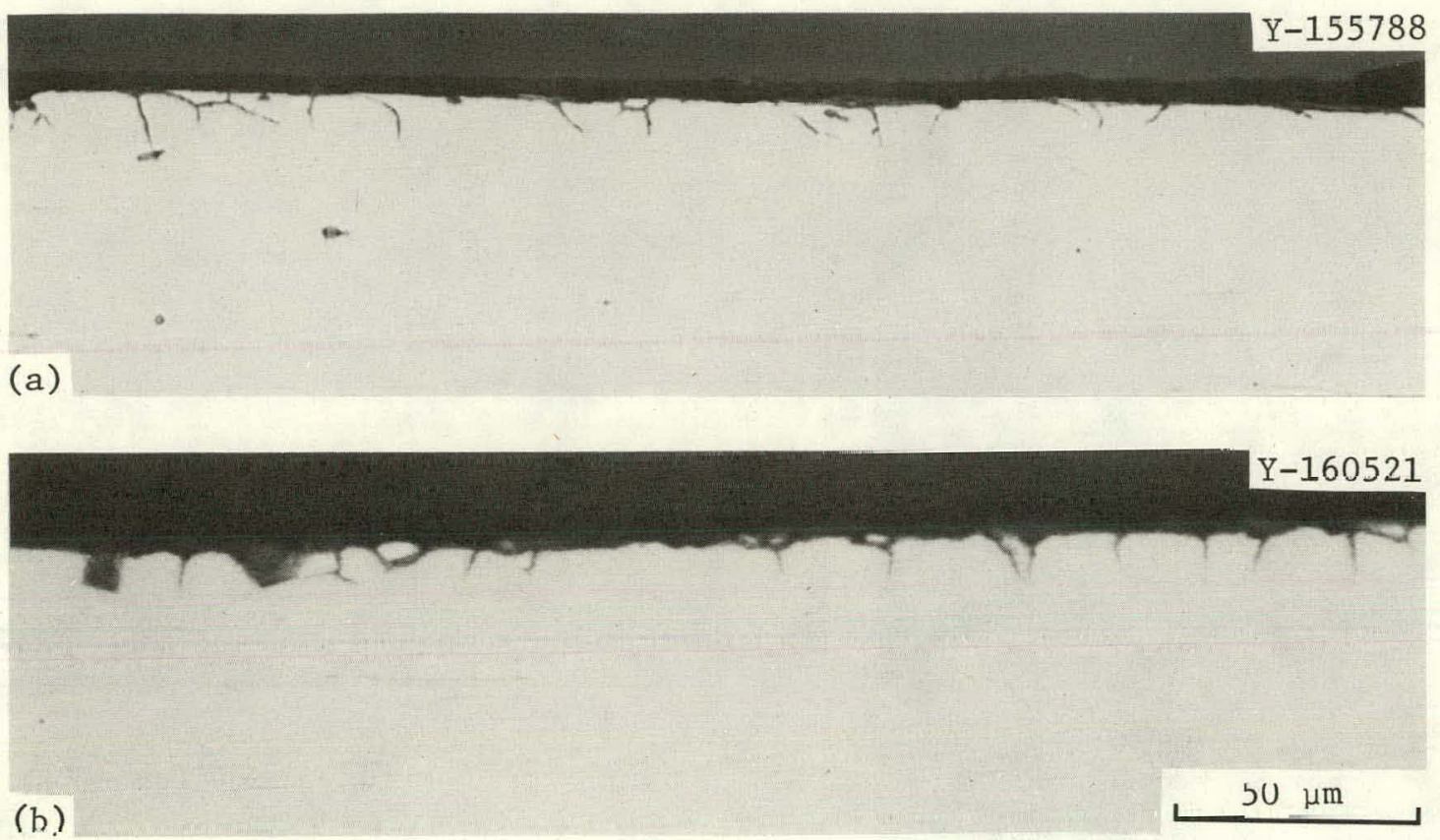

Fig. 41. Type 316 Stainless Steel Specimens Exposed at the Wilsonville SRC Pilot Plant in the Top of the T-105 Fractionation Column (M1). (a) After 2350 operating hours. (b) Similar intergranular penetrations seen after an additional $5730 \mathrm{~h}$.
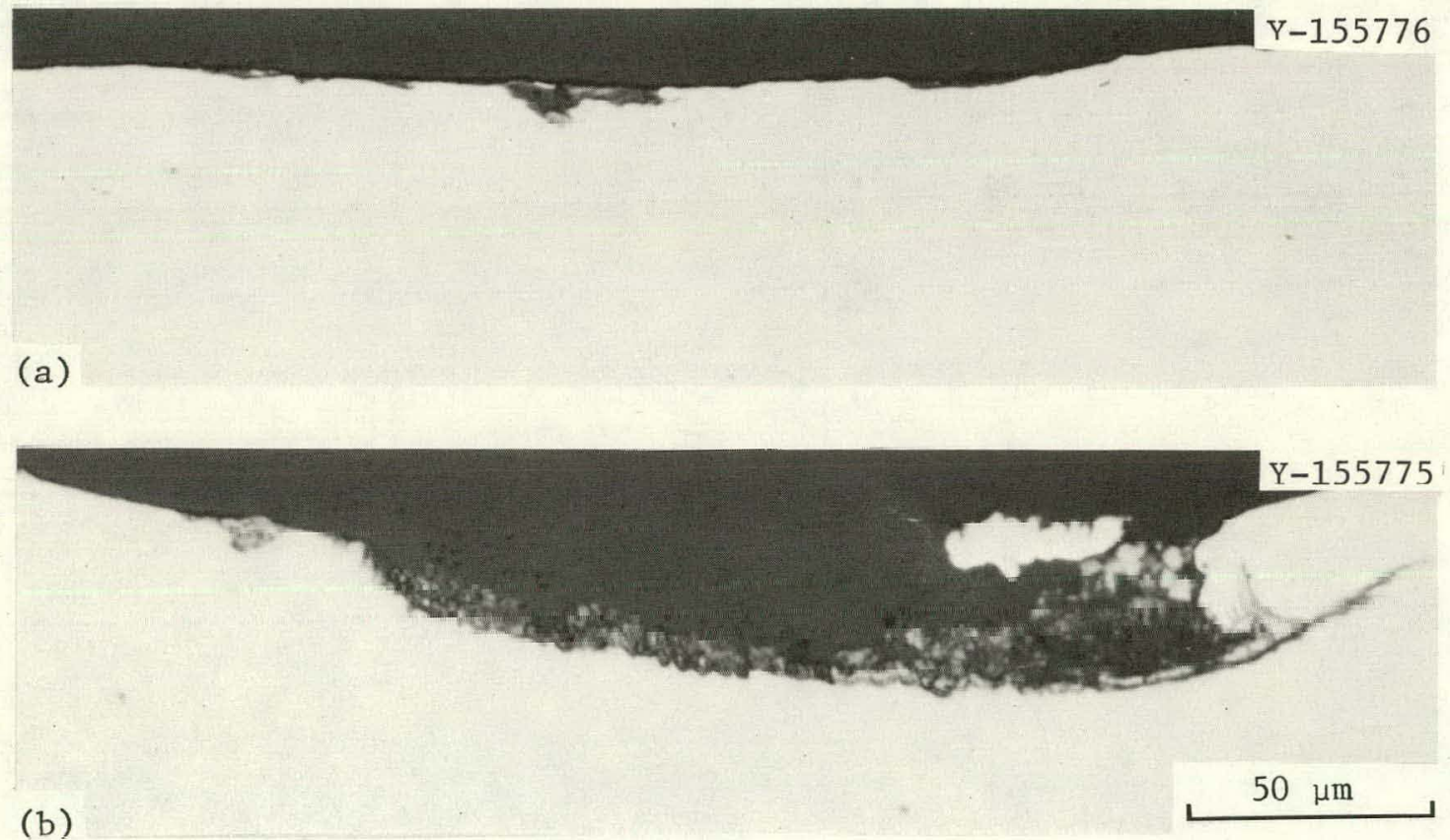

Fig. 42. Carpenter 20 Cb-3 Specimen Exposed for 2350 Operating Hours at the Wilsonville SRC Pilot Plant in the Top of the T-105 Fractionation Column (M1). The specimen displayed the same general characteristics after an additional exposure of $5730 \mathrm{~h}$. 

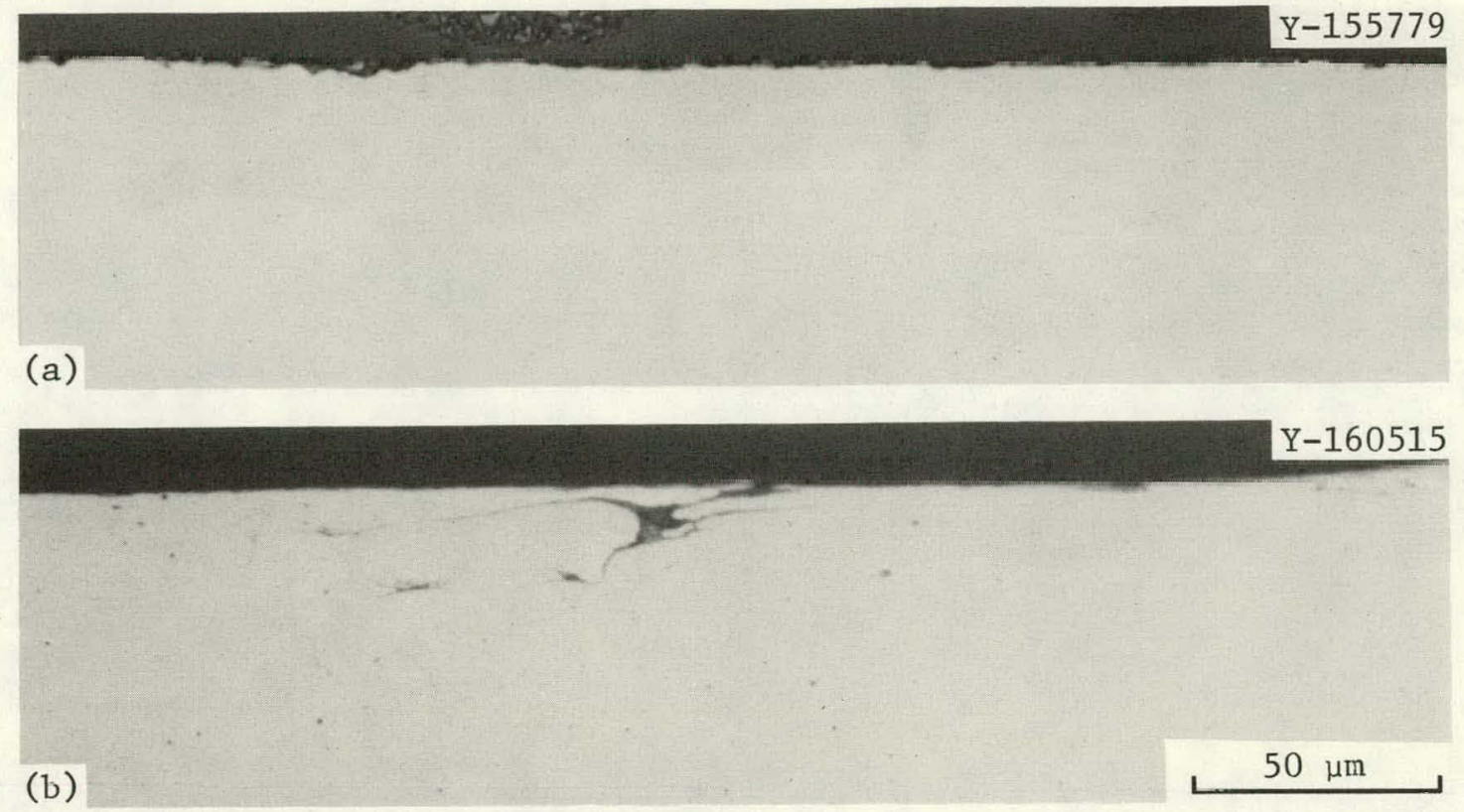

Fig. 43. Type 304L Stainless Steel Specimen Exposed for (a) 2350 Operating Hours and (b) an Additional $5730 \mathrm{~h}$ at the Wilsonville SRC Pilot Plant in the Top of the T-105 Fractionation Column (M1).
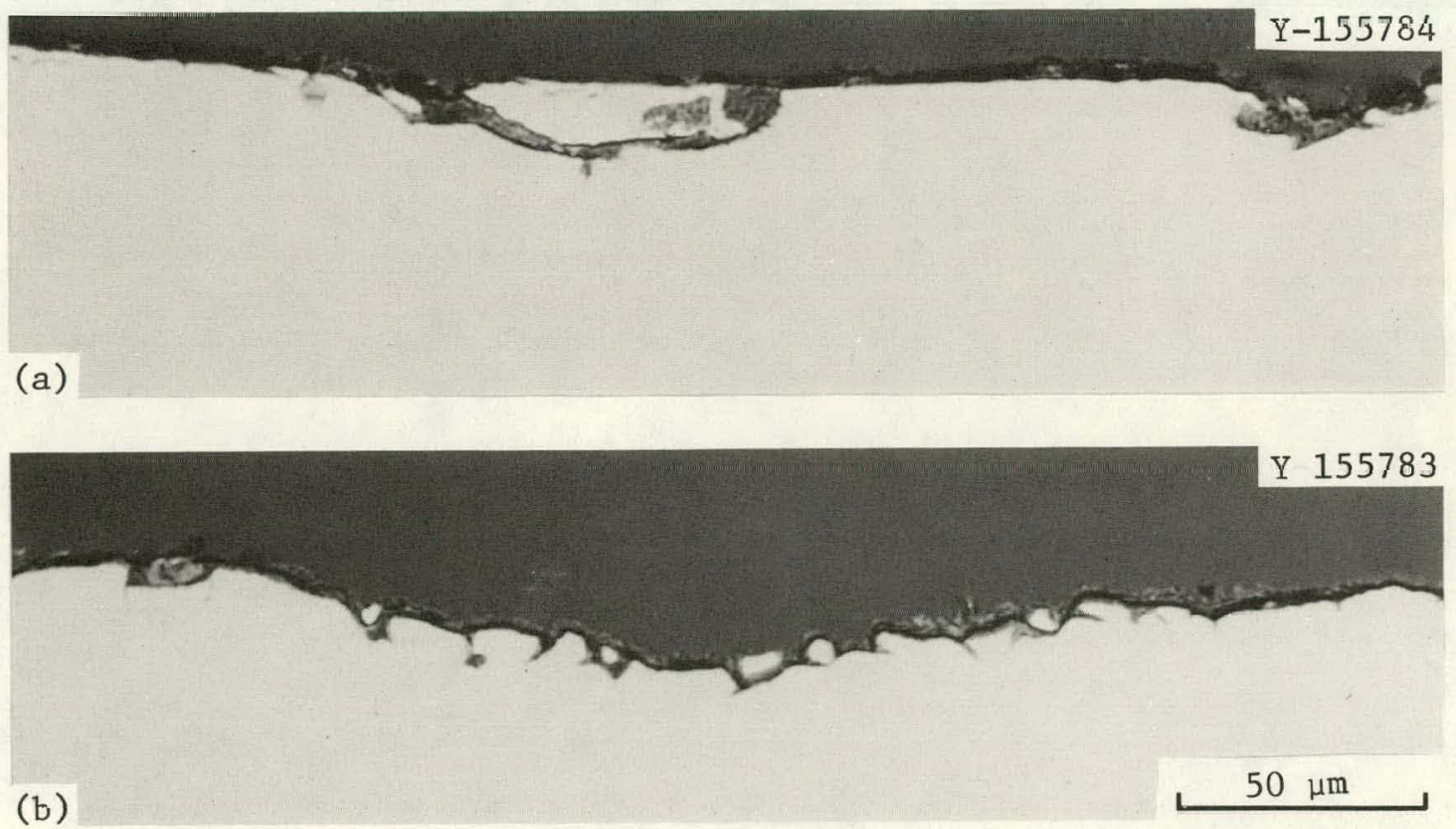

Fig. 44. Type 321 Stainless Steel Specimen Exposed for 2350 Operating Hours at the Wilsonville SRC Pilot Plant in the Top of the T-105 Fractionation Column (M1). After an additional $5730 \mathrm{~h}$ of exposure time the specimen displayed attack in the welded area but otherwise appeared about the same. 

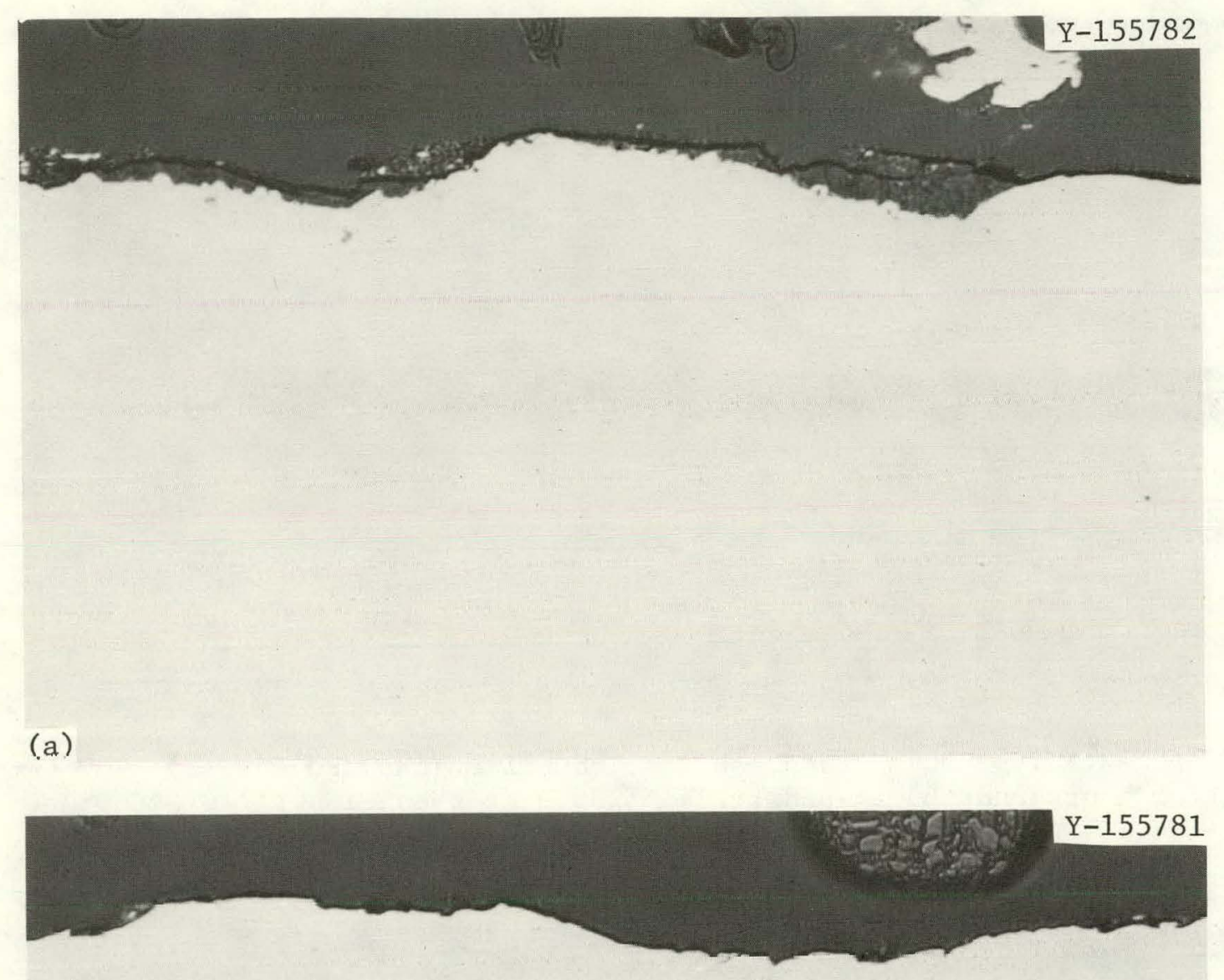

(b)

Fig. 45. Alloy 330 Specimen Exposed for 2350 Operating Hours at the Wilsonville SRC Pilot Plant in the Top of the T-105 Fractionation Column (M1). A cross section of the specimen after the second exposure period of $5730 \mathrm{~h}$ showed deep penetration in the weld. 


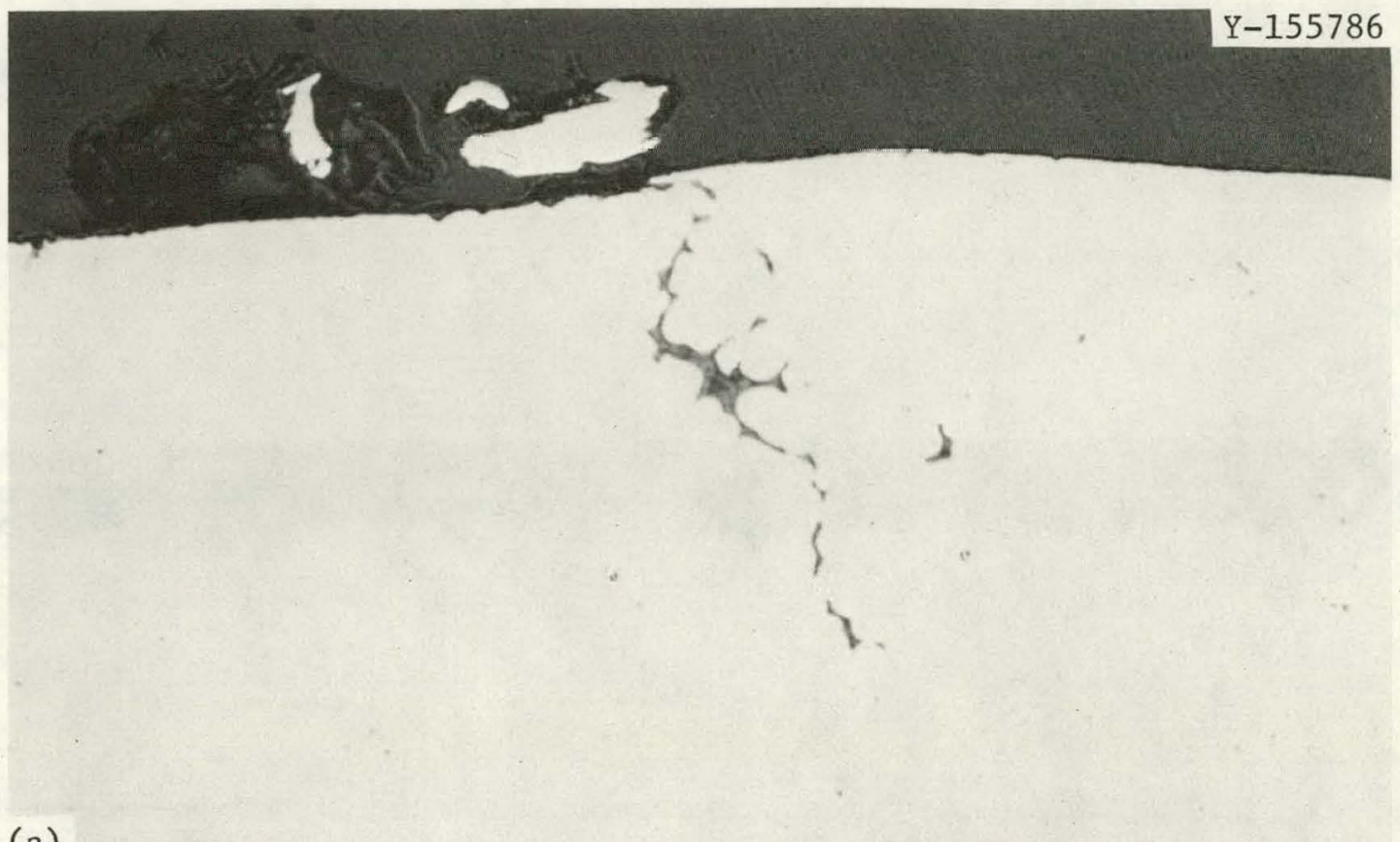

(a)

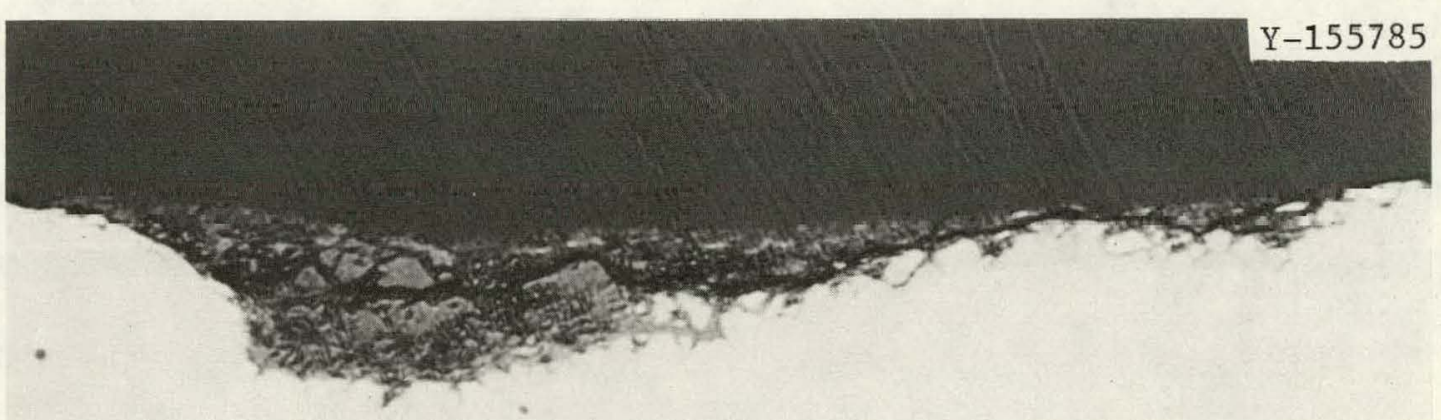

(b)

\section{$50 \mu \mathrm{m}$}

Fig. 46. Type 410 Stainless Steel Specimen Exposed for 2350 Operating Hours at the Wilsonville SRC Pilot Plant in the Top of the T-105 Fractionation Column (M1). The specimen exhibited increased subsurface stringer attack and the same scale characteristics after an additional exposure of $5730 \mathrm{~h}$. 

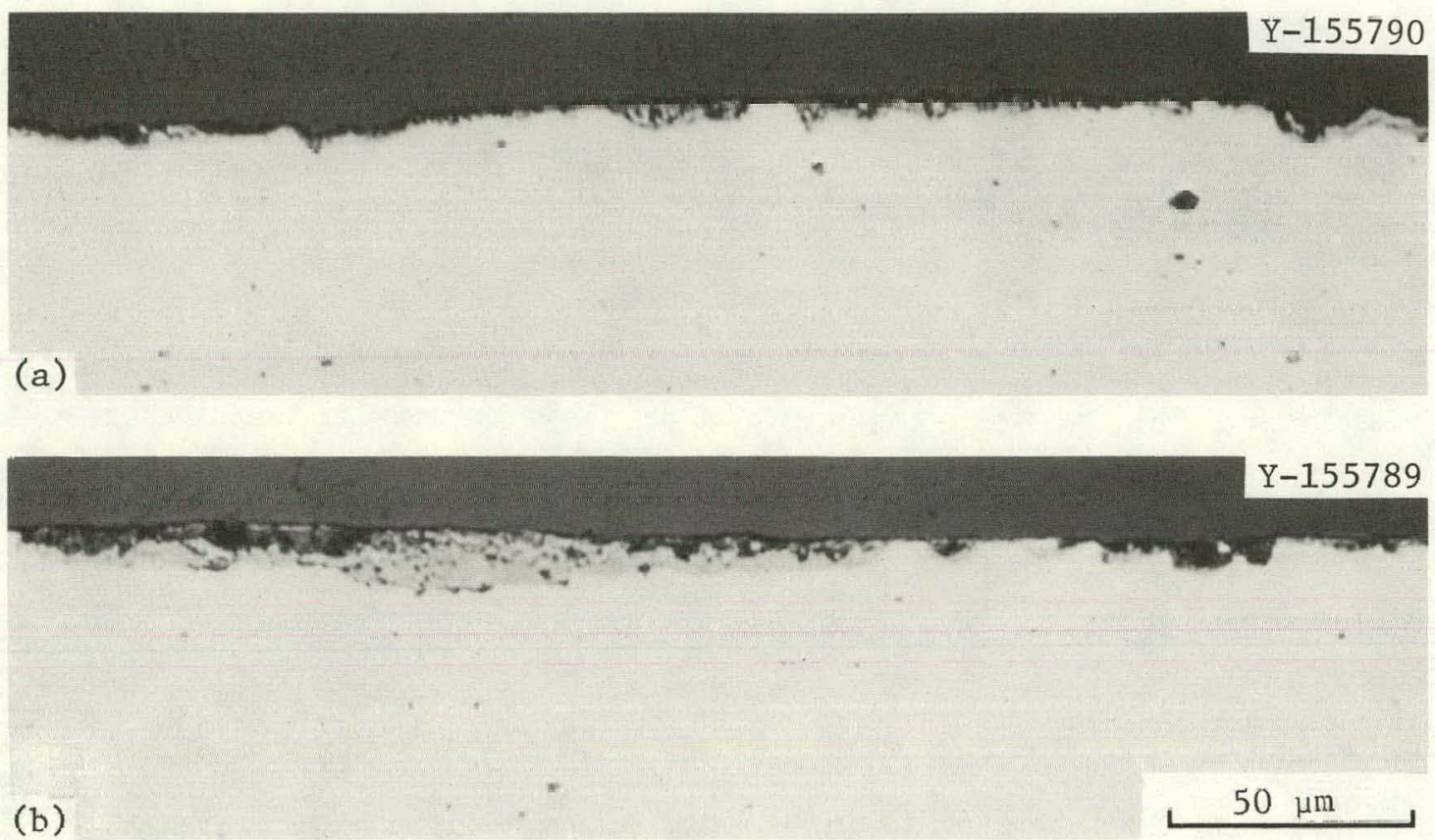

Fig. 47. Specimen of 1018 Carbon Steel exposed for 2350 Operating Hours at the Wilsonville SRC Pilot Plant in the Top of the T-105 Fractionation Column (M1). The depth of penetration on this specimen after an additional $5730 \mathrm{~h}$ of exposure had increased to $30 \mu \mathrm{m}$.
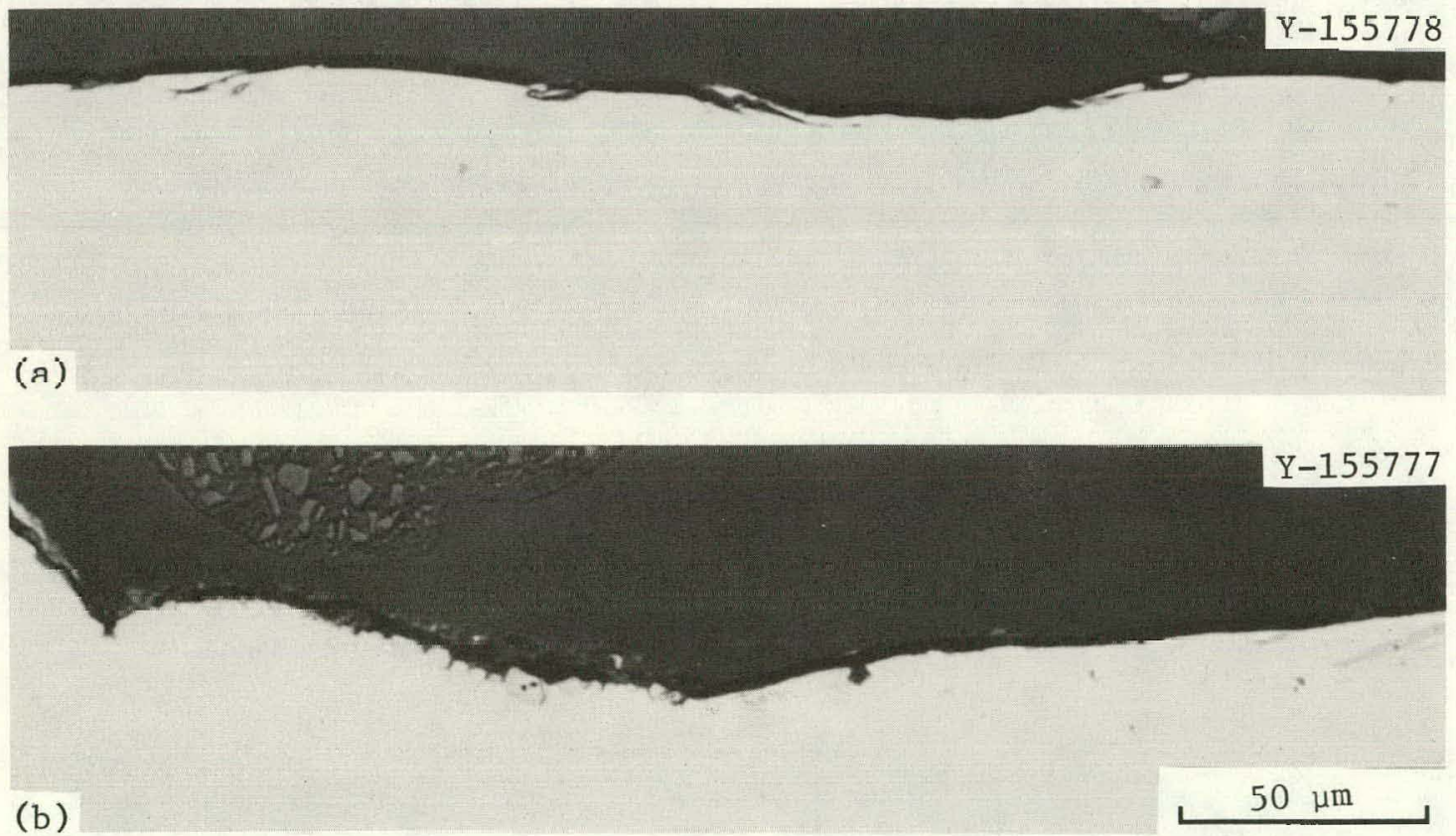

Fig. 48. Alloy 800 Specimen Exposed for 2350 Operating Hours at the Wilsonville SRC Pilot Plant in the Top of the T-105 Fractionation Column (M1). After an additional exposure of $5730 \mathrm{~h}$ the alloy 800 specimen appeared the same. 
rate of any area in the column. A small amount of irregular scale containing metallic inclusions is noted on the alloy 330 [Fig. 45(a)] and alloy 800 [Fig. 48(b)]. Multiphase scale with the subsurface penetration is observed on the carbon steel (Fig. 47), Carpenter 26Cb-3 (Fig. 42), and especially on the type 410 stainless steel (Fig. 46), which has the greatest surface scale thickness and depth of penetration of any samples. Pits up to $100 \mu \mathrm{m}$ deep and subsurface stringers [Fig. 43(b)] were found on the type 304L specimen after the second exposure period. Subsurface attack is also evident in the types 316 [Fig. 41(a)] and 321 (Fig. 44).

A second rack of specimens was exposed to a slightly higher temperature in the middle of the T-105 Fractionation Column (M2). The M2 specimens show greater surface attack and subsurface penetration than the M1 samples. The corrosion rates in this part of the column were higher than for any other area of any other vessel in which coupons were exposed. The type 316 stainless steel (Fig. 49) has a multiphase, multilayer scale deposit and pitting but shows none of the intergranular cracks noted for the Ml sample. The general attack is much greater on the type 304L in this area, with a multilayer scale on an irregular surface [Fig. 50(b)] with some evidence of surface penetration [Fig. 50(a)]. The subsurface attack is as deep on the type 321 M2 sample (Fig. 51) as on the $321 \mathrm{M} 1$; however, the surface scale on the M2 sample is thicker and contains many phases along with what may be process stream material [Fig. 51(b)]. The process material layer also appears on the type 410 specimen [Fig. 52(a)] and the depth of the needle-like penetration is $150 \mu \mathrm{m}$ after the second exposure period. Some pitting is observed on the carbon steel sample up to $40 \mu \mathrm{m}$ deep [Fig. 53(a)] containing corrosion products with metallic inclusions.

The M2 alloy 800 specimen (Fig. 54) also displays greater subsurface penetration than does the Ml sample. Microprobe analysis performed on the M2 alloy 800 specimen (Fig. 55) shows the deposit in Fig. 54(a) to be a complex mixture of sulfides and oxides of chromium, nickel, and iron -in a matrix of nickel-iron oxide. Figure 56 shows that the subsurface product in Fig. $54(\mathrm{~b})$ is a result of extensive sulfidation. Of interest is that the dark band contains small amounts of many different elements [Fig. 56(e)] including silicon, aluminum, and titanium in addition to the 

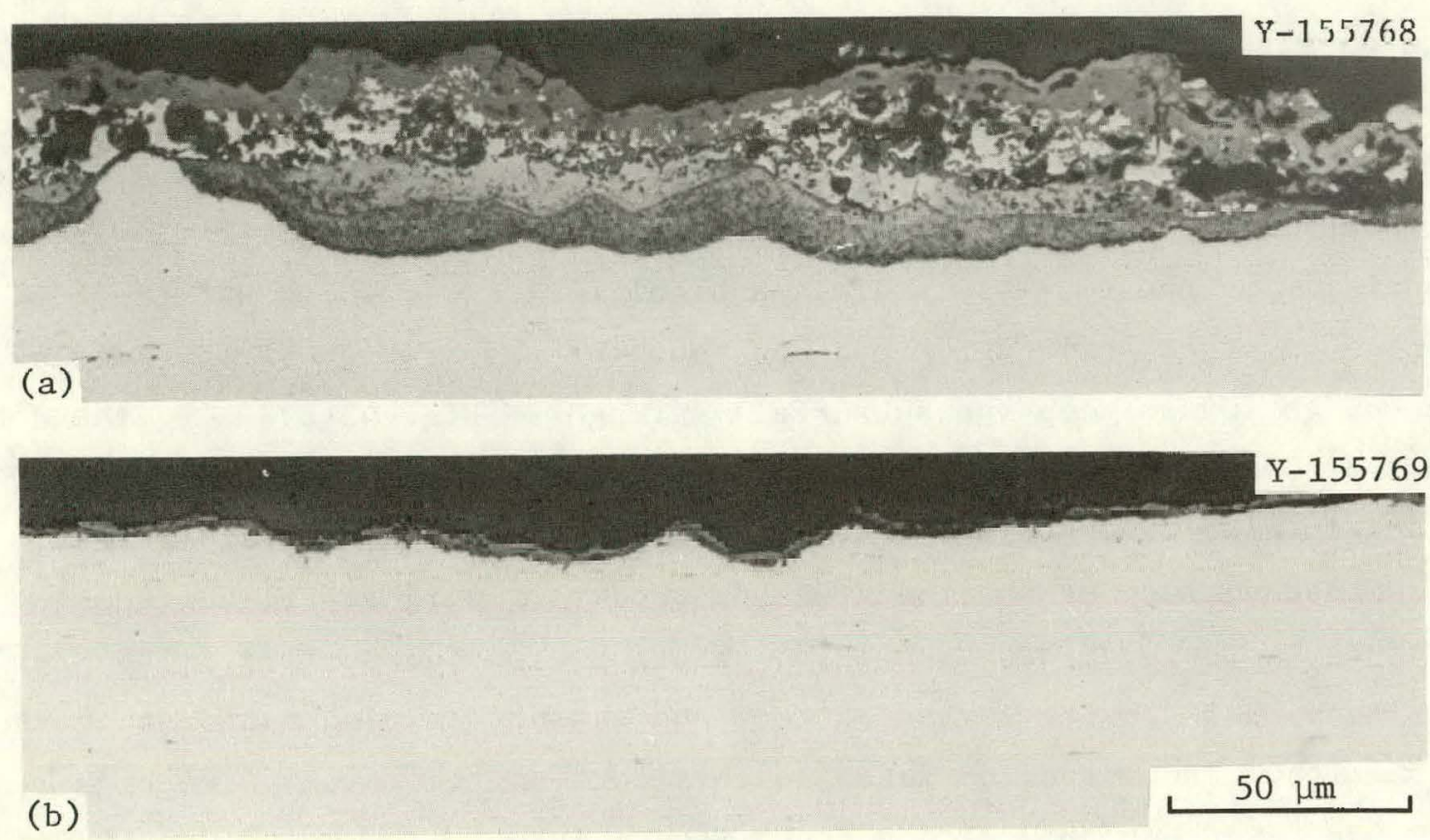

Fig. 49. Type 316 Stainless Steel Specimen Exposed for 2350 Operating Hours at the Wilsonville SRC Pilot Plant in the Middle of the T-105 Fractionation Column (M2).
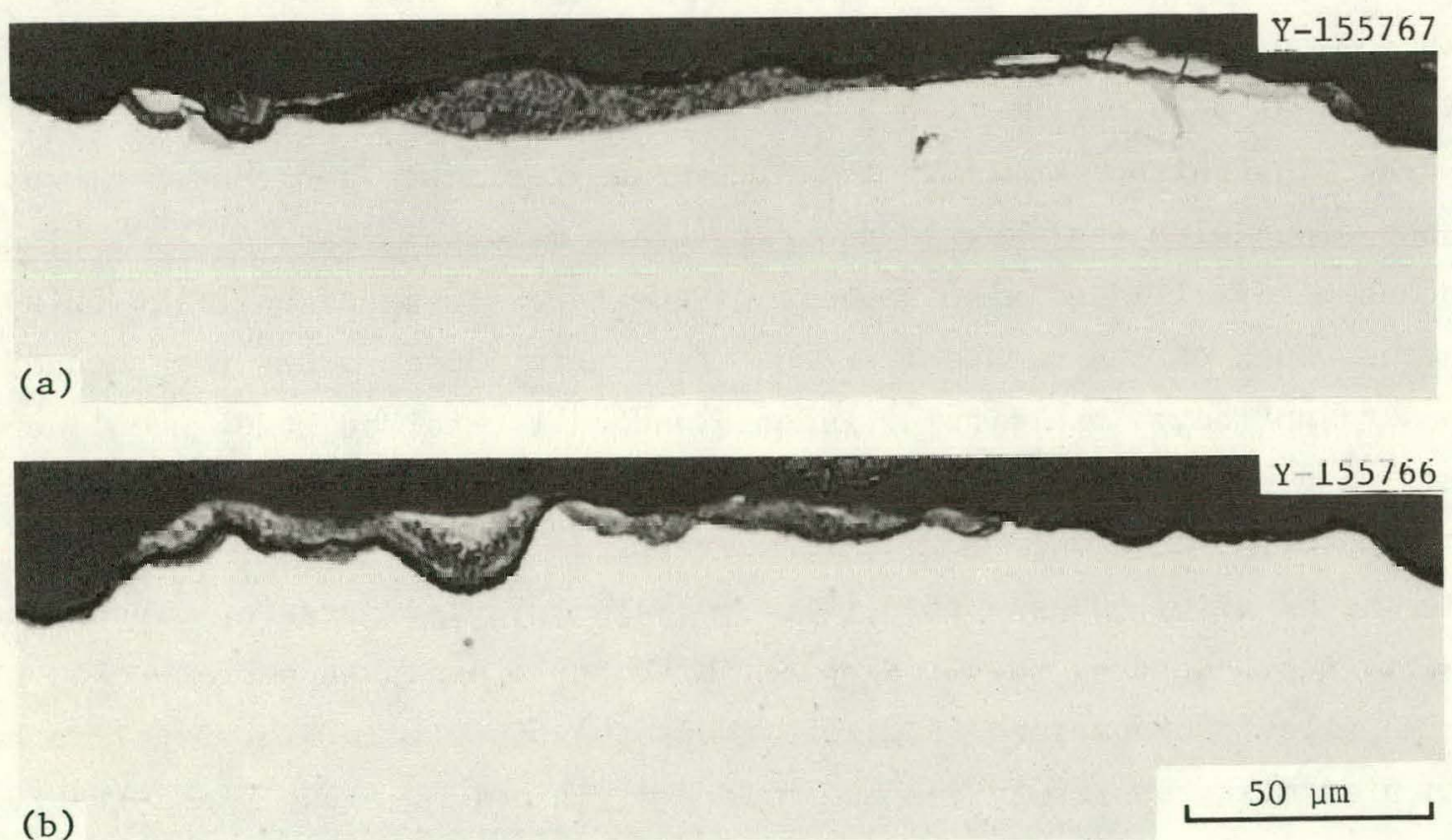

Fig. 50. Type 304L Stainless Steel Specimen Exposed for 2350 Operating Hours at the Wilsonville SRC Pilot Plant in the Middle of the T-105 Fractionation Column (M2). After an additional $5730 \mathrm{~h}$ of exposure the specimen displayed the same general appearance. 


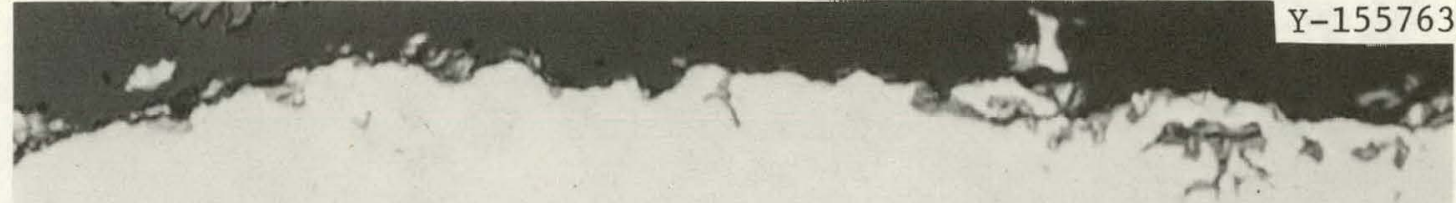

(a)

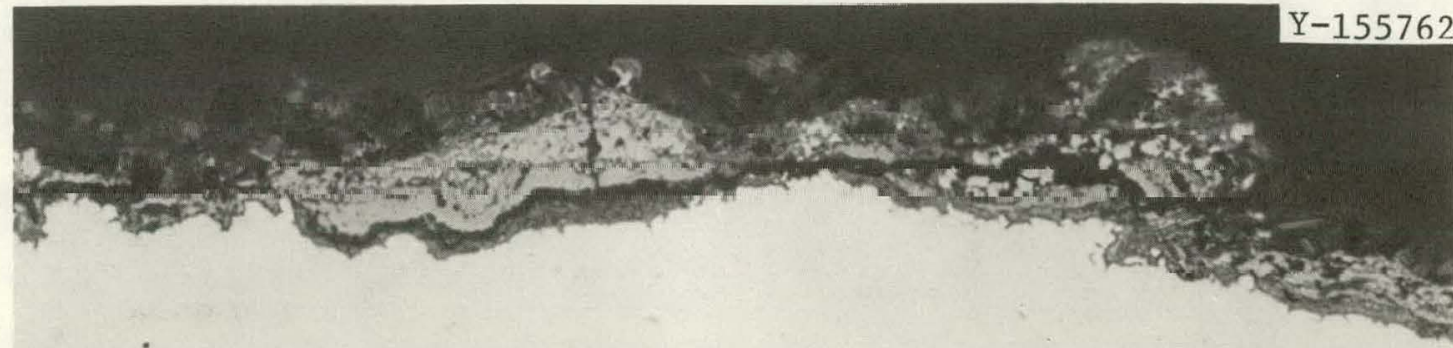

(b)

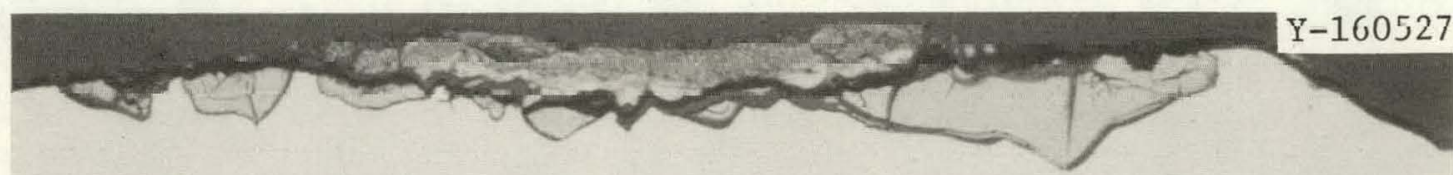

(c)

Fig. 51. Type 321 Stainless Steel Specimen Exposed at the Wilsonville SRC Pilot Plant in the Middle of the T-105 Fractionation Column (M2). (a,b) Two views after 2350 operating hours. (c) The subsurface penetration increased during an additional exposure of $5730 \mathrm{~h}$. 

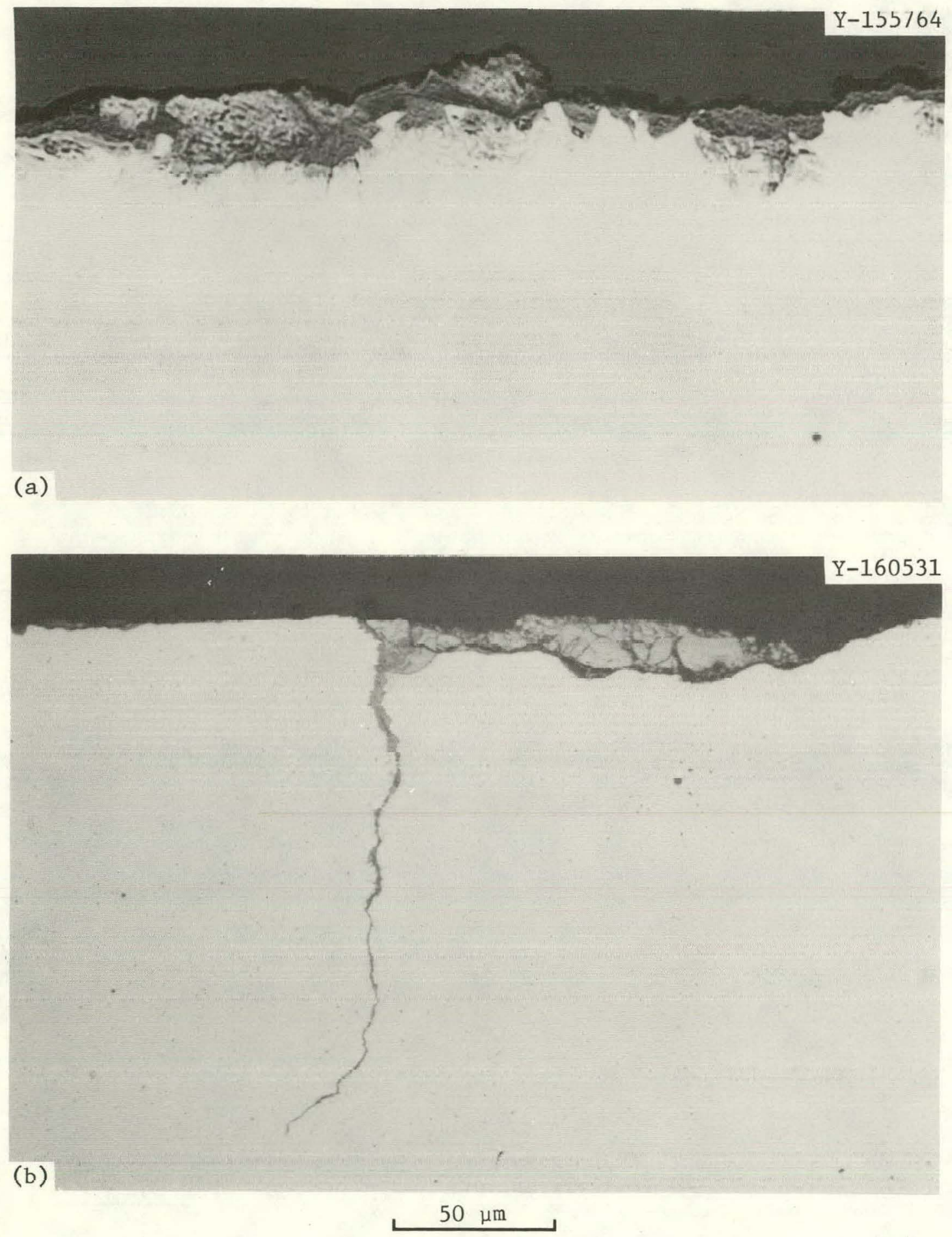

Fig. 52. Type 410 Stainless Steel Specimen Exposed for (a) 2350 Operating Hours and (b) After an Additional $5730 \mathrm{~h}$ at the Wilsonville SRC Pilot Plant in the Middle of the Fractionation Column (M2). 

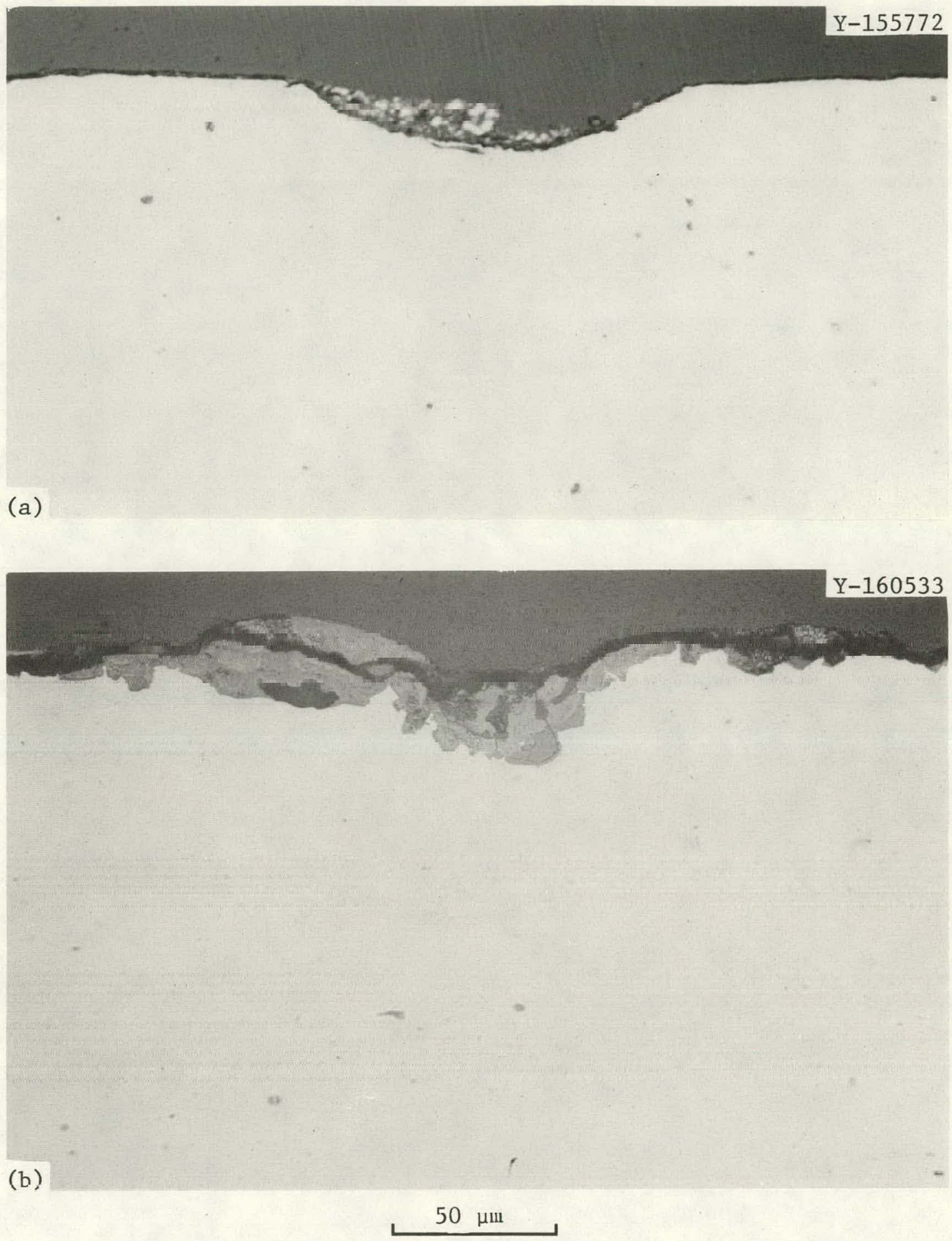

Fig. 53. Specimen of 1018 Carbon Steel Exposed for (a) 2350 Operating Hours and (b) an Additional $5730 \mathrm{~h}$ at the Wilsonville SRC Pilot Plant in the Middle of the T-105 Fractionation Column (M2). 

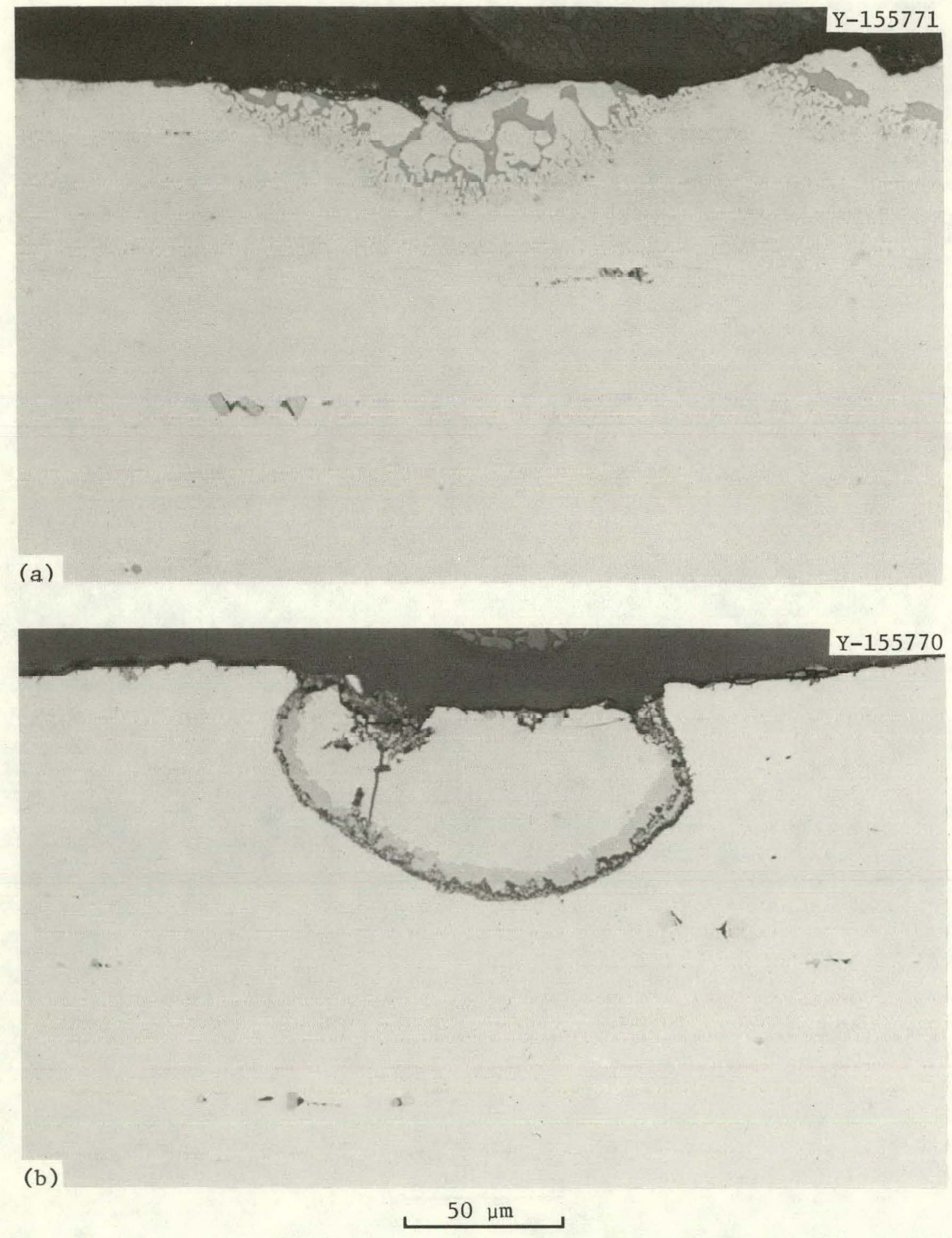

Fig. 54. Alloy 800 Specimen Exposed for 2350 Operating Hours at the Wilsonville SRC Pilot Plant in the Middle of the T-105 Fractionation Column (M2). 


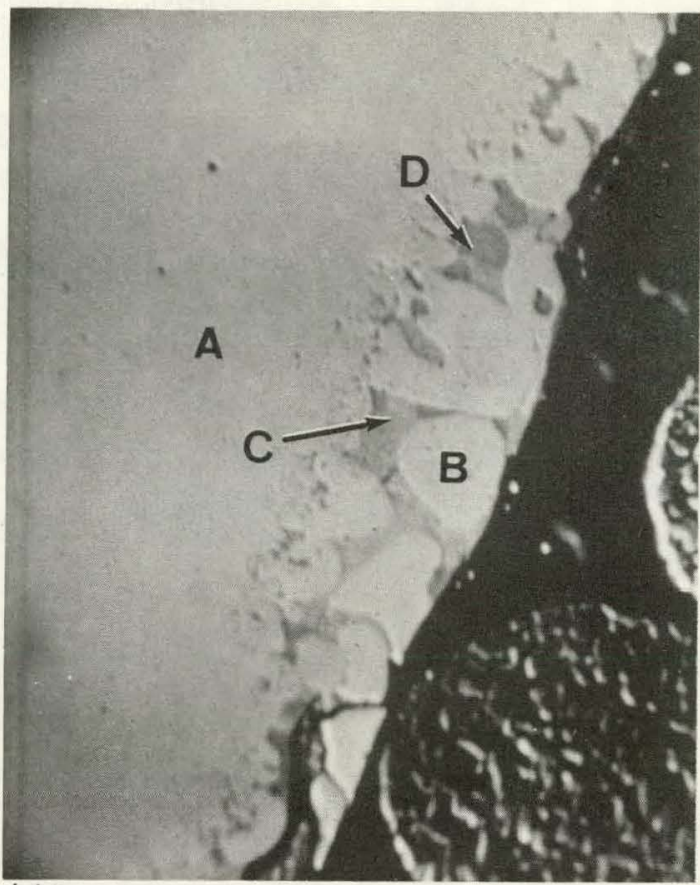

(a)

Fig. 55. Microprobe Analysis of Alloy 800 Sample Shown in Fig. 54(a) After Exposure in the Middle of the T-105 Fractionation Column (M2).
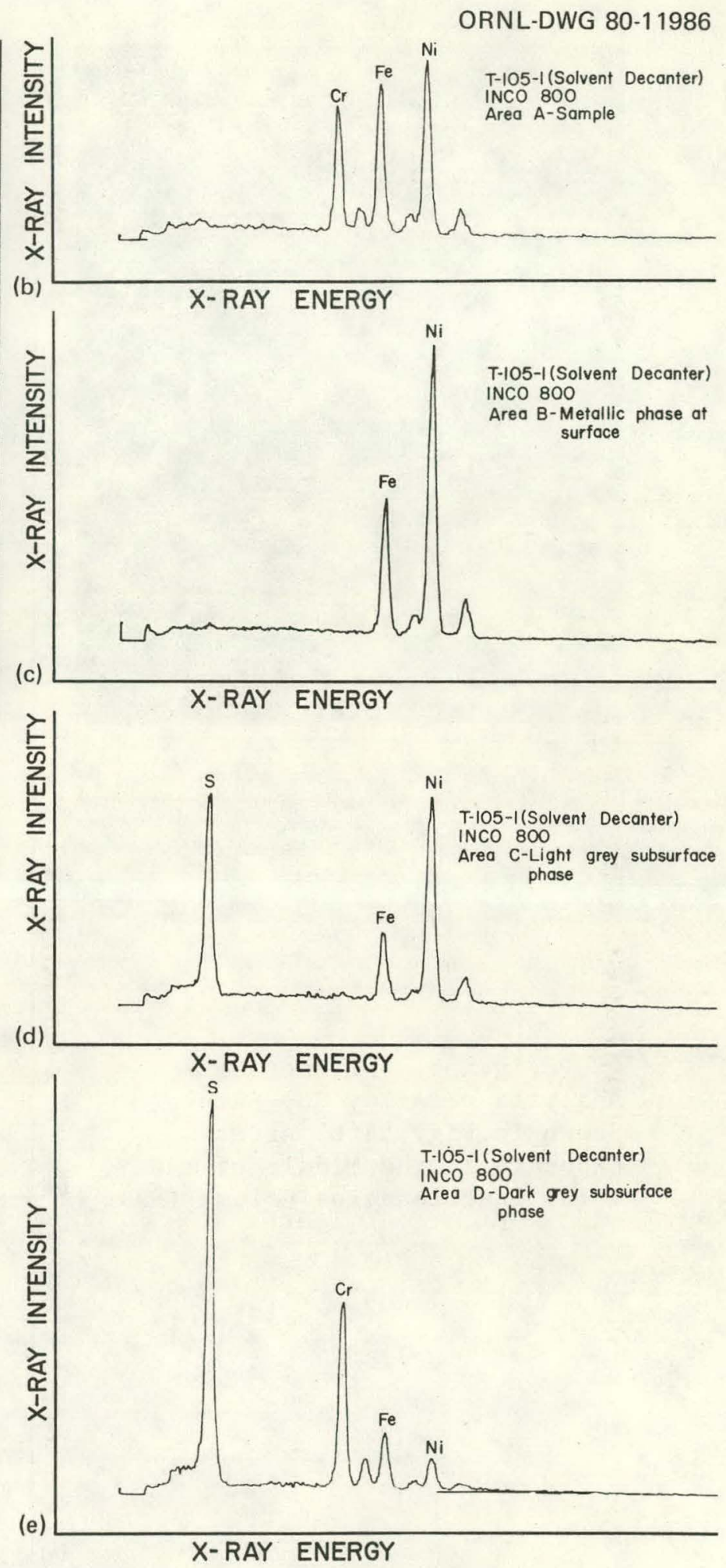

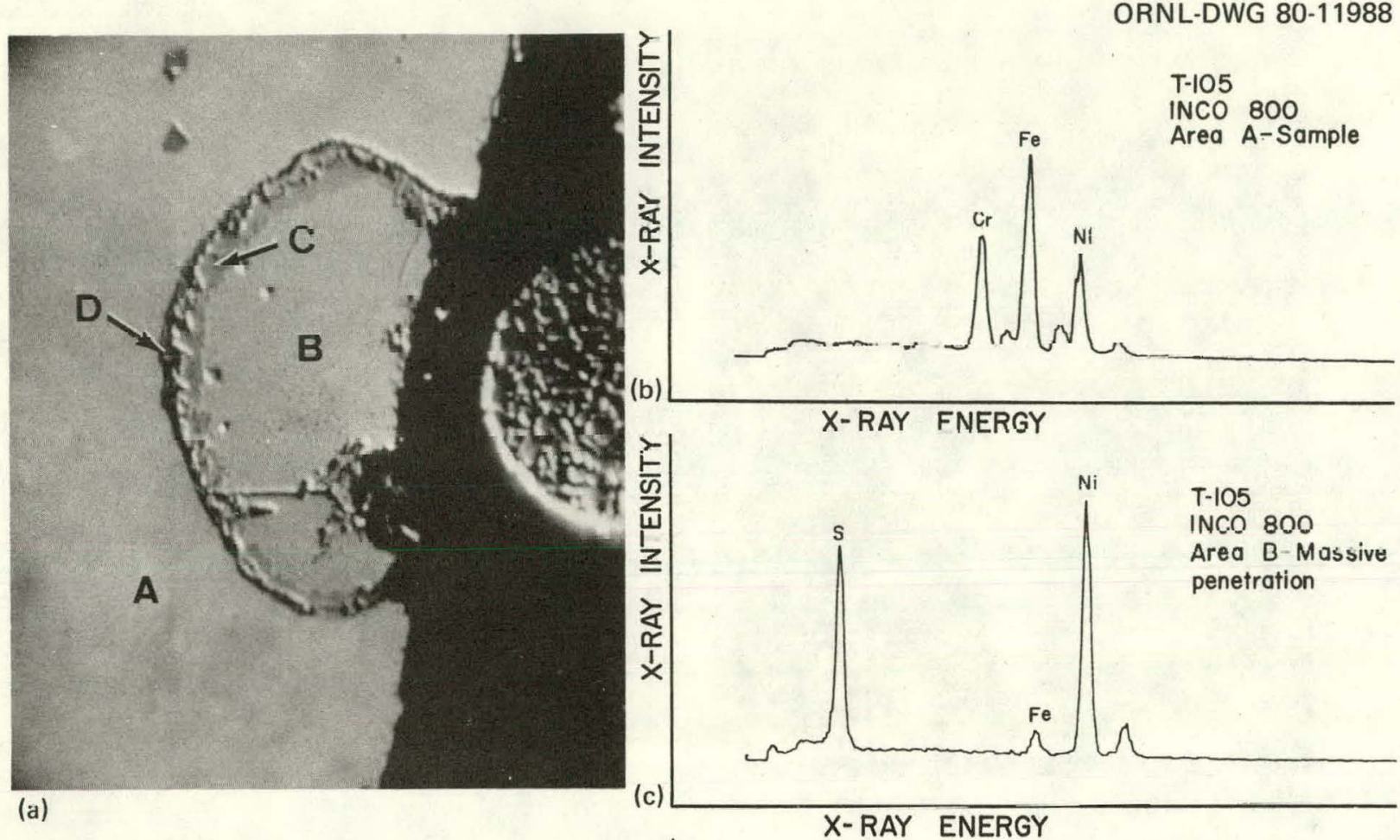

(a)

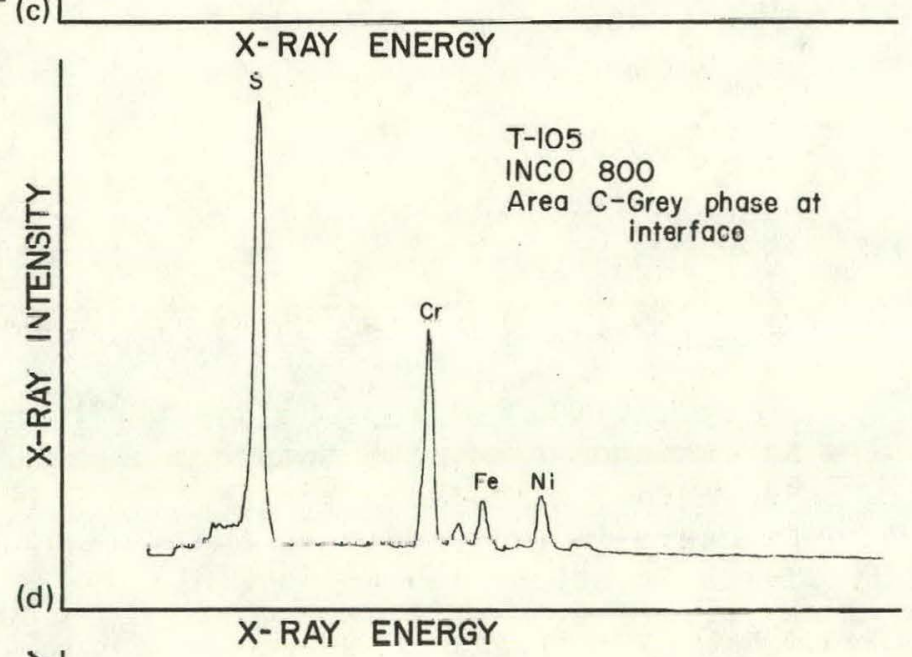

Fig. 56. Microprobe Analysis of Alloy 800 Sample Shown in Fig. 54(b) After Exposure in the Middle of the T-105 Fractionation Column (M2).

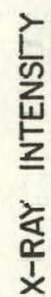

T-105

INCO 800

Area D-Dark phase at inlerface

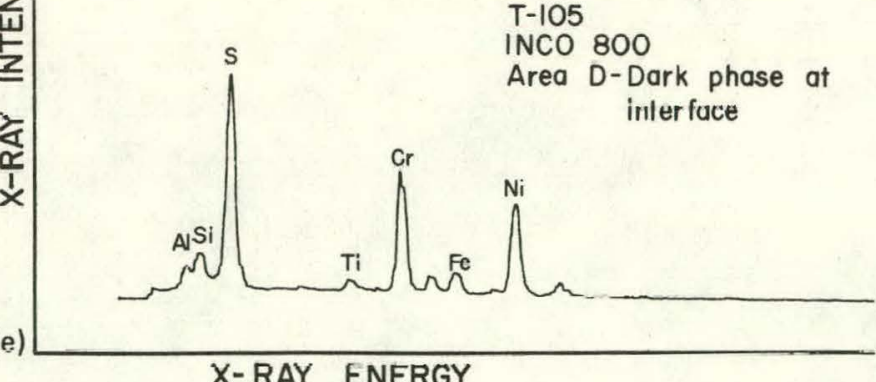


predominant chromium-nickel sulfide. The adjacent gray area contains none of these elements but has significantly more chromium and sulfur, while the interior deposit appears to be mostly nickel sulfide.

The amount of subsurface penetration decreases considerably as expected for the samples exposed to the highest temperature range (M3) in the Fractionation Column. Some penetration or pitting is observed for all specimens; however, the magnitude is less than that observed for the M2 and, especially, the Ml specimens, with the exception of the type 316 stainless steel, which shows some cracking and pitting. In general, the surface scale appearance is similar to that of the other specimens, but the amount of multilayer oxide corrosion deposit is less than on both the M1 and M2 samples. The corrosion rates for most of the specimens in the M3 location were correspondingly low $(<0.05 \mathrm{~mm} /$ year $)$ except for the carbon steel and type 410 stainless steel specinens.

\section{V-178 Light Solvent Surge Tank}

Since the V-178 Light Solvent Surge Tank also contains wash solvent from the T-102, the coupons should exhibit some of the same characteristics as either the samples from the T-102 or those from the T-105. In general, the V-178 specimens do not show the same degree of subsurface penetration but have about the same amount of scale of the same generai appearance as the $\mathrm{T}-102$ and/or $\mathrm{T}-105$ samples. For example, the multilayer deposit on the type 316 stainless steel resembles that shown in Fig. 49(a). As seen previously, the type 304L exhibits relatively little surface scale, with most damage being below the surface. The dendritic growth patterns in the type 410 corrosion deposit have been observed previously [Fig. 36(b), p. 53]. The scale on the carbon steel contains dark particles in a multilayer matrix. The alloy 800 is relatively unattacked; it exhibits a thin deposit containing metallic inclusions and process stream material with some subsurface cracks.

\section{DISCUSSION}

Since the purpose of the pilot plant is to investigate the process under varying conditions, the variation in process conditions within a 
single vessel over a six-month interval may be quite large. Thus, these corrosion results cannot be related to variations in temperature, pressure, and other process variables. For example, while the coupons in the lowest temperature vessel $\left(66^{\circ} \mathrm{C}\right)$ generally exhibited the least surface scale, these same materials exhibited a relatively large amount of scale at only a slightly higher temperature $\left(93^{\circ} \mathrm{C}\right)$ in the Vacuum Column and relatively little scale (except for the type 410 stainless steel) at a much higher temperature $\left(260^{\circ} \mathrm{F}\right)$ in the same vessel. Since any poorly adherent scale may have been removed by brushing, generalizations on corrosion based on surface scale thickness are difficult. The amount of surface scale also may mislead the corrosinn rate determination and interpretation.

Some insight can be gained by studying the relative attack on materials as compared with their compositions. In the dissolver and the high-pressure separator, the materials that had the best overall resistance to surface scaling and subsurface attack were the alloy 22-13-5 and the alloy 26-1. These materials do not have many close similarities in composition, except for being slightly higher in chromium and conLalulng more alloying additions (especially molybdenum) than the other materials tested. The behavior of the type 410 stainless steel was paradoxical; its surface corrosion deposit was among the thickest observed, yet it was relatively unattacked below the surface. since the type 410 contains no nickel, which is known to be susceptible to sulfidation, then the degree of subsurface attack may be related to nickel content of the dlloy in the dissolver and high-pressure separator.

Not surprisingly, in most locations where carbon steel was tested it proved to be among the least resistant materials to surface scale buildup; however, in general, it did not experience as much subsurface attark as did many of the more highly alloyed materiala. The type 410 suilulesu accel was also among the least resistant alloys to both surface and subsurface attack in all locations except the dissolver and high-pressure separator. These two ferritic materials are the lowest in chromium (the carbon stepl has none), the highest in carbon, and the only two materials tested outside the dissolver-separator area that contain no nickel. While the absence of 
nickel in the dissolver-separator area may play a role in preventing subsurface attack, in other areas of the plant the high nickel content of the material appears to be a major factor in corrosion resistance.

Corrosion rate measurements do not indicate corrosion to be a particular problem during the year and a half of coupon exposure. The highest corrosion rates were observed in the middle of the T-105 Fractionation Column for both time periods, yet these rates are within reasonable design allowances. While in general the austenitic stainless steels outperforned the ferritics (with the exception of $26 \mathrm{Cr}-1$ Mo in the dissolver), even the 1018 carbon steel performed acceptably in most locations during the two periods of exposure examined.

As a result of varying operating conditions coupled with gradients in process stream cheinistry, the corrosion deposits found in this exanination are quite complex, usually consisting of multiphase layers of oxides and sulfides. Because of the changing conditions determination of a single corrosion mechanism is not feasible, but the microprobe results reveal some interesting characteristics that warrant further investigation. For exanple, on the carbon steel sample exposed to the environment of the $\mathrm{V}-111$ Reclaim Tank, the analysis of one area reveals an oxide deposit containing iron and trace elements from the process stream including, Mn, Si, Ti, and A1. They may be process stream trace elements or may have come from adjacent corrosion coupons. On another area of the same sample, the scale consists of two layers of iron sulfide (one penetrates the surface) sandwiching a layer containing sulfides and probably some oxides of iron, silicon, and chivuium, the latter two nf which are not contained in carbon steel. Why the scale varies so much from site to site on the sample and how the trace elements came to be in the middle of the iron sulfide deposit can perhaps be ascribed to changing process conditions during exposure coupled with scale exfoliation and weld spatter. For example, it may be hypothesized that the middle layer formed during shutdown while the plant was changluy from proccssing the Emery coal to the Indiana V coal, and both coals cause the formation of sulfide. The number of layers, however, on the type $304 \mathrm{~L}$ stainless steel coupon in the same tank suggests that this explanation is probably too simple.

The complex changes in scale composition and morphology from vessel to vessel are also not easily explained. For example, the process stream 
in the fractionation area, specifically in the T-102 Vacuum Column and T-105 Fractionation Column, should contain little sulfur (mostly organic) and no active oxygen. The amount of oxidation that occurred, however, indicates the activity of oxygen to be unexpectedly high. It has been speculated that exposure of plant vessels to air during shutdown and/or possible air leaks could result in the presense of oxygen in the system at this point. The amount of sulfur reaching this area has ranged from 0.27 to 0.64 wt $\% .5$ However, coal liquefaction streams containing 0.3 to $0.8 \%$ surfur have caused sulfidation corrosion above $250^{\circ} \mathrm{C} .6$ Thus, while some sulfidation may be expected (even though the temperature is low) the oxidation is surprising.

The behavior of alloying elements in forming corrosion produrt scalee is also complex. For exanple, the tendency of the nickel and chronium to form oxides and/or sulfides relative to that of the irun was quite variable, as shown in the analysis of the alloy 800 specimen exposed to the middle (M2) of the T-105 Fractionation Column. In onc region layers of primarily chromium and sulfur on the inside and one of chronium-nickel and sulfur, with trace elements from either the process stream or the metal, band a reginn containing villually all nickel sulfide with no chromiuni. In another region on the same coupon the base metal near the deposit is very rich in nickel as is a chromium-frep metallic phase at lle surface. Between these two arcas are Lwo phases, one of predominantly nickel sulfide, with no chromium, and one of predominantly sulfur and chromium with no nickel. These observations attest to the variability of the process stream chemistry during the sample exposure and to the probability that the corrosion involves a ecquence of uxldation-sulfidation reactions.

\section{RECOMMENDATIONS}

Recommendations below are based on two exposure periods of selected coupons, which may or may not be realistic materials of construction for future demonstration plants.

1. In the high-temperature, high-pressure areas ( $R-101$ Dissolver and V-103 High Pressure Separator), the relatively high resistance to corrosion attack of the alloy 22-13-5 and the alloy 26-1 suggest that the most 
resistant iron-base alloy for this application would be high in chromium (greater than 20\%) and contain a variety of alloying elements, especially molybdenum. A high nickel content would not be advisable because of the potential for sulfidation.

Although the $26 \mathrm{Cr}-1$ Mo steel showed good corrosion resistance, it is a ferritic stainless steel and is therefore subject to a degradation in mechanical properties due to long exposure above $425^{\circ} \mathrm{C}$. We recommend that this alloy not be considered as a material for pressure containment at this temperature and that this alloy would be more appropriately tested in the lower temperature areas of the plant.

Refinery experience dictates that the vessels for pressure containment in this region will more likely be a low-alloy steel (such as $21 / 4$ $\mathrm{Cr}-1 \mathrm{Mo}$ ) overlaid with type 347 stainless steel or a duplex layer of types 309 and 347. Further testing of low-alloy ferritics and the stablized austenitics is recommended.

2. In the lower temperature and pressure areas of the plant, the better corrosion resistance in this environment of type 304L over the stablized austenitic stainless steels suggests that other alloys to test should include $316 \mathrm{~L}$ and $317 \mathrm{~L}$ as well as the high-nickel alloys such as Hastelloy $G$ and perhaps a duplex ferritic-austenitic alloy. Other program additions could include alloys 801 and 825 .

3. The above recommendations are based on corrosion resistance of the alloys and do not take into consideration the mechanical properties and freedom from fabrication sensitivity and stress corrosion cracking resistance necessary for thesc applicatione. A program is under way at ORNL to determine the susceptibility to stress corrosion cracking in coal liquefaction environments of some of these alloys. Mechanical properties testing in these environments has been limited.

\section{SUMMARY}

Welded coupons of various alloys were exposed to varying process conditions at the Wilsonville SRC pilot plant at ten locations in seven vessels. The temperature, pressure, and process stream compositions varied during the nominal six-month and one-year exposures. These variations dictate the general nature of all comments. 
1. All exposed coupons had corrosion deposits, most being multiphase and multilayer with some degree of subsurface penetration. The specific characteristics of the scale, such as the composition and morphology of the phases, the adherence to the surface, and the thickness and/or depth of penetration varied not only from location to location and sample to sample, but even varied from one site to another on individual coupons.

2. Sulfidation and possibly oxidation were the primary mechanisms of scale buildup and penetration, and neither type of attack was particularly predominant. Oxides and sulfides were formed of iron, chronium, and nickel, somctimes containing trace elements, probably from the process stream or weld spatter. There was no pattern observed as to the number of layers and the order in which sulfidation and oxidation occurred.

3. High-chromium, molybdenum-containing alloys had the best resistance in the high-temperature, high-pressure areas of the plant and were not tested in other locations. In the other areas, the low carbon, higher nickel, and chromium.steels performed best; those that were high in carbon, low in chronium, and free of nickel or alloying additions performed worst.

4. The depth of penetration, thickness of scale, and weight change. measurements do not indicate corrosion to be an overwhelming problem after the first two exposures; however, varying process conditions may alter the corrosion resistance of these alloys considerably. The corrosion rates observed for the two exposures were similar with a few exceptions.

\section{$\Lambda$ CKNOWLEDCMENTE}

'l'he authors wish to thank Julius Ciccalese, Catalytic, Inc., Philadelphia, Project Manager for Wilsonville SRC; Harry Lewis, Catalytic, Inc:, Wilsunville, Ceneral Manager of Wilsonville SRC; Everett Huffman, Southern Services, Inc., Birmingham, Project Manager for Wilsonville SRC; and George Usnick, Conoco, then Production Superintendent at Wilsonville, now at Library, Pennsylvania, for their cosperation in supplying surveillance coupons. 
We alșo would like to thank K. F. Russell, C. W. Houck, and M. D. Allen of Oak Ridge National Laboratory for metallographic preparation and photomicrographing. Appreciation is also due to S. J. Dapkunas, Jim Batchelor, and Harold Fisher at DOE for sponsoring the program and allowing access to the plant. Finally, we wish to thank R. W. Swindeman and J. R. Keiser for reviewing the manuscript; S. Peterson for editing, and $P$. T. Thornton for the final preparation of the manuscript.

\section{REFERENCES}

1. Monthly, quarterly, and annual progress reports are available for. Solvent Refined Coa1 (SRC) Process: H. E. Lewis et al., Operation of Solvent Refined Coal Pilot Plant at Wilsonville, Alabama, Catalytic, Inc., FE-2270-(1-55).

2. Pittsburg and Midway Coal Mining Company, Development of a Process for Producing an Ashless, Low Sulfur Fuel From Coal: Volume III Pilot Plaint Development Work, Part 3 -Start-up and Operation of the SRC Pilot Plant, FE-496-T13 (May 1977).

3. D. R. Canfield, S. Ibarra, and J. D. McCoy, "Materials Performance at the Pittsburg and Midway Coal Mining Company's Solvent Refined Coal Liquefaction Pilot Plant," paper presented at Corrosion/79, NACE, Atlanta, Georgia.

4. V. B. Baylor, J. R. Keiser, B. C. Leslie, M. D. Allen, and R. W. Swindeman, Analysis of T-105 Fractionation Column Failure at lihe Wilsonville, Alabama, Solvont Refined Cont. Pit.ot Plant, ORNL/TM-7327, in press.

5. R. E. Balzhiser, "Fossil Fuel and Advanced Systems Division: R\&D Status Report," EPRI J. 3(5): 34-41 (June 1978).

6. E. Lendvai-Lintner and G. Sore11, "Materials Evaluation Progran for the Exxon Donor Solvent Coal Liquefaction Process," Mater. Perform. $19(4): 19-25$ (May 1980). 


\section{THIS PAGE \\ WAS INTENTIONALLY \\ LEFT BLANK}


ORNL/TM-7365

INTERNAL DISTRIBUTION

Category UC -90
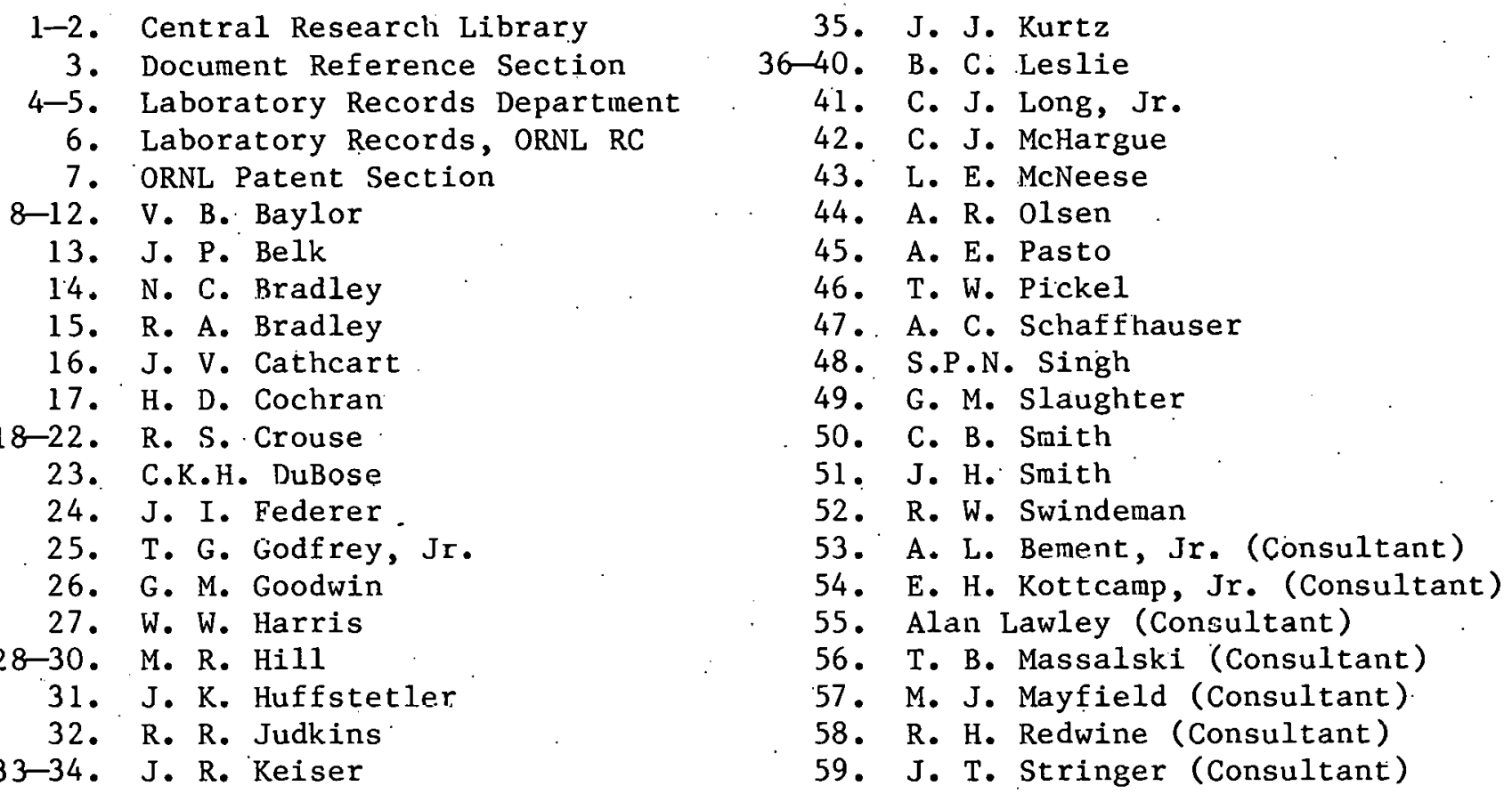

EXTERNAL DISTRIBUTION

60. AIR PRODUCTS AND -CHEMICALS, INC., P.0. Box 538, Allentown, PA 18105

K. L. Baumert

61. ARGONNE NATIONAL LABORATORY, 9700 South Cass Avenue, Argonne, IL 60439

R. W. Weeks

62. BATELLE-COLUMBUS LABORATORIES, 505 King Avenue, Columbus, $\mathrm{OH}$ 43201

D. Maykuth

63-64. CATALYTIC, INC., Center Square West, 1500 Market Street, Philadelphia, PA 19102

J. Ciccalese

K. C. Taber 
65-68. CATALYTIC, INC., Highway 25 North, Wilsonville, AL 35186
W. P. Barnett
G. Boykin
H. L. Lewis
A. Patko

69-73. DOE OFFICE OF FOSSIL ENERGY, Washington, DC 20545
J. Batchelor
S. J. Dapkunas
T. Simpson
I. Wender
K. Youssef

74. ELECTRIC POWER RESEARCH INSTITUTE, 3412 Hillview Avenue, Palo Alto, CA. 94304

R. I. Jaffee

75. ELECTRIC. POWER RESEARCH INSTITUTE, Highway 25 North, Wilsonville, AL $\cdot 35186$

W. Weber

76. EXXON RESEARCH AND ENGINEERING, P.0. Box 101, Florham Park, NJ 07932

$$
\text { G. Sorell }
$$

77. GULF RF.SF.ARCH AND DEVELOPMENT CO., P.0. Drawer 2038, Pittsburgh, PA 15230

S. .1. Iharra

78. KENTUCKY CENTER FOR FNFRGY RESEARCH LABORATORY, IUSLILUזe for Mining and Minerals Research, Iron Works Pike, Box 13015, Lexington, KY 40583

A. A. Sagues

79. NATIONAL BUREAU OF STANDARDS, Materials Building B-120, Washington, DC $2 \cap 234$

R. Dobbyn

80-81. PITTSBURG AND MIDWAY COAL MINING CUMPANY, P.0. BoX 199, Dupont, WA 98327
D. E. Canfield
J. Ward

82. SOUTHERN COMPANY SERVICES, P.0. BOX 2625, Birm1ngham, AL 35202 E. L. Huffman 
83. SOUTHWEST RESEARCH INSTITUTE, P.0. Drawer 285.10, San Antonio, TX 78284

R. Arey

84. SPRAGUE ELECTRIC CO., Marsha11 Street, North Adams, MA 01247

R. T. King

85-88. DOE, OAK RIDGE OPERATIONS OFFICE, P.O. Box E, Oak Ridge, TN 37830

Office of Assistant Manager for Energy Research and Development

C. W. DiBella

E. E. Hoffman

J. A. Reaf snyder

89-115. DOE, TECHNICAL INFORMATION CENTER, OFFICE OF INFORMATION SERVICES, P.0. Box 62, Oak Ridge, TN 37830 